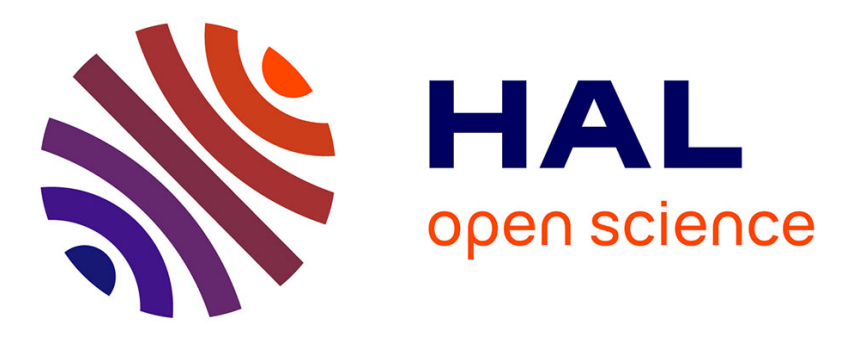

\title{
Making Base-Assisted C-H Bond Activation by Cp*Co(III) Effective: A Noncovalent Interaction-Inclusive Theoretical Insight and Experimental Validation
}

Fule Wu, Christophe Deraedt, Yann Cornaton, Julia Contreras-García, Mélanie Boucher, Lydia Karmazin, Corinne Bailly, Jean-Pierre Djukic

\section{To cite this version:}

Fule Wu, Christophe Deraedt, Yann Cornaton, Julia Contreras-García, Mélanie Boucher, et al.. Making Base-Assisted $\mathrm{C}-\mathrm{H}$ Bond Activation by $\mathrm{Cp}{ }^{*} \mathrm{Co}(\mathrm{III})$ Effective: A Noncovalent Interaction-Inclusive Theoretical Insight and Experimental Validation. Organometallics, 2020, 39 (14), pp.2609-2629. 10.1021/acs.organomet.0c00253 . hal-02921992

\section{HAL Id: hal-02921992 https://hal.science/hal-02921992}

Submitted on 4 Jan 2021

HAL is a multi-disciplinary open access archive for the deposit and dissemination of scientific research documents, whether they are published or not. The documents may come from teaching and research institutions in France or abroad, or from public or private research centers.
L'archive ouverte pluridisciplinaire HAL, est destinée au dépôt et à la diffusion de documents scientifiques de niveau recherche, publiés ou non, émanant des établissements d'enseignement et de recherche français ou étrangers, des laboratoires publics ou privés. 


\title{
Making Base-Assisted C-H Bond Activation by $\mathrm{Cp} * \mathrm{Co}$ (III) Effective: A Noncovalent Interaction-Inclusive Theoretical Insight and Experimental Validation.
}

\author{
Fule WU†, Christophe DERAEDT ${ }^{\dagger}$, Yann CORNATON`, Julia CONTRERAS-GARCIA, đ Mélanie \\ BOUCHER ${ }^{\dagger}$, Lydia KARMAZIN ${ }^{\ddagger}$ Corinne BAILLY ${ }^{\ddagger}$ and Jean-Pierre DJUKIC ${ }^{\dagger *}$
}

†Laboratoire de Chimie et Systémique Organométalliques, Institut de Chimie de Strasbourg UMR 7177 CNRS, Université de Stras-
bourg, 4 rue Blaise Pascal, 67000 Strasbourg, France.
『Laboratoire de Chimie Théorique UMR 7616 CNRS, Sorbonne Université, Site Jussieu, 4 place Jussieu, 75052 Paris cedex, France.
‡Service de Radiocristallographie, Fédération de Chimie Le Bel FR 2010, Université de Strasbourg, 1 rue Blaise Pascal, 67000
Strasbourg, France.

ABSTRACT: The base-assisted cyclometallation of 2-phenylpyridine (2-phpyH) by Cp*Co(III) was holistically addressed both theoretically and experimentally. Combined DFT and DLPNO-CCSD(T) methods assisted by QTAIM-based noncovalent interactions plots (NCI plots), interacting quantum atoms (IQA), and local energy decomposition (LED) analyses have been used for a comparative study of the CMD-promoted cyclocobaltation and the parent cycloiridation of the 2-phpyH. Results suggest a remarkable contribution of noncovalent interactions, especially local electrostatic interactions, in the evolution of the reactive site giving a rational for the optimization of cyclocobaltation. The theoretically predicted benefits of using the acetamidate anion as a base is rationalized and verified experimentally. Cobaltacycle [Cp*Co(2-phpy- $\kappa C, \kappa N) \mathrm{I}] \mathrm{was}$ efficiently synthesized from the air-stable $\left[\mathrm{Cp}^{*} \mathrm{CoI}_{2}\right]_{2}$ and 2-phpyH, in the presence of LiNHAc as base in $83 \%$ yield whereas with anhydrous $\mathrm{NaOAc}$ as base only $12 \%$ yield were achieved under similar conditions. By applying the [NHAc] ${ }^{-}$-promoted cyclometallation various cobaltacycles were synthesized, analytically characterized and their structures resolved by X-ray crystallization analysis, confirming the importance of the acetamidate in the base-assisted cyclometallation. Experimental kinetic isotope effect (KIE) studies validated by Bigeleisen equation-based KIE computations confirm that the formation of the agostic transient is indeed the kinetic determining step of the CMD mechanism in dichloromethane. Application of the $\left[\mathrm{Cp}^{*} \mathrm{CoI}_{2}\right]_{2} / \mathrm{LiNHAc}$ mixture to the catalysis of the condensation of 1,2-diphenyacetylene to various aromatics reveals the coexistence of two mechanisms, i.e. CMD and electrophilic C-H activation.

\section{INTRODUCTION}

Transition metal-catalyzed $\mathrm{C}-\mathrm{H}$ bond functionalization reactions are powerful and potentially superior to traditional organic reactions using stoichiometric activating reagents. ${ }^{1-3}$ After several decades of development of late transition metal promoted $\mathrm{C}-\mathrm{H}$ bond activation catalysis new efforts are now being focused on the challenging use of $3 \mathrm{~d}$ transition metal complexes, the chemistry of which has mostly been studied at higher oxidation states. ${ }^{4,5} \mathrm{Re}$ producing the well documented metal-induced $\mathrm{C}-\mathrm{H}$ bond activation chemistry of 4-5d transition metals with $3 d$ ones $^{6}$ requires thorough knowledge of the intimate nature of the physical and chemical effect that enable $\mathrm{C}-\mathrm{H}$ bond metallation. Among the various transition metal catalysts developed for $\mathrm{C}-\mathrm{H}$ bond functionalization catalysis, cationic $\mathrm{Cp}^{*} \mathrm{Rh}(\mathrm{III})$ and $\mathrm{Cp}$ (Ir(III) complexes have been widely applied to various $\mathrm{C}-\mathrm{C}, \mathrm{C}-\mathrm{N}$, and many other $\mathrm{C}-\mathrm{X}$ bondforming reactions and have already proven successful. ${ }^{7-10}$ In contrast, the catalytic activity of $\mathrm{Cp}^{*} \mathrm{Co}$ (III) complexes has long been ignored and remained mostly unexplored until recently. The recent upsurge of publications dealing with the use of $\mathrm{Cp}^{*} \mathrm{Co}$ (III)-catalysts in $\mathrm{C}-\mathrm{H}$ bond functionalizations ${ }^{11-16}$ was triggered by the remarkable reports by Kanai and Matsunaga ${ }^{17-33}$ (scheme 1) and by Ackerman et al. ${ }^{34-45}$ and followed by a number of other reports. ${ }^{46,47}$ In many reported cases this powerful class of cobalt catalysts ${ }^{11}$ presents reactivity profiles that differ from their rhodium and iridium analogues. It has been argued that this difference is likely due to the lower electronegativity and increased Lewis acidity of cobalt compared to rhodium and iridium. ${ }^{48}$ Up to recently there has been seldom ${ }^{43}$ attempts to construct a rational around the key problem of $\mathrm{C}-\mathrm{H}$ bond activation using $3 \mathrm{~d}$ metals ${ }^{4,49}$ that would connect all the dimensions of chemical bonding, including the role of noncovalent interactions. In a recent report, ${ }^{49}$ we have attempted to rationalize the differences existing between the well established Pd(II)-acetate and the less documented $\mathrm{Ni}(\mathrm{II})$-acetate cyclometallation by focusing mainly on the role of noncovalent interactions in the so-called Concerted-Metallation-Deprotonation mechanism (abbr. CMD) also assimilated to the Ambiphilic Metal Ligand Activation (AMLA) mechanism, ${ }^{50-52}$ which is central to the now widely studied catalytic applications of Pd(II) systems to $\mathrm{C}$-H bond functionalization. ${ }^{2-4}$ From this study, that was carried out using state-of-the-art ab initio as well as DFT-based QTAIM analysis, it appeared that the key kinetic determining step, i.e the formation of an agostic intermediate, was centrally depending on the electrostatic repulsion existing between 
the metal center and the target $\mathrm{C}-\mathrm{H}$ bond of the aromatic substrate; the main consequence being for $\mathrm{Ni}$ (II) that electrostatic repulsions were inducing activation barriers about twice higher than those with Pd(II). ${ }^{49}$

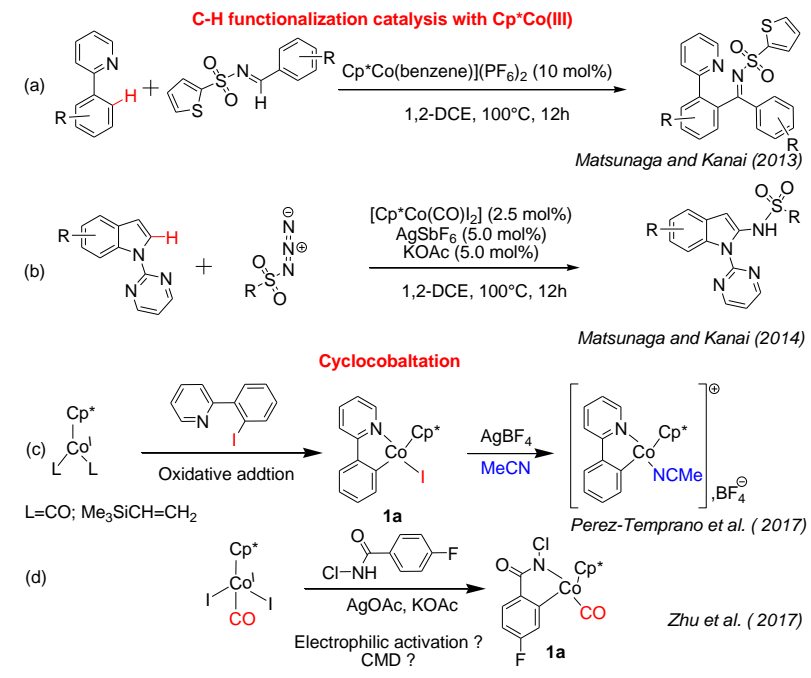

Scheme 1. Examples of high-valent catalytic C-H functionalization protocols using cobalt as catalyst. (a) First example of $\mathrm{Cp}^{*} \mathrm{Co}(\mathrm{III})$-type catalytic protocol. ${ }^{17}$ (b) First example of the use of $\left[\mathrm{Cp}^{*} \mathrm{Co}(\mathrm{CO}) \mathrm{I}_{2}\right]$ as catalyst. ${ }^{18}$ (c) ${ }^{53}$ and (d) ${ }^{54}$ examples of preparative syntheses of cobaltacycles.

It was found that one way to reduce this barrier with $\mathrm{Ni(II)}$ was to replace the auxiliary base and ligand, i.e the acetato, by a more basic one, i.e an acetamidato, which abates the repulsive $\mathrm{C}$-H-to-metal electrostatic burden. ${ }^{49}$ We now decided to test experimentally the conclusions drawn from the theoretical study of the Ni(II)/Pd(II) model dyad to the CMD mechanism-promoted cyclometallation reaction by focussing our interest on the $\mathrm{Cp}^{*} \mathrm{Co}$ (III) system, having in scope that a good part of the recent applications of $\mathrm{Cp}^{*} \mathrm{Co}(\mathrm{III})$ catalysts ${ }^{17,55,56}$ to $\mathrm{C}-\mathrm{H}$ bond functionalization apparently proceed by a different mechanism, i.e via the electrophilic activation ${ }^{57}$ of the $\mathrm{C}-\mathrm{H}$ bond. Recent reports tend indeed to priviledge the electrophilic pathway58,59 even though in some cases the formal formulation of the mechanism makes the distinction with the $\mathrm{CMD}^{16,60,61}$ one rather difficult. It is important to mention that known syntheses (scheme 1 ) of $\mathrm{Cp}^{*} \mathrm{Co}$ (III)-metallacycles are based on the use of sensitive $\mathrm{Cp}^{*} \mathrm{Co}(\mathrm{I}) \mathrm{L}_{2} \quad(\mathrm{~L}=\mathrm{CO}$; $\mathrm{Me}_{3} \mathrm{SiCH}=\mathrm{CH}_{2}$ ) complexes and rely on an oxidative addition step requiring expensive iodo-arene substrates such as 2(2-iodophenyl)pyridine (oxidative addition). ${ }^{53}$ A variant operating via electrophilic metallation inspired from the early applications to catalysis of Matsunaga and Kanai ${ }^{17}$ ${ }_{33,48}$ makes use of $\left[\mathrm{Cp}^{*} \mathrm{Co}(\mathrm{III})(\mathrm{MeCN})_{3}\right]\left(\mathrm{BF}_{4}\right)_{2}{ }^{56}$ and excess of 2-phenylpyridine, i.e 2-phpyH (scheme 1c). Another one proposed by Zhu et al. ${ }^{16,54}$ with $\mathrm{Cp}^{*} \mathrm{Co}(\mathrm{CO}) \mathrm{I}_{2}$ requires 2 eq of silver acetate to promote the formation of cobaltacycles (scheme 1d) with no evidence of the dominance of the CMD mechanism.

In this report we address the cyclometallation reaction by $\mathrm{Cp}^{*} \mathrm{Co}(\mathrm{III})$ species by adapting the procedure commonly used for cycloiridation and cyclorhodation promoted by the base assisted CMD mechanism, that is by considering the use of the stable $\mu$-iodo dimer $\left[\mathrm{Cp}^{*} \mathrm{CoI}_{2}\right]_{2}$ and demonstrate that such metallacycles are far from being "elusive". 53 This study is enlightened in a unique way by a complete theoretical comparative investigation of the cyclocobaltation and cycloiridation reactions that includes considerations on the central role of noncovalent interactions in the $\mathrm{C}-\mathrm{H}$ bond activation and a comparative probe of the effect of the auxiliary base on a model alkyne-arene condensation reaction that stages $\left[\mathrm{Cp}^{*} \mathrm{CoI}_{2}\right]_{2}$ as catalyst. The CMD cyclorhodation was not addressed being basically not qualitatively different in its mechanism from the CMD cycloiridation.

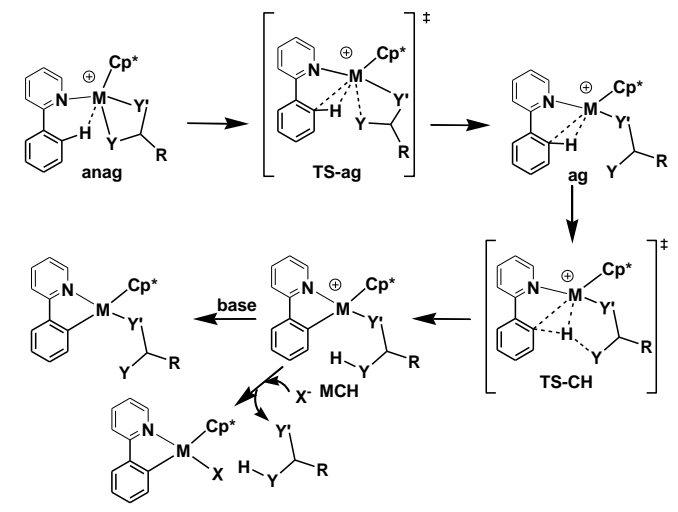

Scheme 2. The Concerted Metallation Deprotonation mechanism applied to group 9 transition metal Cp*M(III) complexes $^{49}$ : anag, the reactive complex precursor of the agostic intermediate ag, via TS-ag; $\mathbf{M C H}$, the immediate cyclometallation product arising from the proton transfer reaction occurring via TS-CH from ag.

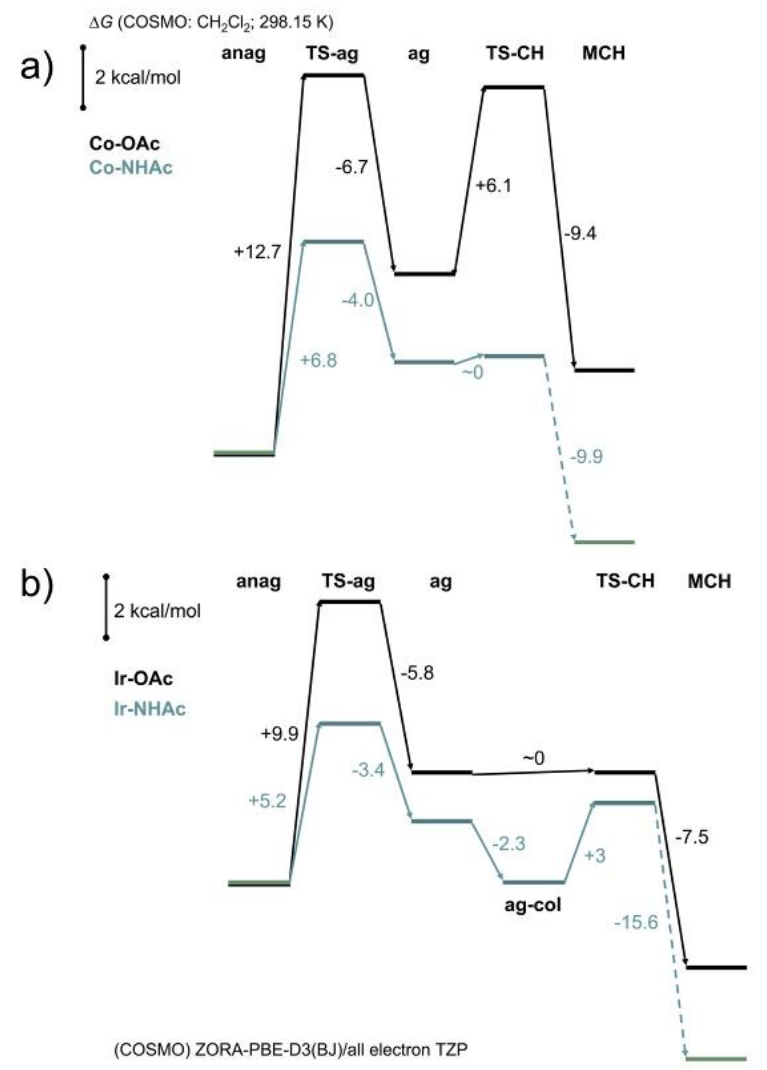

Figure 1. GGA-DFT-D energy profiles for the cyclometallations of 2-phpyH assisted by acetato (black lines) or by acetamidato (cyan lines) bases: a) $\mathrm{Cp}^{*} \mathrm{Co}(\mathrm{III})$ system, b) $\mathrm{Cp}^{*} \operatorname{Ir}(\mathrm{III})$ system. 


\section{RESULTS AND DISCUSSION}

\section{Predictive DFT Energy Profile Study and the Role of Noncovalent Interactions}

DFT-D Reaction Energy Profile. The CMD (or AMLA) mechanism is a simplified scenario that implies the formation of a reactive complex anag, i.e. $\left[\mathrm{Cp} * \mathrm{M}\left(\kappa^{\mathrm{N}}-2-\right.\right.$ $\left.p h p y H)\left(\kappa^{2}-Y A c\right)\right]^{+}$, established between the ligand to be metallated and a coordinatively unsaturated metal complex that undergoes a series of intramolecular transformations, namely (scheme 2): the formation of the CH...metal agostic ${ }^{62-66}$ intermediate ag via transition state TS-ag, the C-H bond breaking by metallation and concerted proton abstraction by an intramolecular base via transition state $\mathbf{T S}-\mathbf{C H}$ to form intermediate $\mathbf{M C H}$, i.e. $\left[\mathrm{Cp}^{*} \mathrm{M}\left(\kappa^{2}\right.\right.$ 2-phpy)(AcYH) $]^{+}$, the release of the protonated base and eventually the coordination of any anionic ligand (halogen, or anionic base) to the metal centre, which was not considered here. It is worth mentioning that a variant ${ }^{57}$ to this mechanism considers the external capture of the proton $\mathrm{HAr}^{+}$in the bond-breaking step. In the case studied here, implicit solvation was accounted for by a continuum screening model (COSMO ${ }^{67-69}$ ) assuming a fully intramolecular process. Another variant was also put forward by Jones et al. ${ }^{59}$ for cycloiridation and cyclorhodation based on the determination of kinetic isotopic effects which suggested by their rather high value of KIE $\sim 3$ a base (namely acetate)-assisted electrophilic $\mathrm{C}-\mathrm{H}$ bond activation, the proposed formulation of which ressembles that of the CMD mechanism, though. The anionic base-devoid electrophilic activation option is also addressed farther.

It is worthy to note that most theoretical studies on the $\mathrm{Cp}^{*} \mathrm{Co}(\mathrm{III})$-catalysed $\mathrm{C}-\mathrm{H}$ activation did not investigate thoroughly the mechanism of cyclometallation, and focussed on the influence of different substitutions on the reactive species.6,13-16,60,61 Most of them simplified the cyclometallation step. To the best of our knowledge no other DFT study followed a thorough NCI-inclusive approach of the cyclometallation part of the mechanism.

Figure 1 depicts the Gibbs enthalpy profiles for the cyclocobaltation (Co-OAc, Co-NHAc) and cycloiridation (IrOAc, Ir-NHAc) of 2- $p h p y H$ assisted by acetate and acetamidate. The singlet ground state intermediates and transition states, which where built based on existing structures of metallacycles, were all optimized at the COSMO ${ }^{67-69}$. ZORA-PBE ${ }^{70}$-D3(BJ) ${ }^{71-73}$ /all electron TZP level. It is important to stress that the choice of the DFT functional was guided by repeated failure to localize TS-CH by using the dispersion corrected ${ }^{71,73}$ version of the functional that was initially used by Macgregor et al.51,52,74 in their early investigations of the cycloiridation of $\mathrm{N}, \mathrm{N}$-dimethylbenzylamine. The dispersion-inclusive hybrid functional PBE0 ${ }^{75}-\mathrm{ddsc}^{76}$, which performed well in localizing all stationary points, was nonetheless found too costly and of low benefit in terms of computational time and accuracy owing to the calculation of statistical thermodynamic data from vibrational data accessible only by numerical differentiation, which presented a risk of inaccuracy arising from the COSMO ${ }^{67-69}$ solvation treatment. We therefore used the dispersion corrected generalized gradient approximation (GGA) PBE ${ }^{70}$-D3(BJ) $)^{71-73}$ functional and applied analytical frequency calculations throughout the study. Worthy to note, in terms of geometry convergence PBE-D3(BJ) and PBE0-ddsc were rather equivalent for all stationary points. However, even though the localization of TS-CH succeeded in all four systems, i.e Co-OAc, Co-NHAc, Ir-OAc, Ir-NHAc, it was noticed with both functionals that the potential surface between ag and TS-CH was relatively shallow with a clear functional dependency emerging for the geometry of ag. In most cases at the GGA level ag was localized at a local minimum with the carboxy base plane almost parallel with that of the phenyl moiety of the 2-phpyH ligand. In the case of Ir-NHAc only, was the rotamer with the carboxy oxygen atom aligned with the $\mathrm{C}-\mathrm{H}$ bond axis, i.e agcol, isolated around $2.5-3 \mathrm{kcal} / \mathrm{mol}$ below both ag and TS$\mathbf{C H}$ in a local shallow potential well. Intermediate ag-col is the actual reactive complex leading to $\mathbf{T S}$-CH. Test linear transit computations considering the rotation of the metalbound base following the excursion of dihedral angle $\mathrm{C}_{\mathrm{Ar}}{ }^{-}$ $\mathrm{M}$ (Co or Ir)- $\mathrm{O}_{\mathrm{d}}$ (or $\mathrm{N}_{\mathrm{d}}$ in Co-NHAc)- $\mathrm{C}_{\mathrm{sp2} \text {-base }}$ suggest that geometries similar to ag-col in Co-Ac and Ir-OAc systems are of high energy, offering no chance of being localized at this level of theory. Like shown farther in this study, extending the investigation of the reaction energy profile with the ab initio DLPNO-CCSD(T) ${ }^{77-83}$ method provided a qualitative estimate of the reliability of the DFT method used here particularly for the kinetic determining step and for the critical proton transfer step.

The Ir and Co systems display analogous energy profiles (Figure 1). The common feature shared by the two metal systems is the activation barrier for the formation of $\mathbf{a g}$, which is about two fold higher when the auxiliary base is the acetate instead of the acetamidate. Similarly to the $\mathrm{Ni} / \mathrm{Pd}$ case ${ }^{49}$ the kinetic determining step is the formation of ag and the overall exothermicity of the anag-to-MCH process is higher with the acetamidato as a base. Quite interestingly anag-to-ag activation barriers with the same base ( $\mathrm{AcO}^{-}$or $\mathrm{AcNH}^{-}$) are only slightly lower for the Ir system as compared to the Co one by ca. 1.5 and $3 \mathrm{kcal} / \mathrm{mol}$.

In the case of Co-OAc, ag is localized in a significant energy well at almost equal energy distance from TS-ag and TSCH, whereas in Co-NHAc the ag-to-MCH barrier is virtually inexistent at the GGA level. If one considers the endothermicity of the anag-MCH process of about $\Delta G \sim+3 \mathrm{kcal} / \mathrm{mol}$ in Co-OAc at $298.15 \mathrm{~K}$ it can be inferred that on the grounds of thermochemistry alone the cyclometallation with $\mathrm{AcO}^{-}$as auxiliary base is to be less efficient than that with $\mathrm{AcNH}$, which was indeed verified experimentally (vide infra).

Noncovalent Interactions. Noncovalent interactions (abbr. NCI) can be addressed with several state-of-the-art tools. NCIplot, ${ }^{84,85}$ a Quantum Theory of Atoms in Molecule (QTAIM)-based treatment of the electron density topology provides an intuitive spatial map of local repulsive, nonbonding and attractive NCI materialized by isosurfaces of the signed reduced density gradient. The QTAIMInteracting Quantum Atoms (QTAIM-IQA) method computes and decomposes in a basis-set independent way interatomic interaction energies into covalent and ionic contributions. ${ }^{49,86-88}$ Also relevant are the so-called QTAIM 
-or Bader- charges that have proven reliable in expressing the local charge density distribution. ${ }^{89}$
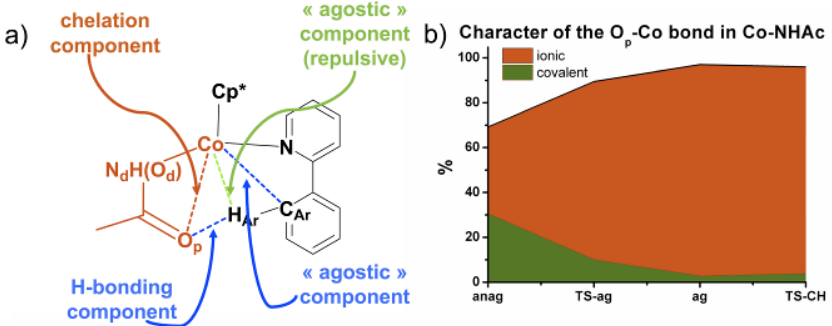

c)

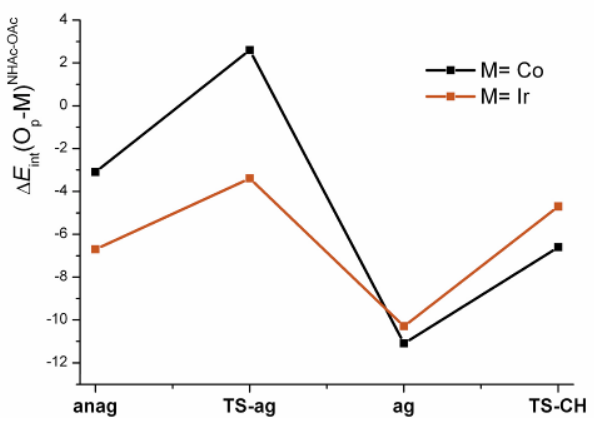

Figure 2 a) scheme of the reactive site during the cyclocobaltation of 2-phpyH via the CMD mechanism. b) evolution of the ionic and covalent character of the $\mathrm{O}_{\mathrm{p}}$-Co interaction in the course of the CMD process expressed as a percentage of the associated interatomic QTAIM-IQA energy of interaction $E_{\text {int. }}$. c) evolution of the QTAIM-IQA $\Delta E_{\text {int }}\left(\mathrm{O}_{\mathrm{p}}\right.$-M) ${ }^{\mathrm{NHAc}-\mathrm{OAc}}$ value (in $\mathrm{kcal} / \mathrm{mol})$ in the course of the CMD process where $\Delta E_{\text {int }}\left(\mathrm{O}_{\mathrm{p}}\right.$ M) ${ }^{\mathrm{NHAc}-\mathrm{OAc}}=E_{\text {int }}\left(\mathrm{O}_{\mathrm{p}}-\mathrm{M}\right)^{\mathrm{NHAc}}-E_{\text {int }}\left(\mathrm{O}_{\mathrm{p}}-\mathrm{M}\right)^{\mathrm{OAc}}$.

The analysis of NCI was essentially focused on the "reactive site" of the molecule where the $\mathrm{C}-\mathrm{H}$ bond disruption occurs during the anag $\rightarrow$ TS-ag $\rightarrow \mathbf{a g} \rightarrow \mathbf{T S}-\mathbf{C H} \rightarrow \mathbf{M C H}$ sequence. This reactive site is the group of atoms comprising Co or Ir, $\mathrm{C}_{\mathrm{Ar}}, \mathrm{H}_{\mathrm{Ar}}, \mathrm{O}_{\mathrm{p}}$ (proximal to $\mathrm{H}_{\mathrm{Ar}}$ ), $\mathrm{O}_{\mathrm{d}}$ or $\mathrm{N}_{\mathrm{d}}$ (distal to $\mathrm{H}_{\mathrm{Ar}}$ ), which undergoes various phenomena that are illustrated by Figure $2 \mathrm{a}$ and were already outlined with the $\mathrm{Ni} / \mathrm{Pd}$ dyad previously. Restricting our reasoning to this reactive site does not discard the role of the ligand retinue, i.e here the pentamethylcyclopentadienyl and the pyridyl fragment of 2-phpyH that respond in benign ways as the reactive site evolves (vide infra the DLPNO-CCSD(T)/LED analysis).

As a chemical event, the $\mathrm{C}_{\mathrm{Ar}}-\mathrm{H}_{\mathrm{Ar}}$ bond cleavage can be considered as an evolution of the precarious balance between the agostic interaction of the $\mathrm{C}_{\mathrm{Ar}}-\mathrm{H}_{\mathrm{Ar}}$ bond in question with the metal centre and the buildup of $\mathrm{H}$-bonds mainly with $\mathrm{O}_{\mathrm{p}}$ and to a lesser extent with $\mathrm{O}_{\mathrm{d}}$ or $\mathrm{N}_{\mathrm{d}}$ (Figure 2a). Within the term "agostic interaction" that we use here we include the attractive and repulsive components that are constitutive of the $\mathrm{C}_{\mathrm{Ar}}-\mathrm{H}_{\mathrm{Ar}}$...metal interaction.

Interacting Quantum Atoms. IQA-data (cf. Supporting Information) show clearly that in all ag intermediates the $\mathrm{C}_{\mathrm{Ar}}$-metal interaction is attractive with a dominating covalent character. The $\mathrm{H}_{\mathrm{Ar}}$-metal interactions are more contrasted. In both Ir-OAc and Ir-NHAc systems the interaction is always repulsive and climbs to a maximum of repulsion at TS-CH. In Co-OAc and Co-NHAc the $\mathrm{H}_{\mathrm{Ar}}$-metal interaction is significantly attractive only in ag $\left(E_{\text {int }} \sim-9\right.$ $\mathrm{kcal} / \mathrm{mol}$ ) and becomes repulsive at TS-CH. In such a re- duced space around the metal, the existence of a residual $\kappa^{2}$ chelation of the metal centre by the base is evident from the values of the $E_{\text {int }}$ for the $\mathrm{O}_{\mathrm{p}}$-metal interaction that vary approximately from $\sim-220 \mathrm{kcal} / \mathrm{mol}$ in ang to $\sim-100$ $\mathrm{kcal} / \mathrm{mol}$ in TS-CH. For reference, the $E_{\text {int }}$ value of the interaction of the distal heteroatom with the metal centre, i.e. $\mathrm{O}_{\mathrm{d}}-\mathrm{M}$ and $\mathrm{N}_{\mathrm{d}}-\mathrm{M}$ (where $\mathrm{M}=\mathrm{Co}$ or $\mathrm{Ir}$ ) is $\sim-200 \mathrm{kcal} / \mathrm{mol}$ throughout the anag -to- TS-CH process in all four systems, Co-OAc/NHAc and Ir-OAc/NHAc. The value of $E_{\text {int }}$ $\left(\mathrm{O}_{\mathrm{p}}\right.$-metal $)$ is higher than that of the $\mathrm{H}$-bonding interaction $\mathrm{O}_{\mathrm{p}}-\mathrm{H}_{\mathrm{Ar}}(\sim-30 \mathrm{kcal} / \mathrm{mol})$ in all stages of the reaction except TS-CH where $E_{\text {int }}\left(\mathrm{O}_{\mathrm{p}}-\mathrm{H}_{\text {Ar }}\right)$ equals or slightly supersedes $E_{\text {int }}$ $\left(\mathrm{O}_{\mathrm{p}}\right.$-metal $)$ with values of $\sim 100-120 \mathrm{kcal} / \mathrm{mol}$. This residual chelation therefore contributes to the anag -to- ag barrier of activation. It is a challenger of the concerted carbometallation deprotonation when the strength of the chelation interaction prohibits the establishment of the $\mathrm{O}_{\mathrm{p}}$ $\mathrm{H}_{\text {Ar }}$ interaction and a tighter interaction of $\mathrm{C}_{\mathrm{Ar}}$ with the metal centre. In all the four systems considered here the evolution of the $\mathrm{O}_{\mathrm{p}}$-metal interaction shows that the covalent component of the interaction recedes to the ionic character to become residual at TS-CH (Figure 2b).

To rationalize the effect of the base on the reaction energy profiles the difference of interaction energy $E_{\text {int }}$ for the $\mathrm{O}_{\mathrm{p}}$ metal bond in the acetamidato and acetato systems, i.e $\Delta E_{\text {int }}\left(\mathrm{O}_{\mathrm{p}}-\mathrm{M}\right)^{\mathrm{NHAc}-\mathrm{OAc}}=E_{\text {int }}\left(\mathrm{O}_{\mathrm{p}}-\mathrm{M}\right)^{\mathrm{NHAc}}-E_{\text {int }}\left(\mathrm{O}_{\mathrm{p}}-\mathrm{M}\right)^{\mathrm{OAc}}$, was calculated and is plotted in Figure 2c. It shows that the effect of the replacement of $\mathrm{AcO}^{-}$by $\mathrm{AcNH}^{-}$at each stage of the CMD mechanism is in fact the highest at the agostic intermediate ag were $\Delta E_{\text {int }}\left(\mathrm{O}_{\mathrm{p}}-\mathrm{M}\right)^{\mathrm{NHAc}-0 \mathrm{Ac}}$ amounts $\sim-11$ $\mathrm{kcal} / \mathrm{mol}$, which in other terms means that the substitution of $\mathrm{AcO}^{-}$for $\mathrm{AcNH}^{-}$favors the access to ag by reducing significantly the residual chelation. Worthy to note the $E_{\text {int }}$ value for the $\mathrm{H}$-bonding interaction in the $\mathrm{O}_{\mathrm{p}}-\mathrm{H}_{\mathrm{Ar}}$ interactions displays a low sensitivity to the change of base in both Co and Ir systems (cf supporting information).

NCI Indexes. In order to analyse both the attractive and the repulsive contributions to the $\mathrm{C}-\mathrm{H}$ bond cleavage we have resorted to the NCI index ${ }^{84,85}$ in ag and the Ir-NHAcag-col geometries. NCI provides intuitive surfaces that identify local non covalent interactions in a system. Strong and directional interactions are revealed as blue pellets, delocalized weak interactions appear as long green surfaces, and repulsive regions are revealed in red.

Figure 3 shows the results for the ag and Ir-NHAc-ag-col complexes in order to analyse the cleavage of the $\mathrm{C}_{\mathrm{Ar}}-\mathrm{H}_{\mathrm{Ar}}$ bond. If one first looks at the interactions with the metal $(\mathrm{M})$, one can easily see that Ir-NHAc-ag and Ir-NHAc-agcol stand aside from the rest. Co-NHAc-ag, Co-OAc-ag and Ir-OAc-ag show strong interactions between the metal and the $\mathrm{C}_{\mathrm{Ar}}-\mathrm{H}_{\mathrm{Ar}}$ bond which are the deep blue surfaces in Figure 3. Slight differences are observed though within the group. One interesting thing to note here is that whereas QTAIM would have identified $\mathrm{M}-\mathrm{H}_{\mathrm{Ar}}$ or $\mathrm{M}-\mathrm{C}_{\mathrm{Ar}}$ interactions, $\mathrm{NCI}$ clearly highlights the interaction with the full $\mathrm{C}_{A r}-\mathrm{H}_{A r}$ fragment. This is specially so for the Ir-OAc-ag complex, where the blue region extends over a greater region of space (see that it is formed by two deep blue regions that have been highlighted by a discontinuous trace). 
a)

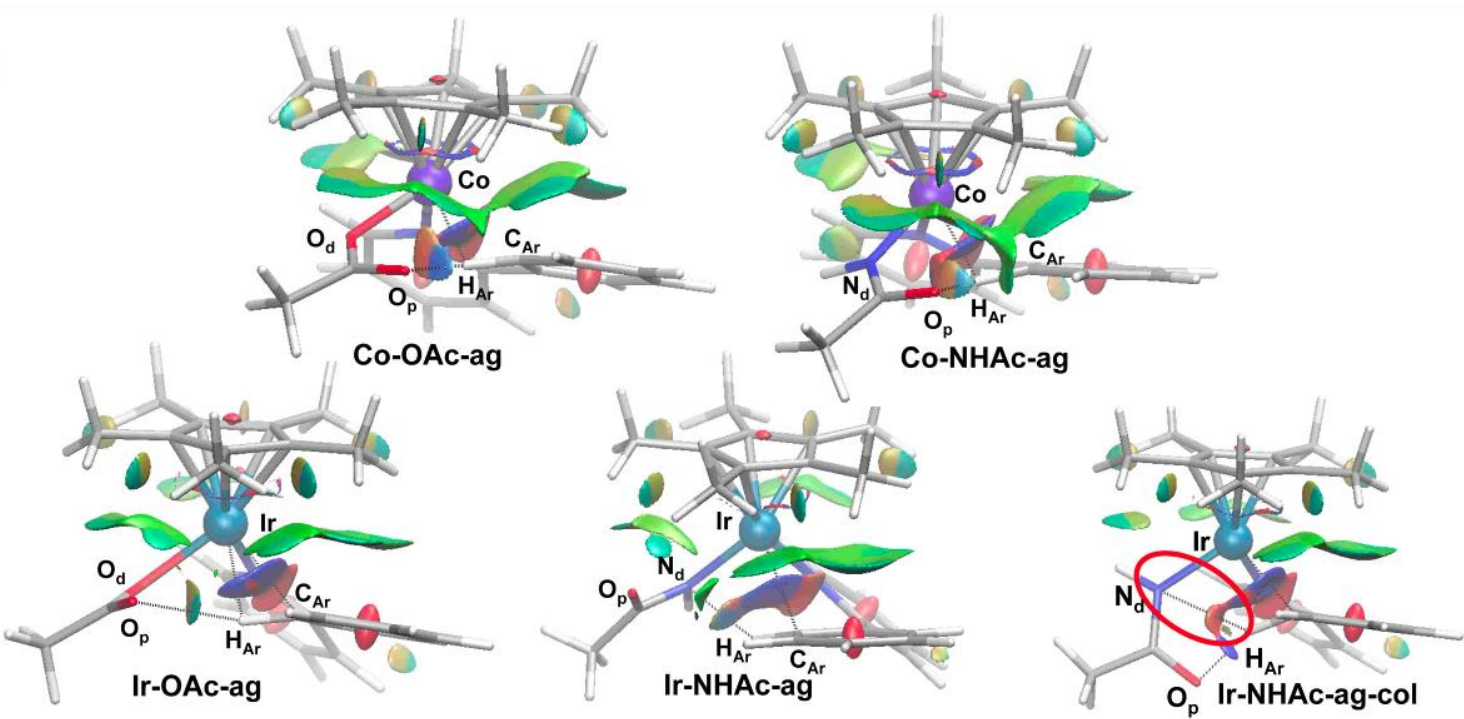

b)

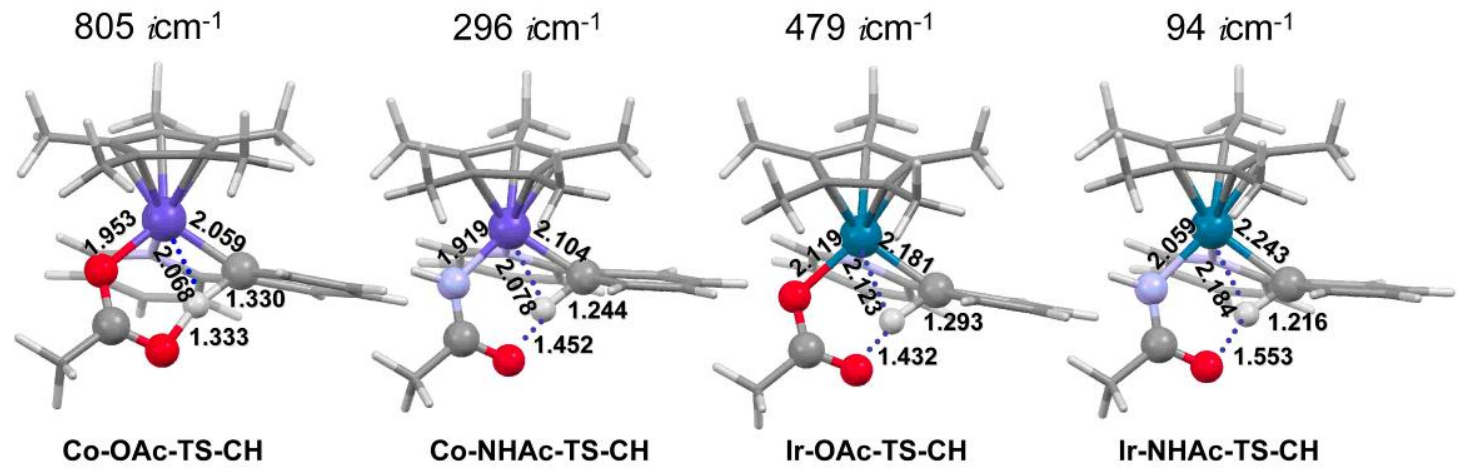

Figure 3. a) NCI surfaces $\left(s=0.3,-0.03<\operatorname{sign}\left(\lambda_{2}\right) \rho<0.03\right)$ for the ag and Ir-NHAc-ag-col complexes (atom color code: light grey, C; dark blue, N; white, H; red, O; violet, Co; cyan, Ir): the circled NCI isosurface in Ir-NHAc-ag-col outlines a rather strong repuslive $\mathrm{N}_{\mathrm{d}}-\mathrm{H}_{\mathrm{Ar}}$ interaction. b) geometries of TS-CH in the Co and Ir- based systems with the associated imaginary vibrational mode frequency as optimized in their singlet state at the $\operatorname{COSMO}\left(\mathrm{CH}_{2} \mathrm{Cl}_{2}\right)$-ZORA-PBE-D3(BJ)/all electron TZP level.

Taking these compounds as reference, we can see that IrNHAc-ag shows in general weaker interactions, whereas Ir-NHAc-ag-col shows stronger ones.

Focusing now on the $\mathrm{O}_{\mathrm{p}}-\mathrm{H}_{\mathrm{Ar}}$ interaction, one sees that it is very weak both in Co-OAc-ag and in Ir-NHAc-ag.

From this information, we can analyse the density at which these interactions are appearing from the $s(\rho)$ plots (Figure S55) in order to quantify the effects of these two intermolecular interactions on the $\mathrm{C}_{\mathrm{Ar}}-\mathrm{H}_{\mathrm{Ar}}$ strength. It is easy to see in Figure 4 that as the interactions of $\mathrm{C}_{\mathrm{Ar}}$ and $\mathrm{H}_{\mathrm{Ar}}$ with other atoms are strengthened, the intra-bond $\mathrm{C}_{\mathrm{Ar}}-\mathrm{H}_{\mathrm{Ar}}$ strength diminishes. Co complexes present intermediate $\mathrm{M}-\left(\mathrm{C}_{\mathrm{Ar}} \mathrm{H}_{\mathrm{Ar}}\right)$ and $\mathrm{O}_{\mathrm{p}}-\mathrm{H}_{\mathrm{Ar}}$ interactions, which weaken the $\mathrm{C}_{\mathrm{Ar}}-$ $\mathrm{H}_{\mathrm{Ar}}$ bond. Ir-NHAc-ag and Ir-NHAc-ag-col complexes show the effect of taking these interactions to the extreme: in Ir-NHAc-ag both interactions are negligible, so that the $\mathrm{C}_{\mathrm{Ar}}-\mathrm{H}_{\mathrm{Ar}}$ bond is very strong. The conformational change to arrive to Ir-NHAc-ag-col leads to the simultaneous strengthening of $\mathrm{M}-\left(\mathrm{C}_{\mathrm{Ar}} \mathrm{H}_{\mathrm{Ar}}\right)$ and $\mathrm{O}_{\mathrm{p}}-\mathrm{H}_{\mathrm{Ar}}$, so that $\mathrm{C}_{\mathrm{Ar}}-\mathrm{H}_{\mathrm{Ar}}$ becomes much weaker.

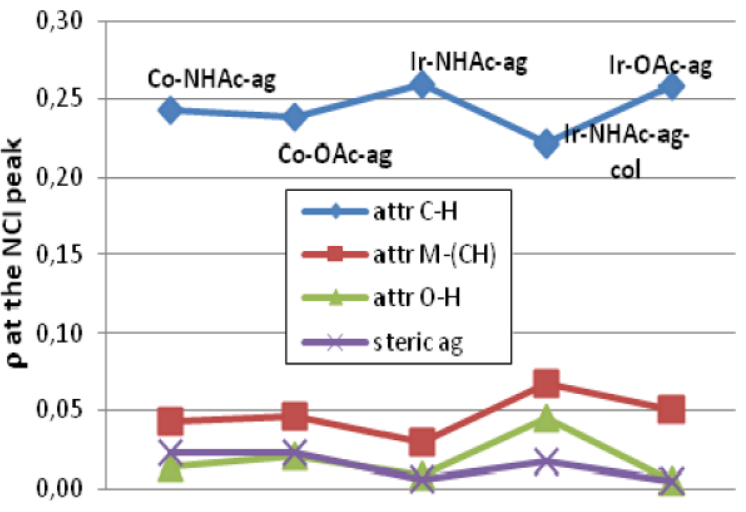

Figure 4. NCI peak densities for ag and Ir-NHAc-ag-col complexes.

Moreover, in Ir-NHAc-ag-col the $\mathrm{M}-\left(\mathrm{C}_{\mathrm{Ar}} \mathrm{H}_{\mathrm{Ar}}\right)$ interaction is mainly with $\mathrm{C}_{\mathrm{Ar}}$ : this leads to opposite forces pulling the $\mathrm{C}_{\mathrm{Ar}}-\mathrm{H}_{\mathrm{Ar}}$ atoms away from each other. $\mathrm{M}$ pulling from $\mathrm{C}_{\mathrm{Ar}}$, and simultaneously, $\mathrm{O}_{\mathrm{p}}$ pulling from $\mathrm{H}_{\mathrm{Ar}}$. 
In line with previous observations, we have also analysed the overall evolution of attraction and repulsion in the non covalent region by means of integrals on the NCI region (Figure S56, Supporting Information). ${ }^{90,91}$ An overall increase in steric repulsion is observed in Ir-NHAc-ag-col with respect to the other ag complexes. Indeed, the atoms becoming closer together, the repulsion between non bonded atoms increases, which also favors atom migration.

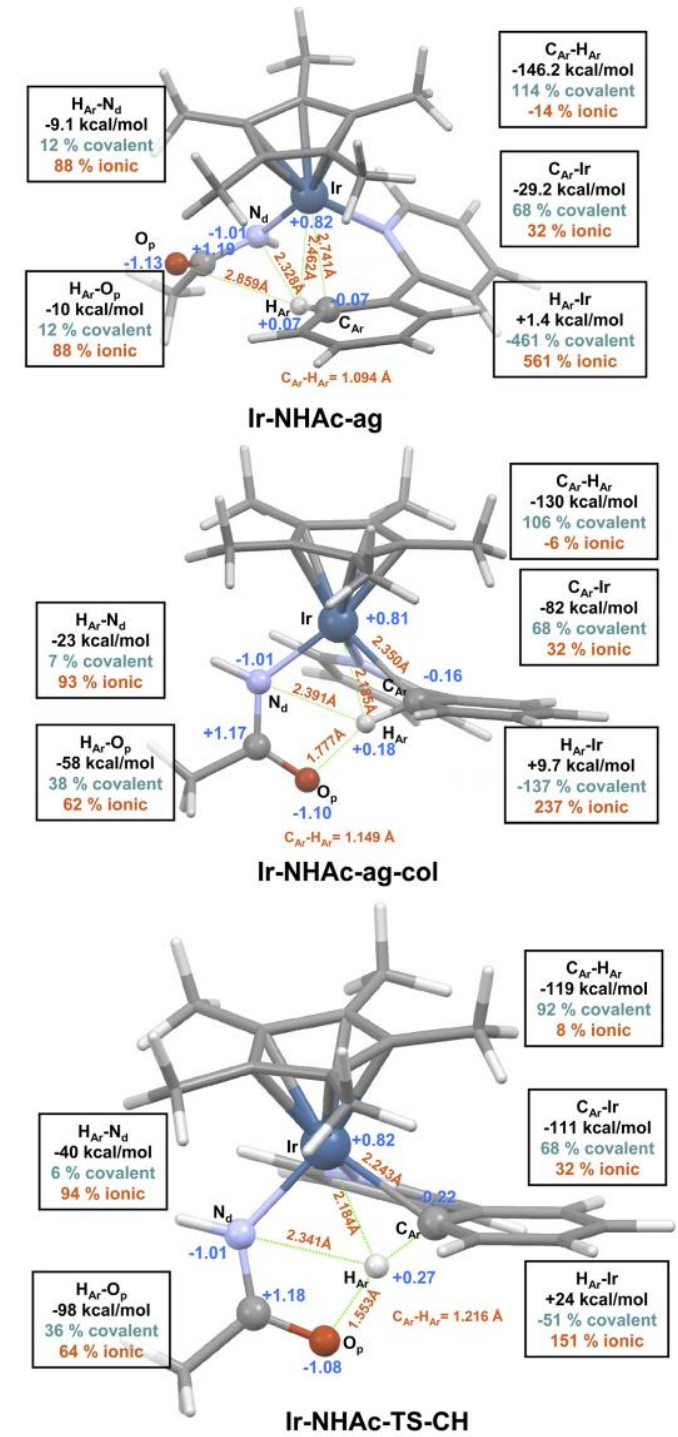

Figure 5. Singlet geometries of Ir-NHAc-ag, Ir-NHAc-ag-col and Ir-NHAc-TS-CH with atom numbering, atomic QTAIM charges (blue colored numbers) main interatomic distances and the main QTAIM-IQA interatomic interaction energies $E_{\text {int }}$ decomposed into covalent (green colored) and ionic (red colored) percentage of contribution. Positive and negative values of $E_{\text {int }}$ indicate repulsive and attractive interactions respectivelly.

This is easily seen in Figure 3, where an important $\mathrm{H}_{a r}-\mathrm{N}_{\mathrm{d}}$ repulsion is observed. This further reinforces the weakening of the $\mathrm{C}_{\mathrm{Ar}}-\mathrm{H}_{\mathrm{Ar}}$ bond, which also leads to a visible deformation. Figure S57 (Supporting information) shows the $\mathrm{H}_{\mathrm{Ar}}-\mathrm{C}_{\mathrm{Ar}}-\mathrm{C}_{\beta}-\mathrm{H}_{\beta}$ dihedral, where the weakening is reflected in the $\mathrm{H}_{\mathrm{Ar}}$ going out of the planarity of the ring to approach $\mathrm{O}_{\mathrm{p}}$. The most representative case being Ir-NHAc-ag-col, where $\mathrm{H}_{\mathrm{ar}}$ adopts the proper angle to form a strong hydrogen bond. Indeed, in this case, a very localized hydrogen bond (deep blue and round isofurface in Figure 3) is observed.

In the case of Ir-NHAc-ag-col, the attractive isosurfaces feature a trend that was already observed in a previous report dealing with the Ni/Pd dyad. The agostic $\mathrm{C}_{\mathrm{Ar}}{ }^{-}$

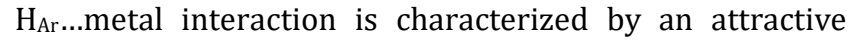
ring and associated with an attractive domain materializing the $\mathrm{C}=\mathrm{O}_{\mathrm{p}} \ldots \mathrm{H}_{\mathrm{Ar}}$ interaction that plays a central role in TS-CH. It was already stated previously ${ }^{49,92}$ that this NCI pattern - or configuration - was the sine qua non condition for the "internal" CMD mechanism to be effective. Analysis of Bader charges (a.k.a. QTAIM charges) and IQA energies support the existence of attractive $\mathrm{O}_{\mathrm{d}} \ldots \mathrm{H}_{\mathrm{Ar}}$ and $\mathrm{N}_{\mathrm{d}} \ldots \mathrm{H}_{\mathrm{Ar}}$ interactions of dominant ionic character in all ag intermediates as well as in Ir-NHAc-ag-col.

Figure 5 depicts Ir-NHAc-ag and Ir-NHAc-ag-col rotamers that differ by the orientation of the acetamidato ligand: in ag the carbonyl lies further away from the $\mathrm{C}_{\mathrm{Ar}}-\mathrm{H}_{\mathrm{Ar}}$ bond than in other agostic intermediates, i.e Co-Ac-ag, CoNHAc-ag and Ir-OAc-ag.

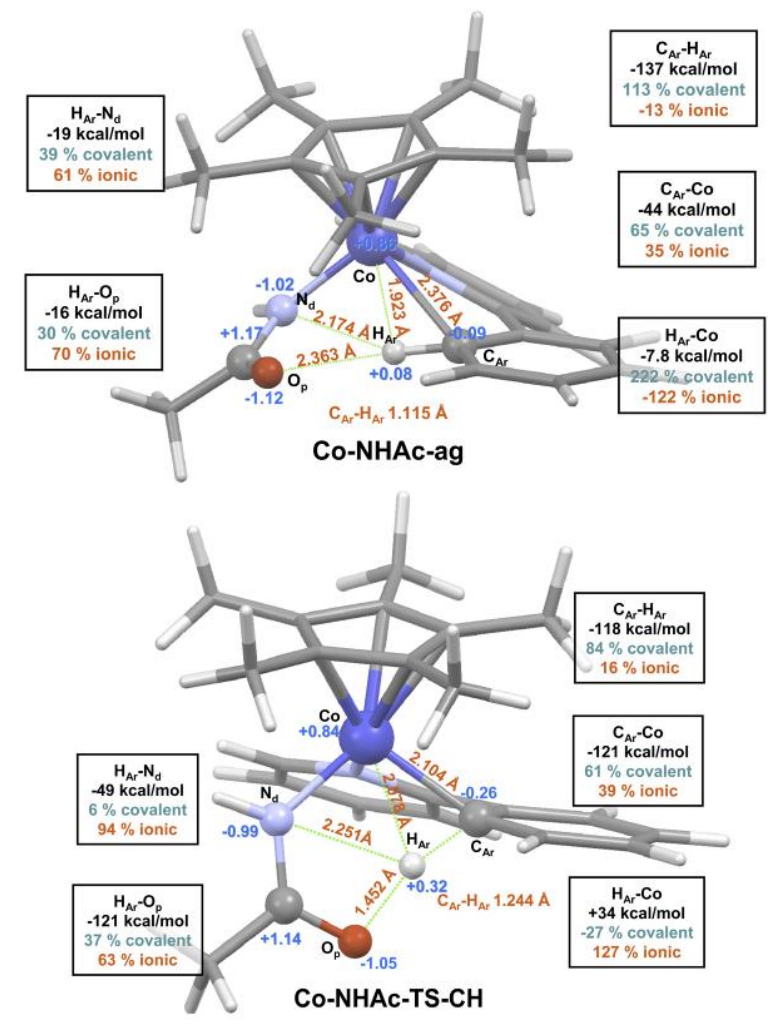

Figure 6. Singlet geometries of Co-NHAc-ag and Co-NHAcTS-CH with atom numbering, atomic QTAIM charges (blue colored numbers) main interatomic distances (red colored numbers ) and the main QTAIM-IQA interatomic interaction energies $E_{\text {int }}$ decomposed into covalent (green colored) and ionic (red colored) percentage of contribution. Positive and negative values of $E_{\text {int }}$ indicate repulsive and attractive interactions respectivelly.

Compared to Ir-NHAc-ag-col, Ir-NHAc-ag has longer $\mathrm{C}_{\mathrm{Ar}}{ }^{-}$ $\mathrm{H}_{\mathrm{Ar}}$...Ir distances, the $\mathrm{C}_{\mathrm{Ar}}-\mathrm{H}_{\mathrm{Ar}}$ bond is surrounded by closely located $\mathrm{N}$ (noted $\mathrm{N}_{\mathrm{d}}$ for distal to the $\mathrm{C}_{\mathrm{Ar}}-\mathrm{H}_{\mathrm{Ar}}$ bond) and $\mathrm{O}$ 
atoms (noted $\mathrm{O}_{\mathrm{p}}$ for proximal) and by positively charged Ir and $s p^{2}$ carboxy carbon atoms.

The environment around the $\mathrm{C}_{\mathrm{Ar}}-\mathrm{H}_{\mathrm{Ar}}$ bond is multipolar and characterized by delocalized electrostatic interactions of the $\mathrm{C}_{\mathrm{Ar}}-\mathrm{H}_{\mathrm{Ar}}$ bond with the carboxy base and the metal. The rotation of the acetamidato ligand around the Co- $\mathrm{N}_{\mathrm{d}}$ axis, which places $\mathrm{O}_{\mathrm{p}}$ nearly collinear with the $\mathrm{C}_{\mathrm{Ar}}-\mathrm{H}_{\mathrm{Ar}}$ axis, enhances the electrostatic interaction with $\mathrm{H}_{\mathrm{Ar}}$ leading to an enhanced polarization ${ }^{74}$ and slight elongation of the $\mathrm{C}_{\mathrm{Ar}^{-}}$ $\mathrm{H}_{\text {Ar }}$ bond. A collateral effect is the increase of about all the values of interatomic interaction energies and of the repulsion between $\mathrm{H}_{A r}$ and the Ir centre that reaches a maximum in TS-CH. Strikingly in Co-NHAc-ag (Figure 6) the $\mathrm{H}_{\mathrm{Ar}}$-Co interaction is slightly attractive with a dominant covalent contribution. In Co-NHAc-TS-CH (Figure 6) this situation reverses and the $\mathrm{H}_{\mathrm{Ar}}$-Co interaction becomes rather strongly electrostatically repulsive, that is by 10 $\mathrm{kcal} / \mathrm{mol}$ more than in Ir-NHAc-TS-CH (Figure 5).

Worthy to note, all the computed vibrational spectra of agostic structures, that is ag and Ir-NHAc-ag-col, show a specific and relatively intense stretching mode of the carboxy base ligand in the $2300-2900 \mathrm{~cm}^{-1}$ region, the lowest wavenumber in this range being found for the $\mathrm{C}=0$ stretching mode of the amidato ligand of Ir-NHAc-ag-col. This information may be useful for tracing down agostic intermediates experimentally by IR techniques, which is not addressed here.

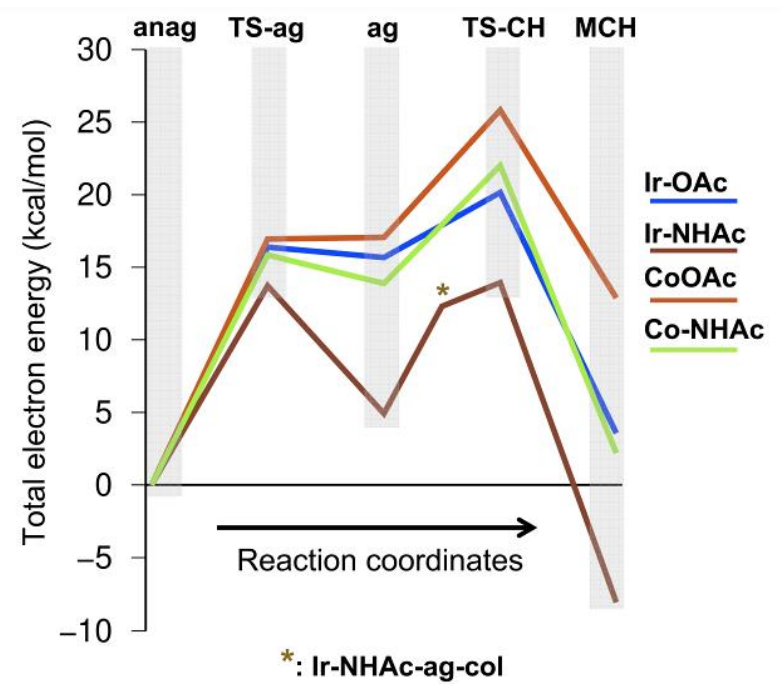

Figure 7. Total electron energy profile for Co \& Ir / -OAc and -NHAc systems computed in the gas phase at the DLPNOCCSD(T)/def2-TZVPP level from geometries computed at the COSMO $\left(\mathrm{CH}_{2} \mathrm{Cl}_{2}\right)$-ZORA-PBE-D3(BJ)/all electron TZP level.

DLPNO-CCSD(T) Computations and Local Energy Decomposition Analysis. Recent reports have depicted DLPNO-CCSD(T) as a computationally time-effective $a b$ initio method suited to the study of agostic interactions in organometallic compounds. ${ }^{93-96}$ The DLPNO-CCSD(T) method combines the high accuracy of the coupled-cluster theory with a computational cost similar to DFT ${ }^{80,96,97}$ arising from the localisation of Hartree-Fock orbitals and the dichotomy between "strong" and "weak" pairs with respect to the inter-orbital distance. The DLPNO-CCSD(T) method, when associated with the Local Energy Decomposition ${ }^{82}$
(LED) analysis, provides a sound access to the role of NCI (including dispersion) by assigning localized orbitals to user-defined fragments, thus allowing the differentiation between intra- and inter-fragment contributions to the interaction energies. The localized orbitals being assigned based on Mulliken charges analysis, an orbital expanding on more than one fragment will always be assigned to the fragment with the most electronegative involved atom. By construction, no counterpoise correction for the BSSE is needed for the calculation of interaction energies within the LED framework. In the Ni/Pd dyad case reported recently, ${ }^{49}$ this method proved useful in outlining the weight of electrostatics particularly in the critical process of formation of the agostic transient ag.

Figure 7 displays the gas phase DLPNO-CCSD(T) total electron energy profiles for the four systems, from the DFToptimized structures, which illustrates in a qualitative fashion the difficulty in accounting for the proton-transfer step ag-to-TS-CH, in which lies the main and somewhat expected discrepancy with the GGA-DFT investigation. In almost all cases shown in Figure 7, the ag-to-TS-CH activation energy amounts about $4-10 \mathrm{kcal} / \mathrm{mol}$, whereas in the GGA-DFT study the span of values from ca. 0 up to $\sim 6$ $\mathrm{kcal} / \mathrm{mol}$ suggests a symptomatic underestimation. Even more critical is the substantial change of individual reaction energy profiles, which is rather diverse at the GGADFT level and more homogenous in feature in the DLPNOCCSD(T) computations. Quite consistently with the DFT study though, the anag-to-ag step still requires the highest activation energy barrier, spanning $14-17 \mathrm{kcal} / \mathrm{mol}$; it remains the kinetic determining step at the DLPNO$\operatorname{CCSD}(\mathrm{T})$ level. The agostic transient ag is at a local minimum in three out of four systems: Co-OAc-ag is slightly destabilized with respect to Co-OAc-TS-ag. With both Co and $\mathrm{Ir}$, the replacement of the acetate ligand by the acetamidato results in a lowering of the anag-to-TS-ag energy barrier and in an energetic stabilization of ag stronger in the Ir system than in the Co one. Quite interestingly also the Ir-NHAc-ag-col transient is no more localized in a local minimum like suggested by DFT but on an ascending path towards TS-CH.

For the LED analysis, the studied systems have been subdivided into five chemically meaningful fragments, as shown in Figure 8a). Fragment 1 has been defined as the metal center, fragment 2 as $\mathrm{H}_{\mathrm{Ar}}{ }^{+}$, fragment 3 as the auxiliary base, fragment 4 as the [2-phpy]- ligand and fragment 5 as the $\mathrm{Cp}^{*}$ ligand. As in the $\mathrm{Ni} / \mathrm{Pd}$ dyad case, the interaction energy between all these fragments is mainly electrostatic in nature, except for the interactions involving fragment 2 that are purely electrostatic. Indeed, the hydrogen constituting fragment 2 being covalently bonded to either $\mathrm{C}_{\text {Ar }}$ of fragment 4 or the $\mathrm{O}_{\mathrm{p}}$ of fragment 5 throughout the reaction path, no orbital has been assigned to this fragment, thus being considered as a proton.

Here, we mainly focus on the interaction energies between the transferred $\mathrm{H}^{+}$and the four other fragments. 
a)
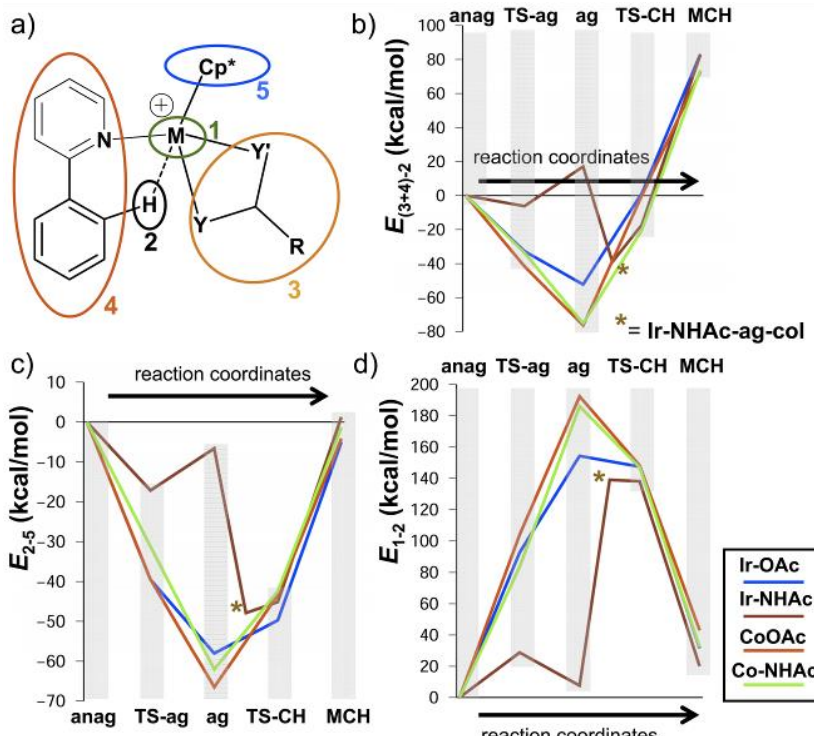

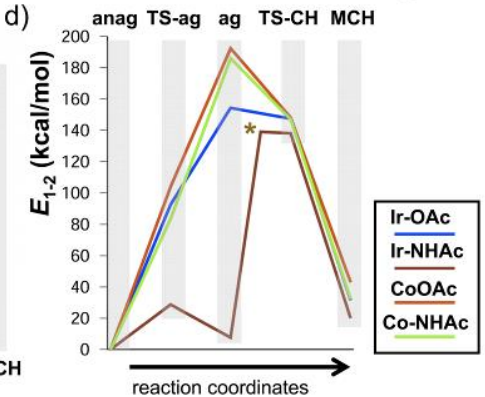

Figure 8. Local Energy Decomposition (LED) analysis for the Ir and Co systems along the reaction coordinates of the CMD mechanism with plots of the inter fragment interaction energies $E_{i-j}$, where $i$ and $j$ are the considered molecular fragment numbers: a) fragmentation scheme and numbering for the LED analysis, b) interaction energy between fragment $2\left(\mathrm{H}^{+}\right)$ and the sum of fragments 3 and $4, c)$ interaction energy between fragments 2 and 5 ( $\mathrm{Cp}^{*}$ ligand), d) interaction energy between fragments 1 and 2 .

The interaction between the transferred $\mathrm{H}^{+}$, i.e fragment 2 (Figure 8a), and [2-phpy], i.e fragment 4, (cf. Supporting Information) decreases by 20 to $45 \mathrm{kcal} / \mathrm{mol}$ for all four systems from anag to ag before increasing by $\sim 500$ $\mathrm{kcal} / \mathrm{mol}$ from ag to $\mathbf{M C H}$, while the interaction between fragment 2 and the auxiliary basis, fragment 3, (cf Supporting Information) decreases by $\sim 30-40 \mathrm{kcal} / \mathrm{mol}$ during the formation of the agostic intermediate before decreasing again by $\sim 400 \mathrm{kcal} / \mathrm{mol}$ along the proton abstraction, except for Ir-NHAc for which the interfragment 2-3 interaction energy increases by $\sim 40 \mathrm{kcal} / \mathrm{mol}$ during the first step. The interaction between the fragment 2 and the superfragment " $3+4$ ", i.e. the sum of interactions between fragments 2 and 3 and between fragments 2 and 4, is shown in Figure 8b. For both cobalt analogues and for IrOAc, this contribution stabilizes the system when forming the agostic intermediate, the stabilization being greater by $\sim 30 \mathrm{kcal} / \mathrm{mol}$ in the cobalt cases, before becoming repulsive when the proton is transferred from fragment 3 to fragment 4. For Ir-NHAc, the contribution becomes repulsive when forming ag and attractive when forming ag-col. In both the cobalt and the iridium cases, concerning the $(3+4)-2$ interaction, no significant difference in stabilization of the agostic intermediate is observed when changing the auxiliary base. This difference in behaviour enlightens the importance of the orientation of the base in the stabilization of the agostic intermediate. The total interaction around the reactive center, i.e. the sum of interaction energies between fragments 2, 3 and 4, still presents its minimum at ag, located $\sim 20 \mathrm{kcal} / \mathrm{mol}$ lower for the cobalt analogues than for the iridium ones, thus defining the

agostic intermediate as the optimal interaction situation within the reactive site.

The interaction between fragment 2 and the "spectator" $\mathrm{Cp}^{*}$ ligand, i.e fragment 5, is shown in Figure 8c. This interaction energy decreases up to the ag stage and then increases towards an almost null final gain in energy $(<5$ $\mathrm{kcal} / \mathrm{mol}$ ). The only variation to this trend happens for $\mathbf{I r}$ NHAc for which the interaction energy decreases from anag to TS-ag then increases to ag, decreases to ag-col before increasing again to $\mathbf{M C H}$. When the auxiliary base is acetamidate instead of acetate, the stabilization of the agostic intermediate is lower in both the cobalt $(\sim 7$ $\mathrm{kcal} / \mathrm{mol})$ and the iridium $(\sim 13 \mathrm{kcal} / \mathrm{mol}$ compared to the Ir-NHAc-ag-col) cases.

The interaction between fragment 2 and the metal center, i.e fragment 1, is shown in Figure 8d. In the case of the cobalt analogues, in Ir-OAc, and in Ir-NHAc if considering only ag-col instead of ag, this repulsive interaction increases up to ag to decline subsequently, the interaction at the $\mathbf{M C H}$ stage being 20-40 $\mathrm{kcal} / \mathrm{mol}$ more repulsive than the one at anag. The main reason for this behaviour is the shortening of the metal- $\mathrm{H}_{\mathrm{Ar}}$ distance at the ag step. In the case of Ir-NHAc, the repulsion at ag is not greater than the one at anag, due to a relatively similar metal- $\mathrm{H}_{\mathrm{Ar}}$ distance which contrasts with Ir-NH-ag-col $\left(\Delta d_{\text {ag-anag }}=0.05 \AA\right.$ vs. $\Delta d_{\text {ag-col-anag }}=0.84 \AA \AA$ ). Due to shorter metal $-\mathrm{H}_{\mathrm{Ar}}$ distances for the cobalt analogues the maximum of repulsion is greater in the cobalt systems than in the iridium ones by more than $40 \mathrm{kcal} / \mathrm{mol}$. In both cobalt and iridium systems, the metal- $\mathrm{H}_{\mathrm{Ar}}$ repulsion is lower in the acetamidate case than in the acetate case by $\sim 14 \mathrm{kcal} / \mathrm{mol}$ for Ir (compared to IrNH-ag-col) and by $\sim 7 \mathrm{kcal} / \mathrm{mol}$ for Co, mainly due to a shorter distance in the acetate case than in the acetamidate one $\left(\Delta d_{\mathrm{AcO}-\mathrm{AcNH}}(\mathrm{Co})=0.04 \AA\right.$ and $\left.\Delta d_{\mathrm{AcO}-\mathrm{AcNH}}(\mathrm{Ir})=0.21 \AA\right)$. Overall, agostic intermediates can be described in the LED analysis as an optimum in interaction between the "transferred $\mathrm{H}^{+"}$ and other fragments. In accord with the QTAIMIQA analysis, the LED analysis shows that stabilizing interactions with the ligands of the polarized $\mathrm{C}-\mathrm{H}$ bond dominate over the destabilizing contribution of the $\mathrm{H}_{\mathrm{Ar}}$-metal interaction.

\section{Experimental Cyclocobaltation of 2-phpyH with Mis- cellaneous Bases}

Previous reports on the synthesis of iridacycles ${ }^{98}$ containing the $\mathrm{Cp}^{*} \mathrm{Ir}$ motive made use of a mixture of the stable dimeric complex $\left[\mathrm{Cp}^{*} \mathrm{IrCl}_{2}\right]_{2}$ and sodium acetate as auxiliary base, 59,99 which is known to operate cycloiridation via the CMD mechanism according to the work of Davies, Macgregor et al. ${ }^{51,100}$ and to a based assisted electrophilic $\mathrm{C}-\mathrm{H}$ bond activation by Jones et al.. 59,101 To synthesize homologous cobaltacycles such as 1a the use of the stable dimeric cobalt (III) complex $\left[\mathrm{Cp}^{*} \mathrm{CoI}_{2}\right]_{2}$ was deemed particularly promising: this air and temperature-tolerant compound can readily be synthesized in two steps from commercial $\mathrm{Co}_{2}(\mathrm{CO})_{8}$ and stored indefinitely away from moisture in an oven at ca. $90^{\circ} \mathrm{C}$. Therefore, the initial study of the optimal conditions for cyclocobaltation was carried out with 2phpyH as a model ligand, $\left[\mathrm{Cp}^{*} \mathrm{CoI}_{2}\right]_{2}$ as the metal source and various carboxy bases privileging a 3:1 base/Co ratio in dichloromethane (abbr. DCM) at $50^{\circ} \mathrm{C}$ (sealed Schlenk 
vessel) by analogy with the optimal conditions established for Ir analogues.

Table 1. Performance of the cyclocobaltation of 2phpyH by $\left[\mathrm{Cp}^{*} \mathrm{CoI}_{2}\right]_{2}$ under various conditions.

\begin{tabular}{|c|c|c|c|}
\hline Entry & Base & Time & Yield \\
\hline 1 & no base & $17 \mathrm{~h}$ & $0 \%$ \\
\hline 2 & $\mathrm{NaOAc}$ & $48 \mathrm{~h}$ & $12 \%$ \\
\hline 3 & $\mathrm{NH}_{2} \mathrm{Ac}$ & $17 \mathrm{~h}$ & $3 \%$ \\
\hline 4 & LiNHAc & $17 \mathrm{~h}$ & $68 \%$ \\
\hline 5 & LiNHAc & $48 \mathrm{~h}$ & $83 \%$ \\
\hline 6 & $\mathrm{Na}[\mathrm{N}(\mathrm{Ph}) \mathrm{Ac}]$ & $17 \mathrm{~h}$ & $0 \%$ \\
\hline 7 & $\mathrm{Na}[\mathrm{N}(i-\mathrm{Pr}) \mathrm{CO}(t-\mathrm{Bu})]$ & $17 \mathrm{~h}$ & $0 \%$ \\
\hline 8 & $\mathrm{Na}[\mathrm{N}(\mathrm{Et}) \mathrm{Ac}]$ & $48 \mathrm{~h}$ & $39 \%$ \\
\hline 9 a & LiNHAc & $17 \mathrm{~h}$ & $60 \%$ \\
\hline $10^{\mathrm{a}}$ & LiNHAc & $48 \mathrm{~h}$ & $65 \%$ \\
\hline $11^{b}$ & $\mathrm{NH}_{2} \mathrm{Ac}$ & $17 \mathrm{~h}$ & $18 \%$ \\
\hline $12^{c}$ & $\mathrm{NH}_{2} \mathrm{Ac}$ & $17 \mathrm{~h}$ & $18 \%$ \\
\hline $13^{\mathrm{d}}$ & $\mathrm{NH}_{2} \mathrm{Ac}$ & $17 \mathrm{~h}$ & $29 \%$ \\
\hline
\end{tabular}

General conditions: 2-phpyH (0.2 mmol, 2 eq), [Cp* $\left.\mathrm{CoI}_{2}\right]_{2}(0.1$ mmol, 1 eq), base $(0.6 \mathrm{mmol}, 6 \mathrm{eq}), \mathrm{DCM}(5 \mathrm{~mL}), 50^{\circ} \mathrm{C}$. ${ }^{a}$ same conditions but at room temperature. ${ }^{b}$ same conditions but with 4 eq of 2-phpyH. ${ }^{c}$ same conditions but with 8 eq of 2phpy. $d$ same conditions as $b+2$ eq of $\mathrm{Na}_{2} \mathrm{CO}_{3} \cdot 1,3,5-$ Trimethoxybenzene was used as internal ${ }^{1} \mathrm{H}$ NMR reference.

In the absence of base no trace of the desired complex 1a was observed in ${ }^{1} \mathrm{H}$ NMR after $17 \mathrm{~h}$ (Table 1 , entry 1 ). The first base probed for the cyclocobaltation was $\mathrm{NaOAc}$, which performed well in the iridium case, affording $\mathbf{2 a}$ in $\sim 93 \%$ yield for an overnight reaction $(17 \mathrm{~h}) .{ }^{99}$ In the case of cobalt, a maximum yield of $12 \%$ in the brown-greencoloured 1a complex was achieved after 2 days of reaction (Table 1, entry 2) in the presence of dry NaOAc. Like suggested by theory (Figure 1), the $\mathrm{C}-\mathrm{H}$ activation in the presence of $\mathrm{NaOAc}$ with $\left[\mathrm{Cp}^{*} \mathrm{CoI}_{2}\right]_{2}$ is much less favorable than with the $\left[\mathrm{Cp}^{*} \mathrm{IrCl}_{2}\right]_{2}$. Various lithium and sodium acetamidates were probed instead of auxiliary base. The use of the neutral acetamide (Table 1, entry 3 ) surprisingly led to $3 \%$ yield in 1a after an overnight reaction, whereas the use of its conjugate base produced by deprotonation of the $\mathrm{NH}_{2}$ group, i.e. $\mathrm{LiNHCOCH}_{3}$, yielded 1 a in $68 \%$ yield (Table 1 , entry 4).

By extending the reaction time to 2 days, 1a was isolated in $83 \%$ yield (Table 1 , entry 5 ). Worthy to note, the latter yield was readily reproduced when the amounts of reactants and solvent were scaled up 10 times. Three other amidate salts were also probed to evaluate the impact of sterics on the performance of the cyclometallation, that is sodium $\quad \mathrm{N}$-ethylacetamidate, sodium $\mathrm{N}$ isopropylacetamidate and sodium $N$-phenylacetamidate : all resulted in lower yields in 1a (Table 1, entries 6-8) suggesting that substitution at the $\mathrm{N}$ atom was strongly detrimental either on steric or electronic grounds.

Lowering the reaction temperature from $50{ }^{\circ} \mathrm{C}$ to room temperature $\left(\sim 20^{\circ} \mathrm{C}\right)$, while keeping reactants' proportions identical resulted into a slight drop of the yield in 1a when $\mathrm{LiNHCOCH}_{3}$ was the base : $60 \%$ yield were achieved when the reaction was conducted at room temperature over $17 \mathrm{~h}$ (entry 9). A longer reaction time of $48 \mathrm{~h}$ was not significantly beneficial (65\% yield in 1a, entry 10). In all experiments carried out in DCM, be it at room temperature or $50^{\circ} \mathrm{C}$, the formation of a purple side-product, putatively $[\mathbf{1 b}]\left[\mathrm{I}_{3}\right]$, was noticed. It presented no ability for cyclocobaltation after we succeeded in isolating it. Its crystallization by the slow diffusion method at $-20{ }^{\circ} \mathrm{C}$ afforded crystals suitable for structural X-ray diffraction analysis. The structure of [1b][I3] (Figure 9) that contains one bridging acetamidato and two bridging hydroxo ligands suggests it results from a reaction between $\left[\mathrm{Cp}^{*} \mathrm{CoI}_{2}\right]_{2}, \mathrm{LiNHCOCH}_{3}$ and adventitious water with concurrent oxidation of iodide into $\mathrm{I}_{3}$.

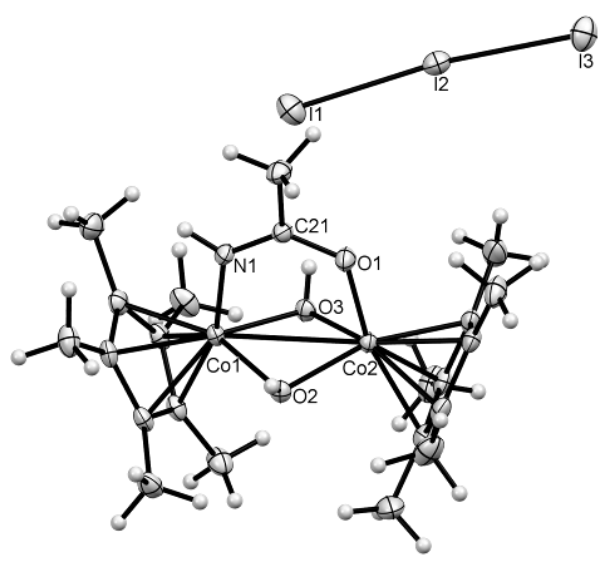

Figure 9. ORTEP diagram of $[\mathbf{1 b}]\left[\mathrm{I}_{3}\right]$ at $50 \%$ probability with partial atom numbering (cf. Supporting information for details).

A similar dinuclear structure containing two acetate bridging ligands was already pointed out by Perez-Temprano et al. for a cyclocobaltation reaction carried out with $\left[\mathrm{Cp} * \mathrm{Co}(\mathrm{MeCN})_{3}\right]^{+}$in the presence of acetate. ${ }^{56}[\mathbf{1 b}]\left[\mathrm{I}_{3}\right]$ is the only indirect but firm structural proof that the displacement of an iodide from $\left[\mathrm{Cp}^{*} \mathrm{CoI}_{2}\right]_{2}$ by the acetamidato ligand may occur in solution. Although the ${ }^{1} \mathrm{H}$ NMR monitoring of reactions of $\left[\mathrm{Cp}^{*} \mathrm{CoI}_{2}\right]_{2}$ with LiNHAc did result in the observation of a few new signals, it was not possible to confirm that those putative new species were related to anything close proposed in the CMD-type acetate promoted cyclometallation, ${ }^{59,100,101}$ such as $\mathrm{Cp} * \mathrm{Co}\left(\kappa^{2}-\mathrm{NHAc}\right)_{2}$ species , or $\mathrm{Cp}^{*} \mathrm{Co}\left(\kappa^{2}-\mathrm{NHAc}\right)^{+}$.

Our efforts to characterize 1a, the X-ray diffraction structure of which was already reported by Perez-Temprano et al., serendipitously led us to isolate a crystal of the formal product of the insertion of $\mathrm{Cp}^{*} \mathrm{H}$ into the cobaltacycle of $\mathbf{1 a}$ that is disclosed here in Figure 10, for it presents features that could open new venues. This salt of $\mathrm{I}_{3^{-}}$, i.e. [1c] $\left[\mathrm{I}_{3}\right]$, is one rare if not an unprecedented example of a product of a reaction of the $\mathrm{Cp}^{*}$ ligand, which is generally considered as spectator ligand, with the heterochelating 2-phpy ligand. 
Unfortunately, we did not succeed in finding the proper conditions to reproduce the synthesis of this organic salt at a preparative scale. Further investigations confirmed that the amount of dissolved $\mathrm{LiNHCOCH}_{3}$ in a given solvent during the cyclocobaltation was crucial in conditioning the yield in 1a. Indeed, it was found that a large excess of $\mathrm{LiNHCOCH}_{3}$ (10 equiv. per cobalt) inhibits the formation of 1a (yield $<5 \%$, Figure 11) and promotes the formation of an inert purple-colored side product.

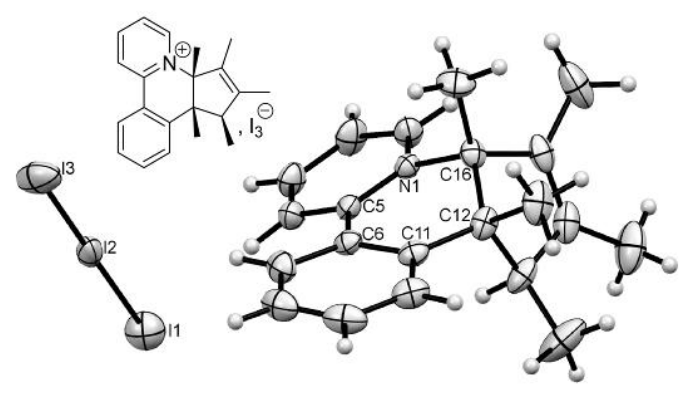

Figure 10. ORTEP diagram of the structure of $[\mathbf{1 c}]\left[\mathrm{I}_{3}\right]$ drawn at $50 \%$ probability (cf. Supporting information for details).

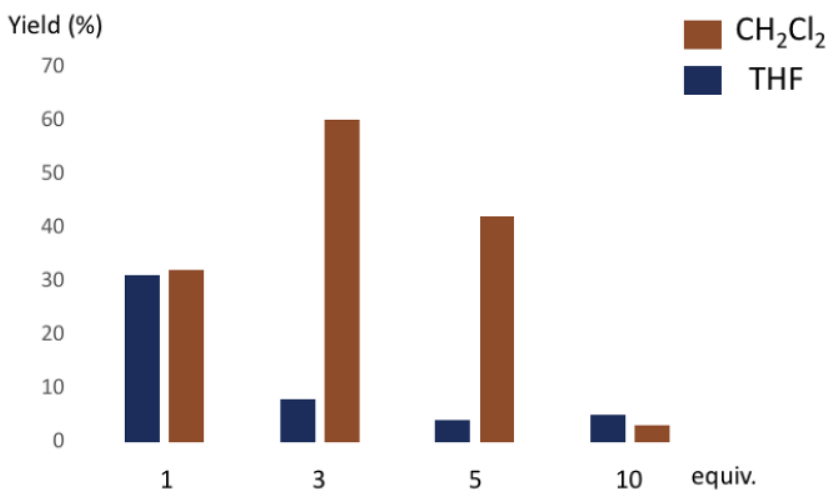

Figure 11. Effect of the solvent (THF vs DCM) on the yield in 1a upon cyclocobaltation of 2-phpy by $\left[\mathrm{Cp}^{*} \mathrm{CoI}_{2}\right]_{2}$ in the presence of various amounts of LiNHAc per Co atom (1, 3, 5 and 10 eqs).

Attempts to perform the cyclocobaltation reaction in tetrahydrofurane (THF), which dissolves acetamidate salts far better than DCM, counter-intuitively led to a significant shut off of the cyclometallation reaction resuting in $8 \%$ yield in 1a at proportions of reactants equivalent to those producing the highest yields in DCM. This result suggests that optimal cyclometallation can only be achieved if competing coordinative saturation of the metal centre and the formation of unproductive Co dimers are minimized not only by incomplete dissolution of the base salt but also by its steady dissolution as the reaction proceeds. DCM obviously meets this condition of heterogeneity of the reaction solution that prevents side reactions from overwhelmingly divert the fate of the cobaltation agent $\left[\mathrm{Cp}^{*} \mathrm{CoI}_{2}\right]_{2}$.

The result suggesting that acetamide could promote cyclocobaltation (Table 1, entry 3) led us to investigate the influence of the effect of higher amounts of 2phpyH on the yield in 1a since a Brønstedt base has to be present in the medium to ensure the irreversibility of the CMD mechanism. Increasing the excess in 2-phpyH from 2 to 4 and 8 fold in the presence of acetamide led to a clear enhancement in the yield in 1a that reached the threshold value of $18 \%$ in the last two cases (Table 1, entries 12 and 13). The addition of the poorly soluble $\mathrm{Na}_{2} \mathrm{CO}_{3}$ (2 eq.) pushed the yield in 1a further to 30\% (Table 1, entry 13). These observations of great importance for further applications suggest that amidate salts are not absolutely required to achieve the cyclocobaltation as long as an amide and a coordinatively non-interfering base are present in solution, the latter having putatively the role of deprotonating a transient Co-bound amide and generate in situ the amidato-Co species required for the metallation of the ligand via the CMD mechanism.

Compound 1a was readily converted into the $\mathrm{BArF}_{24}{ }^{-}$salt of cation $1 \mathbf{d}$ by replacement of the iodo ligand with acetonitrile, the structure of which is similar to that of the $\mathrm{BF}_{4}$ salt reported by Perez-Temprano ${ }^{53,56}$ (cf. Supporting Information for details).

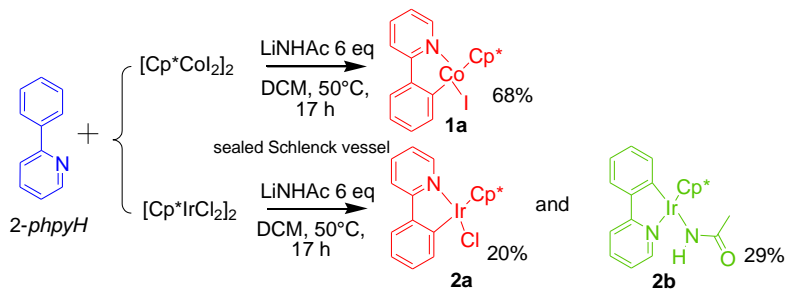

Scheme 3. Cyclocobalation and cycloiridation of 2-phpyH.

For the purpose of comparison cycloiridation was also attempted in the presence of $\mathrm{LiNHCOCH}_{3}$ under conditions identical to those used for cyclocobaltation $\left(50^{\circ} \mathrm{C}\right.$, DCM, 17 hours , 3 eq. per Ir). Interestingly, the overall yield in iridacycle was lower than that of the standard reaction carried out in the presence of $\mathrm{NaOAc}$. In fact, $\mathbf{2 a}$ was formed in only $20 \%$ yield (instead of $93 \%$ with NaOAc) but importantly the acetamidato derivative $\mathbf{2 b}$ was formed alongside in $29 \%$ of yield (scheme 3 ), bringing the overall yield in iridacycles to $49 \%$.

a)

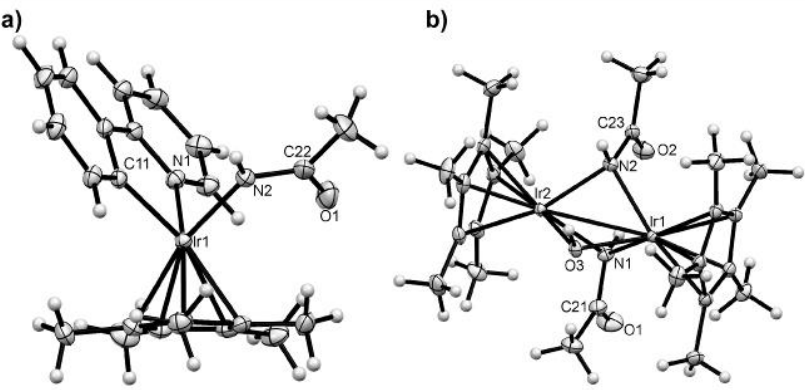

Figure 12. a) ORTEP diagram of $\mathbf{2 b}$ drawn at the $50 \%$ probability level with partial atom numbering (cf. Supporting information for details). c) ORTEP diagram of 2c drawn at the $50 \%$ probability level with partial atom numbering (cf. Supporting information for details)

This new stable complex $\mathbf{2 b}$ was isolated and fully characterized by spectroscopic and analytical methods $\left({ }^{1} \mathrm{H},{ }^{13} \mathrm{C}\right.$ NMR, x-ray diffraction, ESI mass spectroscopy and elemental analysis, cf. Supporting Information) and its structure was established by X-ray diffraction analysis (Figure 12a). 

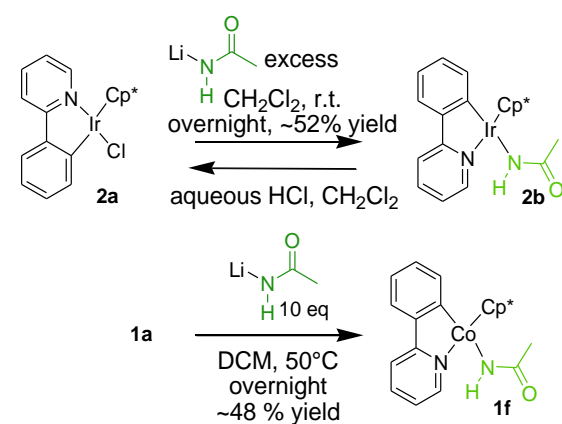

By reducing to 1 eq the amount of $\mathrm{LiNHCOCH}_{3}$ during the cycloiridation the formation of complex $\mathbf{2} \mathbf{b}$ was no more observed and only the desired complex $\mathbf{2 a}$ was produced in $92 \%$ yield. Evidence of the potential formation of $\mathbf{2} \mathbf{b}$ from a competing reaction of $\mathbf{2 a}$ with unreacted excess of $\mathrm{LiNHCOCH}_{3}$ during the cyclometallation process was readily demonstrated by the conversion of $\mathbf{2 a}$ into $\mathbf{2 b}(52 \%$ NMR yield) upon reaction of the former with 2 eq. of $\mathrm{LiNHCOCH}_{3}$ in $\mathrm{DCM}$ at $50^{\circ} \mathrm{C}$ conducted overnight (1). Importantly, $\mathbf{2 b}$, which is rather stable, was found to react quantitatively with aqueous chlorhydric acid to afford $\mathbf{2 a}$ (1). It was also shown that a too large excess of base could promote the formation of a dinuclear $\operatorname{Ir}($ III) amidato identified as complex $2 \mathbf{c}$ that could cause a significant drop of the yield in $\mathbf{2 a}$. The structure of $\mathbf{2} \mathbf{c}$ was solved by X-ray diffraction analysis (Figure $12 \mathrm{~b}$ ). This compound contains, apart from the $\mathrm{Cp}^{*}$ ligand, one hydroxo and two acetamidato ligands all $\mu$-bridging the two Ir(III) centres.

Quite interestingly, whilst no trace of a similar Coacetamidato complex, i.e 1f, was ever detected at the end of the cyclocobaltation reaction, this complex could be synthesized in ca. 48\% yield (NMR yield) from 1a by reaction with a large excess ( $>10$ fold) of $\mathrm{LiNHCOCH}_{3}$ (2). This stable complex 1f, which formed quantitatively was fully characterized by conventional analytical and spectroscopic methods $\left({ }^{1} \mathrm{H},{ }^{13} \mathrm{C}\right.$ NMR, ESI mass spectroscopy and elemental analysis, cf. supporting information) and its structure solved by X-ray diffraction analysis (Figure 13).

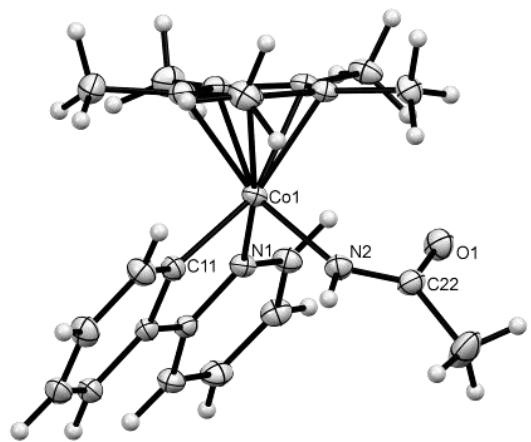

Figure 13. ORTEP diagram of $\mathbf{1 f}$ drawn at $50 \%$ probability with partial atom numbering. Molecules of solvents were omitted for the sake of clarity (cf. Supporting information for details).

Reaction of $\mathbf{1 f}$ with excess amounts of either $\mathrm{NaI}$ or $\left[n \mathrm{Bu}_{4} \mathrm{~N}\right] \mathrm{I}$ in $\mathrm{CH}_{2} \mathrm{Cl}_{2}$ at $50^{\circ} \mathrm{C}$ in a sealed Schlenk vessel for over $17 \mathrm{~h}$ produced complex $1 \mathrm{a}$ in $\sim 50 \%$ yield, thus suggesting that the formation of $\mathbf{1 f}$ under the conditions of cyclocobaltation is most probably precluded by amidato ligand's labity and by the higher affinity of the Co centre for the iodo ligand. DFT modeling of acetamidato ligand displacement by $\mathrm{I}^{-}$and $\mathrm{Cl}^{-}$in $\mathbf{1 f}$ and $\mathbf{2 b}$ respectively, produced slightly endoergonic processes, by only 1 $\mathrm{kcal} / \mathrm{mol}$ more favorable to the Co system.

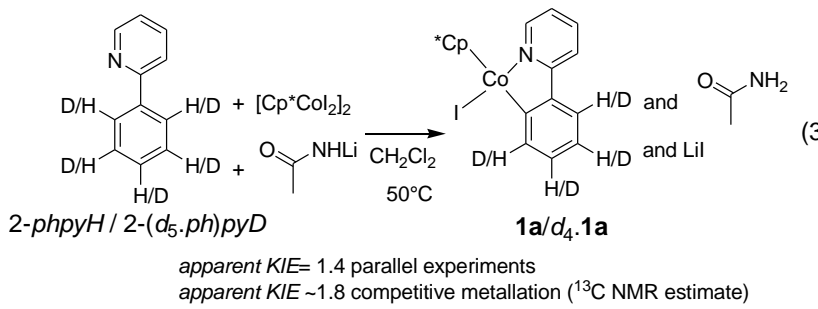

a)

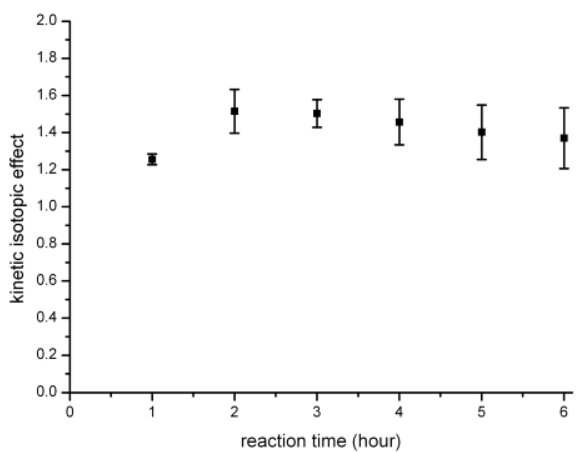

b)

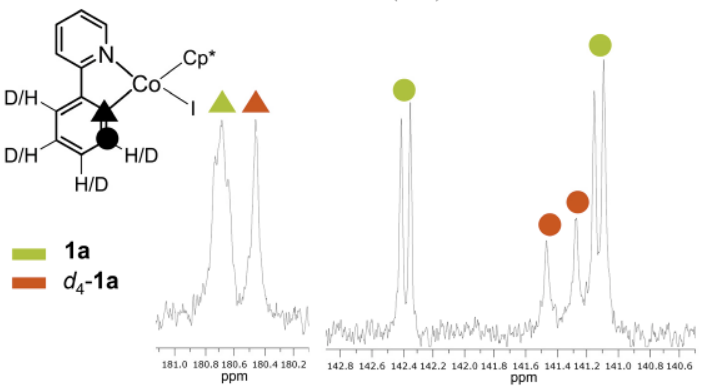

Figure 14. a) evolution of the KIE with error bars over 6 hours for independent cyclocobaltation reactions carried out under identical conditions in a sealed vessel in $\mathrm{CH}_{2} \mathrm{Cl}_{2}$ at $50^{\circ} \mathrm{C}$ with 2-phpyH and 2-(d5.ph)pyD. b) exerpts of the ${ }^{1} \mathrm{H}$ coupled ${ }^{13} \mathrm{C}$ NMR spectrum of the raw product displaying isotope shifts of resonances for the characteric signals used for the estimation of the KIE from their integration.

\section{Kinetic Isotope Effect}

The kinetic isotopic effect (KIE) of the cyclocobaltation of 2-phpyH (3) was determined by two independent experimental methods (Figure 14). The first one consisted of two independent time-monitored cyclocobaltation experiments carried out with 2-phpyH and 2- $\left(d_{5} . p h\right) p y D$ with identical amounts of $\left[\mathrm{Cp}^{*} \mathrm{CoI}_{2}\right]_{2}$ and lithium acetamidate in a sealed vessel at $50^{\circ} \mathrm{C}$ in the presence of an inert internal reference. Aliquots extracted every hour during a $6 \mathrm{~h}$ long monitoring were analyzed by ${ }^{1} \mathrm{H}$ NMR spectroscopy to determine the yield in metallacycle and infer the value of the KIE at time $t$ as $\mathrm{KIE}_{t}=$ (yield in 1a)/(yield in $d_{4}-\mathbf{1 a}$ ) (Figure 14a). Time monitoring of KIE was deemed important to trace down any significant variation of KIE that could be the symptom of competing mechanisms of metallation or to the raise of a partial equilibration of the cy- 
clometallation process that could occur due to the accumulation in the solution of the acetamide released by the reaction. ${ }^{102-104}$

The second method consisted of the room temperature cyclocobaltation of a 1:1 molar mixture of 2-phpyH and 2(d5.ph)pyD with $\left[\mathrm{Cp}^{*} \mathrm{CoI}_{2}\right]_{2}$ and lithium acetamidate followed by a ${ }^{1} \mathrm{H}$-coupled ${ }^{13} \mathrm{C}$ NMR spectroscopy analysis and integration of the ${ }^{13} \mathrm{C}$ signals typical of $\mathbf{1 a}$ and $d_{4}-\mathbf{1 a}$ that are readily discriminated by isotope shifts. ${ }^{105,106}$ The KIE was determined by comparing the integrations of ${ }^{13} \mathrm{C}$ signals of the Co-bound aromatic carbon of $1 \mathbf{a}$ and $d_{4}-\mathbf{1 a}$ as well as those of the vicinal H/D-bound ortho carbon.

The first method provided an average value of KIE, i.e $\mathrm{KIE}_{\text {average }}=1.4 \pm 0.1$ with no significant variations of $\mathrm{KIE}_{t}$ over time within the experimental error, suggesting no interference of a competing mechanism over time.

The second method based on the analysis of a ${ }^{1} \mathrm{H}$-coupled ${ }^{13} \mathrm{C}$ NMR noise corrected spectrum of a raw reaction mixture gave a larger span or primary KIE values comprised between 1.7 and 2.0 that are most probably biased by different spin-lattice relaxation times $T_{1}$ in $\mathbf{1 a}$ and $d_{4}-\mathbf{1 a}$ for the considered carbon nuclei (Figure 14b) showing up at $\delta \sim 180.6$ and $141.4 \mathrm{ppm}$.

A recent review by Hartwig et al. ${ }^{107}$ is particularly informative of the pitfalls in drawing conclusions from experimental KIEs without the complementary knowledge of reaction energy profiles that theoretical support can provide. To probe the CMD mechanism and its consistency with the experimental apparent KIE we applied the simplified Bigeleisen equation ${ }^{108-113}$ to compute KIEs of the key steps of the CMD mechanism. Quite interestingly this equation has been seldom used in investigations of the CMD mechanism. Most informations available from literature that pertain to the KIE in $\mathrm{C}-\mathrm{H}$ bond activation are extracted from investigations of catalyzed $\mathrm{C}-\mathrm{H}$ bond functionalizations or have been inferred from DFT using the Eyring equation ${ }^{50}$ with the approximation that the ratio between the transmission coefficients is unity, which can be an erroneous approximation. ${ }^{108}$

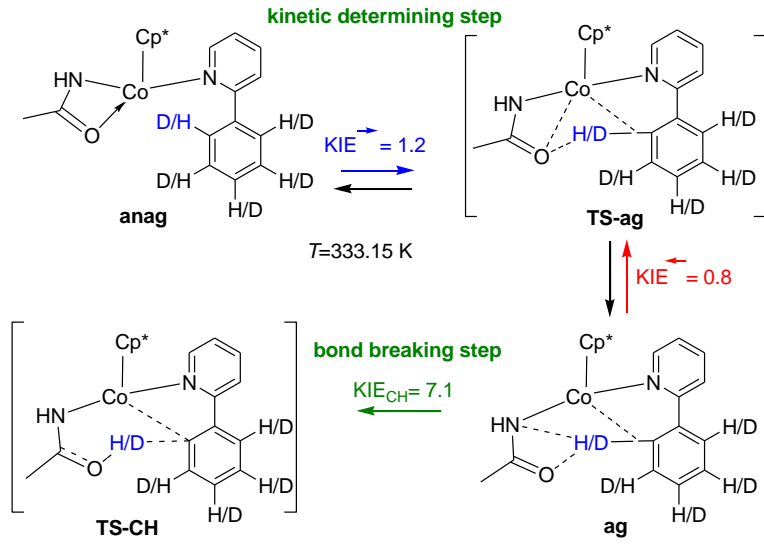

Scheme 4. Kinetic isotope effect computed from DFTcomputed vibrational frequencies with the Bigeleisen equation for key steps in the cyclocobaltation of 2-phpyH and 2-(d5.ph)pyD according to the CMD mechanism.
The simplified Bigeleisen equation ${ }^{114}$ offers ready access to KIEs of every single step in the CMD mechanism, it is deemed "semi-classical" as it neglects tunneling effects that may be relevant in the proton transfer step. ${ }^{115,116}$ In cases where the rate determining step coincides with the bond breaking step computed values of KIE are known to be systematically underestimated. ${ }^{111}$ Nevertheless, this approach has proven efficient in determining KIE for different proton-transfer reactions. ${ }^{111,112}$ In this study, KIEs were determined using solely harmonic vibrational frequencies that were readily calculated by DFT routines assuming the Born-Oppenheimer approximation. ${ }^{114}$ Forward $\mathrm{KIE}^{\rightarrow}$ and backward $\mathrm{KIE}^{\leftarrow}$ for the anag-ag step and $\mathrm{KIE}^{\mathrm{CH}}$ for the forward ag-to-TS-CH step were determined with the vibrational frequencies analytically computed for the considered stationary points at the COSMO $\left(\mathrm{CH}_{2} \mathrm{Cl}_{2}\right)$ ZORA-PBE-D3(BJ)/ all electron TZP level. This provided values of $\mathrm{KIE}^{\rightarrow}$ and $\mathrm{KIE}^{\leftarrow}$ of 1.2 and 0.8 respectively, and 8.9 for $\mathrm{KIE}^{\mathrm{CH}}$ at $T=298.15 \mathrm{~K}$. The values slightly changed at $T=$ $333.15 \mathrm{~K}$ (scheme 4) to $\mathrm{KIE}^{\rightarrow}=1.2, \mathrm{KIE}^{\leftarrow}=0.8$ and $\mathrm{KIE}^{\mathrm{CH}}=$ 7.1. In spite of the physical limitations of the Bigeleisen equation, those values of KIE are consistent with the experimental primary KIE of the cyclocobaltation reaction if one considers the formation of the agostic intermediate as being the kinetic determining step. Quite interestingly the computed $\mathrm{KIE}^{\rightarrow}$ values indicate that the formation of ag is not marked with an "inverse" KIE value typical of formally non-bond-breaking steps (i.e KIE < 1). ${ }^{104}$ Furthermore the $\mathrm{KIE}^{\leftarrow}$ value is consistent with a strengthening of the C-H(D) bond more favourable to the deuterated isomer in the backward ag-to-TS-ag path corresponding to the dismantlement of the agostic C-H...Co interaction. Also important is the fact that KIE ${ }^{\mathrm{CH}}$ holds the highest value, which is consistent with the quasi-linearity of the key bonds being disrupted and formed in TS-CH according to Westheimer's model. ${ }^{117}$

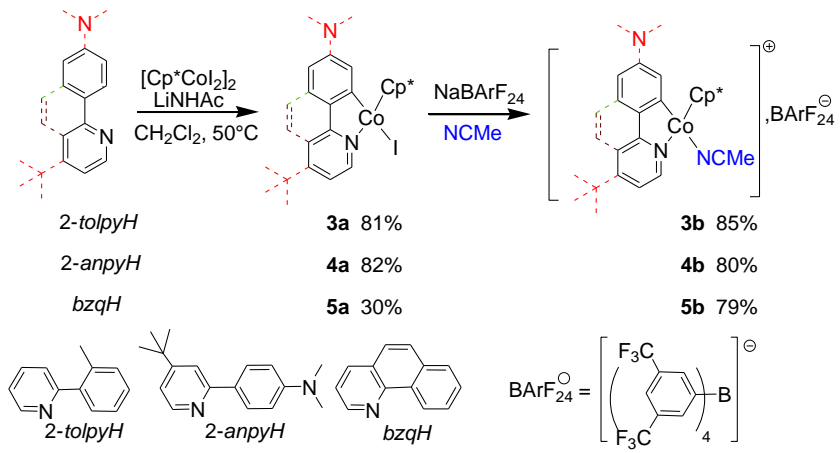

Scheme 5. Cyclocobaltation of 2-tolpy $H, 2$-anpy $H$ and $b z q H$ and the conversion of the resulting iodo cobaltacycles into the acetonitrile solvato complexes.

\section{Amidate-assisted Cyclocobaltation}

The cyclocobaltation method using lithium acetamidate was evaluated with other ligands under the optimized conditions discussed above for 2-phpyH (scheme 5): 7,8benzo[h]quinoline (abbr. bzqH), 4-[4-( $t$-butyl)pyridin-2yl]- $N, N$-dimethylaniline ${ }^{118}$ (abbr. 2-anpyH) and the 2-(2methylphenyl)pyridine (abbr. 2-tolpyH) were successfully used allowing the formation of the corresponding 
complexes 3a, $\mathbf{4 a}$ and $\mathbf{5 a}$ in $81 \%, 82 \%$ and $30 \%$ isolated yield respectively.

These three new complexes were fully caracterized by ${ }^{1} \mathrm{H}$ and ${ }^{13} \mathrm{C}$ NMR, ESI mass spectroscopy and elemental analysis (see also supporting information). All attempts to cyclometallate 1,2-diphenylquinoxaline or $\mathrm{N}, \mathrm{N}$ dimethylbenzylamine failed to produce any traceable organometallic complex. The structures of $\mathbf{4 a}$ and $\mathbf{5 a}$ were determined by X-ray diffraction analysis from suitable single crystals (Figure 15b,d).

Other structural confirmations were obtained by converting quantitatively the three new neutral $\mathrm{Cp}^{*} \mathrm{Co}$ (III) complexes 3-5a into the corresponding acetonitrilo (solvato) complexes $\mathbf{3 - 5 b}$ respectively by displacing the iodo ligand by acetonitrile in the presence of 2 eq of $\mathrm{NaBArF}_{24}$ at room temperature during 1 hour (scheme 5). The new complexes were fully caracterized by ${ }^{1} \mathrm{H},{ }^{13} \mathrm{C} \mathrm{NMR}$, ESI mass spectroscopy and elemental analysis (see supporting information). Structural informations on $\mathbf{3 b}$ and $\mathbf{4 b}$ were obtained by X-diffraction analysis of suitable crystals (Figure 15a,c).

Worthy to note, compounds $\mathbf{3 - 5 b}$ were also probed as potential hydrosilylation catalysts ${ }^{119-121}$ but showed no activity in benchmark catalytic test runs of the dehydro-0silylation of benzyl alkohol. 119 Furthermore, low temperature reaction with $\mathrm{Et}_{3} \mathrm{SiH}$ in $\mathrm{CH}_{2} \mathrm{Cl}_{2}$ carried out in the conditions used with the Ir analogues ${ }^{119-121}$ resulted in the full decomposition of the metallacycle into untraceable products.
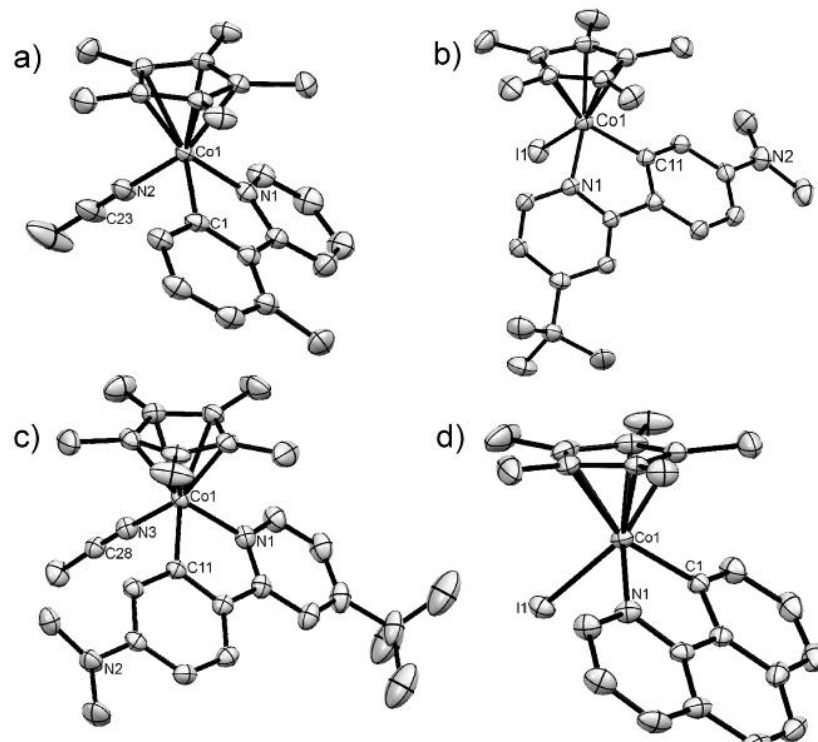

d)

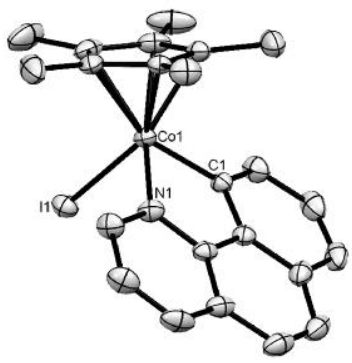

Figure 15. ORTEP diagram of the structures of $\mathbf{3 b}(\mathrm{a}), \mathbf{4 a}(\mathrm{b})$, $4 \mathbf{b}$ (c) and 5a (d) drawn at 50\% probability level with partial atom numbering. $\mathrm{H}$ atoms and molecules of solvent have been omitted for the sake of clarity (cf. Supporting information for details).

5. Catalytic Application of the Amidate Assisted C-H bond Activation to the Condensation of Diphenylacetylene with Aromatic Substrates.
The condensation of alkyne with metallacycles ${ }^{122-126}$ is a well established process that has recently been ported to Cp*Co(III) catalysis by the groups of $\mathrm{Zhu}^{*}{ }^{54} \mathrm{Cheng}^{11}$ and Perez-Temprano. ${ }^{53,55,56,127}$ In the latter's reports particularly, the outlying feature of this catalytic process is the putative electrophilic activation of the $\mathrm{C}-\mathrm{H}$ bond of the main heterocyclic substrate by $\left[\mathrm{Cp}^{*} \mathrm{Co}(\mathrm{MeCN})_{3}\right]^{+}$.

Given the accessibility of $\left[\mathrm{Cp}^{*} \mathrm{CoI}_{2}\right]_{2}$ and its great temperature and air stability, several attempts to achieve the condensation of diphenylacetylene with 2-phpyH were undertaken in this study so as to figure out whether an auxiliary base could be beneficial. Table 2 summarizes the methodology used therein, which was mostly inspired by that used by Perez-Temprano et al.12,16,47 for the purpose of comparison. Quite expectedly blank experiments in the presence of the sole $\mathrm{AgBF}_{4}$ and excluding $\left[\mathrm{Cp}^{*} \mathrm{CoI}_{2}\right]_{2}$ led to no conversion (Table 2, entry 9). The contribution of the electrophilic activation pathway was confirmed by performing the condensation reaction with 2 eq. of $\mathrm{AgBF}_{4}$ relative to 2phpyH and no base, which provided a yield in the condensation product of $49 \%$ (Table 2, entry 1). Under identical conditions the addition of molar $30 \%$ of NaOAc (Table 2, entry 7) did not improve the yield in condensation product. However, the use of molar $30 \%$ of LiNHAc raised the yield up to $71 \%$ (Table 2 , entry 8 ).

Table 2. Performance of the catalyzed condensation 1,2-diphenylacetylene with 2-phpyH.

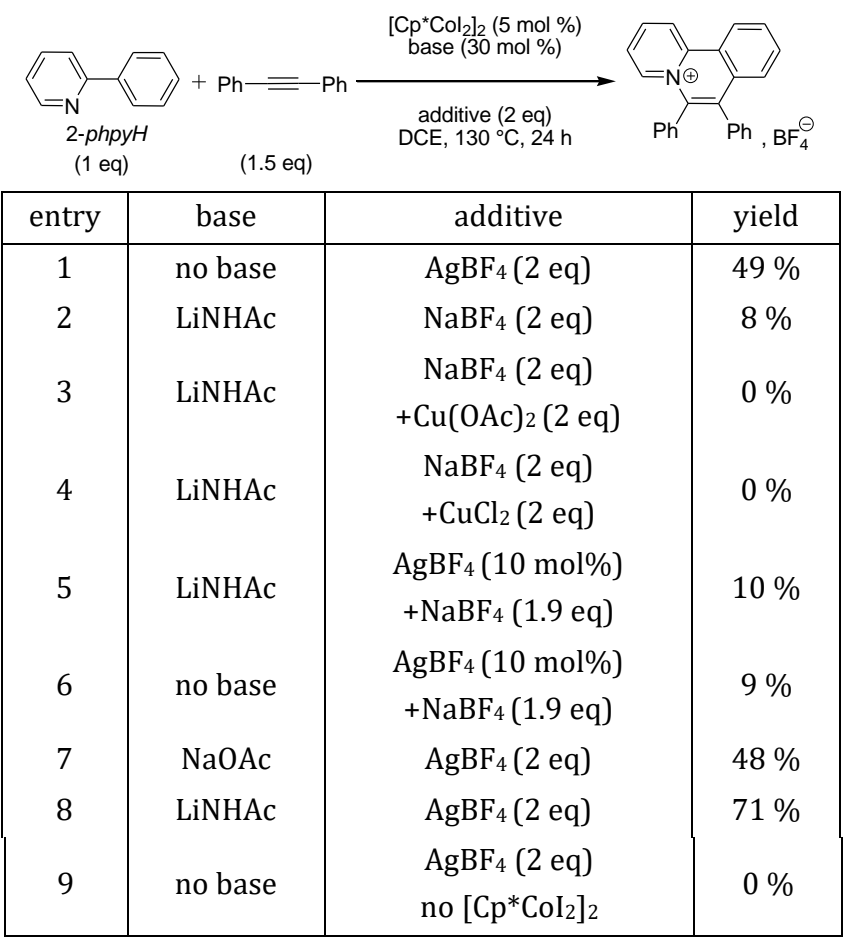

General conditions: 2-phpyH (0.1 mmol, 1 eq), diphenylacetylene $(0.15 \mathrm{mmol}, 1.5 \mathrm{eq}),\left[\mathrm{Cp}^{*} \mathrm{CoI}_{2}\right]_{2}(0.005 \mathrm{mmol}, 5$ mol\%), with or without LiNHAc (0.03 mmol, $30 \mathrm{~mol} \%)$, DCE (5 mL), + additive, at $130{ }^{\circ} \mathrm{C}$ for $24 \mathrm{~h}$. Trimethoxybenzene was used as internal ${ }^{1} \mathrm{H}$ NMR reference.

Other variants entail the use of a preformed solvatocobalt(III) metallacycle of 2-phpy as the catalyst. In almost all cases reported to date with $\mathrm{Cp}^{*} \mathrm{Co}$ catalysts the effective 
assistance of an auxiliary base was either not considered or not established. ${ }^{54}$

The role of the silver salt is particularly important, for it contributes to halide abstraction and to the necessary oxidation of transient $\mathrm{Cp}^{*} \mathrm{Co}(\mathrm{I})$ species produced in the reductive coupling step: reducing its amount to molar 10 $\%$ and replacing it by $\mathrm{NaBF}_{4}$ for the purpose of ionic balance, expectedly cuts the yield in condensation product down to $\sim 10 \%$ (Table 2, entry 5). Worthy to note, its replacement by a copper(II) acetate in the presence of $\mathrm{LiN}$ HAc does not produce any annulation product (Table 2, entry 3).

Table 3. Catalyzed condensation of various aromatic substrates with 1,2-diphenylacetylene.
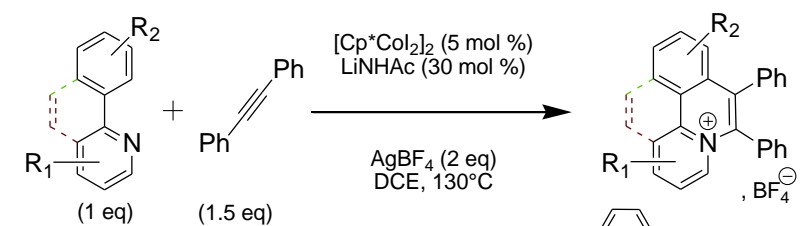

$$
\text { (1 eq) (1.5 eq) }
$$
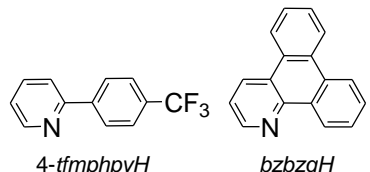

4-tolpyH $b z b z q H$

\begin{tabular}{|c|c|c|c|c|}
\hline entry & substrates & $\begin{array}{l}\text { reac- } \\
\text { tion } \\
\text { time }\end{array}$ & $\begin{array}{c}\text { isolated } \\
\text { yield }\end{array}$ & $\begin{array}{l}\text { product } \\
\text { ref. }\end{array}$ \\
\hline 1 & 2-phpyH & $\begin{array}{r}3 h \\
24 h\end{array}$ & $\begin{array}{l}61 \% \\
71 \%\end{array}$ & 11,46 \\
\hline 2 & $b z q H$ & $24 h$ & $75 \%$ & 11,46 \\
\hline 3 & $b z b z q H$ & $24 \mathrm{~h}$ & $38 \%$ & this study \\
\hline 4 & 2-tolpyH & $\begin{array}{r}3 h \\
24 h\end{array}$ & $\begin{array}{l}27 \% \\
45 \%\end{array}$ & 11,46 \\
\hline 5 & 4-tolpyH & $24 \mathrm{~h}$ & $45 \%$ & 11,46 \\
\hline 6 & 4-tfmphpyH & $24 h$ & $50 \%$ & 11,46 \\
\hline 7 & 2-апруH & $24 \mathrm{~h}$ & $0 \%$ & \\
\hline 8 & $\begin{array}{l}N, N \text {-dimethyl } \\
\text { benzylamine }\end{array}$ & $\begin{array}{l}3 \mathrm{~h} \\
17 \mathrm{~h}\end{array}$ & $\begin{array}{l}0 \% \\
0 \%\end{array}$ & \\
\hline 9 & $\begin{array}{l}\text { 1,2-diphenyl } \\
\text { quinoxaline }\end{array}$ & $\begin{array}{r}3 \mathrm{~h} \\
17 \mathrm{~h}\end{array}$ & $\begin{array}{l}0 \% \\
0 \%\end{array}$ & \\
\hline
\end{tabular}

General conditions: substrates $(0.1 \mathrm{mmol}, 1 \mathrm{eq})$, diphenylacetylene $(0.15 \mathrm{mmol}, 1.5 \mathrm{eq}),\left[\mathrm{Cp}^{*} \mathrm{CoI}_{2}\right] 2$ (0.005 mmol, 5 mol\%), LiNHAc (0.03 mmol, $30 \mathrm{~mol} \%), \mathrm{AgBF}_{4}(0.2 \mathrm{mmol}, 2$ eq), DCE ( $5 \mathrm{~mL})$, at $130{ }^{\circ} \mathrm{C}$ for $24 \mathrm{~h}$. Trimethoxybenzene was used as internal ${ }^{1} \mathrm{H}$ NMR reference.

Further condensation reactions (Table 3) were undertaken with other aromatic substrates using the conditions that afforded the best yields with 2-phpyH (Table 2, entry 8). All the considered substituted 2-arylpyridines provided the condensation products with yields higher than $60 \%$ after $3 \mathrm{~h}$ of reaction at $130^{\circ} \mathrm{C}$ in DCE in a sealed Schlenk tube. Worthy to note, 1,2-diphenylquinoxaline and $\mathrm{N}, \mathrm{N}$ dimethylbenzylamine, which already showed no propensity to afford a cobaltacycle were left unchanged. Furthermore, bzqH, which showed moderate ability to form cobaltacycle 5a provided the condensation product in $75 \%$ yield after $24 \mathrm{~h}$ of reaction under the conditions of catalysis. Its parent dibenzo[f,h]quinoline, i.e $b z b z q \mathrm{H}$, reacted more sluggishly affording the annulation product in $34 \%$ yield after $24 \mathrm{~h}$.

If these informations plead in favour of a dominant electrophilic $\mathrm{C}-\mathrm{H}$ bond activation pathway where an auxiliary base such as the heterocyclic substrate itself or any other base could act unbonded to the metal center for instance, the contribution of a concurrent CMD mechanism cannot be ruled out when LiNHAc is present. Worthy to note, in the case of a domino catalysis promoted by $\mathrm{Cp}^{*} \mathrm{Co}(\mathrm{III})$, Ackermann et al. ${ }^{58}$ have indeed recently priviledged the socalled base assisted intramolecular electrophilic-type substitution (BIES) mechanism rather than the CMD one even though the formulation of their mechanism is again very similar to that of the CMD where the formation of an agostic intermediate remains crucial.

However, this contribution might be minor if one considers that in the absence of $\mathrm{AgBF}_{4}$ the conversion in the conditions required for the CMD mechanism to operate corresponds to the maximum achievable value in the absence of any oxidizing agent with $10 \mathrm{~mol} \%$ catalyst (Table 2, entry 2).

Situations where two mechanisms might coexist are not specific to Co though and have been considered earlier by Davies, Macgregor et al. for the condensation of alkynes with 3-arylpyrazoles catalyzed by either $\left[\mathrm{Cp}^{*} \mathrm{Rh}(\mathrm{MeCN})_{3}\right]\left[\mathrm{PF}_{6}\right]_{2}$ or $\left[(p \text {-cymene }) \mathrm{RuCl}_{2}\right]_{2 .}{ }^{124}$ Another example adressed by $\mathrm{Qu}$ and Cramer $^{15}$ for the $\mathrm{C}-\mathrm{H}$ bond functionalization with diazo compounds catalyzed by Cp*Co(III)/Rh(III) complexes tends to suggest the possible coexistence of two mechanisms of $\mathrm{C}-\mathrm{H}$ bond activation. On the basis of the data collected in the present study the KIE might be a good indication of the nature of the dominating mechanism : an electrophilic activation (abbr. EA) of a C-H bond being expected to produce a much higher KIE than that of a reaction governed by the CMD mechanism ${ }^{59}$ for which the kinetic determining step is the formation of the agostic intermediate ag. This assumption is supported by the data published by Cheng et al. ${ }^{46}$ for the annulation reaction of 2-phpyH with 1,2-diphenylacetylene promoted by the $\left[\mathrm{Cp}^{*} \mathrm{RhCl}_{2}\right]_{2} / \mathrm{Cu}\left[\mathrm{BF}_{4}\right]_{2} / \mathrm{O}_{2}$ mixture in $1,2-$ dimethoxyethane, which showed KIE values spanning 2.03 -2.84 . 


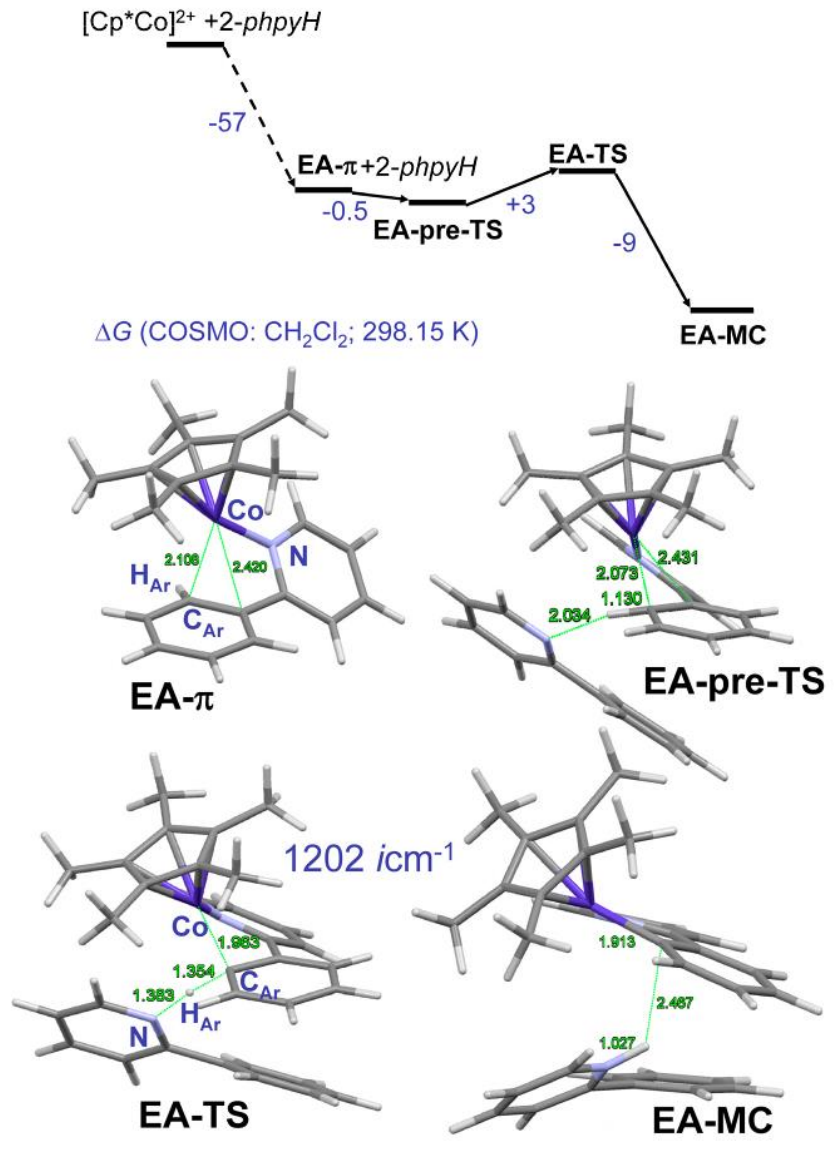

Figure 16. Top: Gibbs enthalpy profile (in $\mathrm{kcal} / \mathrm{mol}$ at $T=$ $298.15 \mathrm{~K})$ computed at the $\operatorname{COSMO}\left(\mathrm{CH}_{2} \mathrm{Cl}_{2}\right)$-ZORA-PBED3(BJ)/all electron TZP level for a model of the electrophilic activation of the $\mathrm{CAr}_{\mathrm{Ar}} \mathrm{H}_{\mathrm{Ar}}$ bond of 2-phpyH with the exogenous intervention of external 2-phpyH acting as proton acceptor in the EA- $\boldsymbol{\pi}$-to-EA-MC process via dicationic reactive complex EA-pre-TS and transition state EA-TS. Bottom: CSD-Mercury drawings of geometries and selected interatomic distances (green colored fonts) are given in $\AA$.

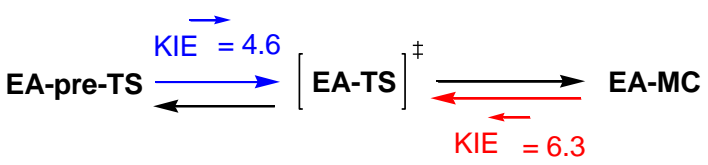

Scheme 6. Kinetic isotope effects as determined by the Bigeleisen method from the Born-Oppenheimer treatment of the vibrational frequencies of protio and deuterio stationary points in Figure 16.

We evaluated the KIE of the cyclocobaltation of a modeled EA mechanism that most likely occurs in reactions wherein excess $\operatorname{Ag}(\mathrm{I})$ salt is used: this hypothesis entails the formation of a 14-electron dicationic $\pi$-complex, i.e EA- $\pi$ from the fictitious $\left[\mathrm{Cp}^{*} \mathrm{Co}\right]^{2+}$ species and 2-phpyH. In this mechanism a second exogenous molecule of 2-phpyH intervenes as a base to form reactive complex EA-pre-TS and abstract the $\mathrm{H}_{\text {Ar }}$ proton via EA-TS to afford a dicationic molecular complex between the new cobaltacycle and the protonated 2-phenylpyridine, i.e $[\mathrm{H}(2-p h p y H)]^{+}$. This scenario is slightly different from the one priviledged by $\mathrm{Qu}$ and $\mathrm{Cramer}^{15}$ for a $\mathrm{Cp} * \mathrm{Rh}(\mathrm{III})$ electrophilic $\mathrm{C}-\mathrm{H}$ bond activation mechanism which considered the preliminary
$\mathrm{Rh}$ binding of the second 2-phpyH ligand prior to its migration to abstract the proton of the $\mathrm{C}-\mathrm{H}$ bond, resulting in a large activation barrier of ca. $16 \mathrm{kcal} / \mathrm{mol}$. The theoretical $\mathrm{KIE}^{\circ}(4.6)$ and $\mathrm{KIE}^{\leftarrow}$ (6.3) values (scheme 6) were computed by applying the simplified Bigeleisen method, ${ }^{114}$ considering the Born-Oppenheimer approximation on the pentadeuterophenyl fragment that undergoes metallation in EA-pre-TS and EA-TS and on the non-bonded $N$-deuterio,2-phenylpyridinium and the tetra deuterated phenylene of the metallacycle in molecular complex EA-MC. In such a scenario the proton abstraction step is the kinetic determining step and requires a rather low Gibbs enthalpy of activation $(+3 \mathrm{kcal} / \mathrm{mol})$ as compared to that required to the acetamidato-promoted CMD mechanism (ca. +7 kcal/mol, Figure 1), which demontrates clearly that the EA mechanism is indeed a serious challenger to the CMD mechanism discussed previously.

\section{CONCLUSION}

This study shows that cobaltacycles are not elusive and can be readily prepared in good yields via the base assisted CMD mechanism provided that the proper base is chosen to optimize the formation of the transient agostic intermediate. This choice of base can be greatly enlightened by theory like shown in this study, which considered necessary to approach the $\mathrm{C}-\mathrm{H}$ bond activation mechanism by focussing attention on the role of the noncovalent interactions. The relevance of noncovalent interactions in the CMD-promoted cyclocobaltation is evident from the evolution of the so-called reaction site along reaction coordinates: the remarkable contribution of local electrostatic interactions and therefore of the multipolar environment to the polarization of the $\mathrm{C}_{\mathrm{Ar}}-\mathrm{H}_{\mathrm{Ar}}$ bond prior to its activation by carbometallation and proton transfer to the neighboring base gives a valid rationale for the optimization not only of cyclocobaltation and cyclonickelation but also of cyclometallations using other $3 \mathrm{~d}$ metals. This account of NCI constitutes in our view the cornerstone to the effective use of $3 \mathrm{~d}$ metal complexes in $\mathrm{C}-\mathrm{H}$ bond activation be it via the CMD or the EA mechanism. In this study, like in the previous one dealing with cyclonickelation ${ }^{49}$ wherein experimental validation was not sought, the benefit of using an acetamidate salt as base inferred from theory has now been confirmed experimentally. This study shows that the use of an acetamidato base/ligand reduces the residual chelation interaction with metal and consequently enhances the polarization of the $\mathrm{C}-\mathrm{H}$ bond that is already engaged in a partly covalent partly noncovalent agostic interaction with the positively charged metal centre. This is a promising basis for the further development of enantioselective $\mathrm{C}-\mathrm{H}$ bond functionalization ${ }^{128,129} \mathrm{Cp}^{*} \mathrm{Co}$ (III) catalysis ${ }^{130}$ since it has been recently reported that amide-based enantiopure ligands ${ }^{92,131,132}$ may not only assist $\mathrm{C}-\mathrm{H}$ bond activation via the CMD mechanism but also induce stereodiscrimination at the level of the agostic transient in Pd(II)-promoted catalysis. By extension to Co(III) stereocentres the same concept could lead to effective stereodifferentiation in the proton transfer-carbometallation step and consequently initiate chiral induction in further 
steps, a feature that the herein merely addressed EA mechanism is less prone to achieve.

\section{EXPERIMENTAL SECTION}

General. All experiments were conducted under a dry argon atmosphere using standard Schlenk lines and dry glovebox techniques. The following compounds were purchased from SigmaAldrich: 2-phenylpyridine (abbr. 2phpyH, $98 \%$ ), benzo[h] quinoline (abbr. bzqH, 97 \%), dibenzo[f,h]quinoline (abbrev. bzbzqH), 2-(o-tolyl)pyridine (abbr. 2-tolpyH, $98 \%$ ), $\mathrm{N}, \mathrm{N}$-dimethylbenzylamine (99\%); diphenylacetylene (98\%). The following compounds were purchased from TCI Chemicals: 2-( $p$-tolyl)pyridine (abbr. 4-tolpyH, $97 \%$ ), 2-[4-(trifluoromethyl)phenyl]pyridine (abbr. 4-tfmphpyH, $98 \%$ ). The following compounds were purchased from Alfa Aesar: 1,2,3,4,5pentamethylcyclopentadiene (abbr. Cp*, $94 \%$ ), and sodium tetrakis[3,5-bis(trifluoromethyl)phenyl]borate (NaB$\mathrm{ArF}_{24}, 97 \%$ ). Anhydrous sodium acetate (NaOAc, $99 \%$ ), was purchased from Fluka. $\mathrm{Co}_{2}(\mathrm{CO})_{8}$ was purchased from Pressure Chemical Co. The compound 4-tertiobutyl,2-(4$\mathrm{N}, \mathrm{N}$-dimethylaminophenylene)pyridine (abbr. 2-anpyH), 2,3-Diphenylquinoxaline and the cobalt(III) complexes $[\mathrm{Cp} * \mathrm{Co}(\mu-\mathrm{I}) \mathrm{I}]_{2}$ were prepared as reported in the literature. ${ }^{19,133,134}$ All solvents were distilled over sodium or $\mathrm{CaH}_{2}$ under argon before use. Deuterated solvents were dried over sodium or $\mathrm{CaH}_{2}$, filtered over activated neutral alumina, and stored under argon before use. ${ }^{1} \mathrm{H}(300,400$, 500 , and $600 \mathrm{MHz}),{ }^{11} \mathrm{~B}(128 \mathrm{MHz}),{ }^{13} \mathrm{C}$ (75 and $\left.126 \mathrm{MHz}\right)$, and ${ }^{19} \mathrm{~F}$ (282 MHz) NMR spectra were measured on Bruker DPX 300 and 400, Avance I 500, and Avance III 600 spectrometers. Chemical shifts (expressed in parts per million) were referenced against solvent peaks or external reference standards $\left(\mathrm{CF}_{3} \mathrm{C}_{6} \mathrm{H}_{5}\right.$ in $\mathrm{CDCl}_{3}$ for ${ }^{19} \mathrm{~F}$, and $\mathrm{NaBH}_{4}$ in $\mathrm{D}_{2} \mathrm{O}$ for ${ }^{11} \mathrm{~B}$ ). Mass spectra were run on a MicroTOF Bruker Daltonics spectrometer, using a TOF-ESI coupling analysis system. Elemental analyses were achieved with Thermo Scientific FLASH 2000 CHNS/O analyzers.

Structural X-ray Diffraction Analyses. The crystals were placed in oil, and a single crystal was selected, mounted on a glass fibre and placed in a low-temperature $\mathrm{N}_{2}$ stream. For complexes 1b, 1c, 4a and 5a, X-Ray diffraction data collection was carried out on a Bruker APEX II DUO KappaCCD diffractometer equipped with an Oxford Cryosystem liquid $\mathrm{N}_{2}$ device, using Mo-K $\alpha$ radiation $(\lambda=0.71073 \AA)$. The crystal-detector distance was $38 \mathrm{~mm}$. The cell parameters were determined (APEX3 software) ${ }^{135}$ from reflections taken from three sets of 12 frames, each at $10 \mathrm{~s}$ exposure. The structures were solved using the program SHELXT2014.136 The refinement and all further calculations were carried out using SHELXL-2014137 or SHELXL-2018. ${ }^{137}$ The $\mathrm{H}$-atoms were included in calculated positions and treated as riding atoms using SHELXL default parameters. The non-H atoms were refined anisotropically, using weighted full-matrix least-squares on $F^{2}$. A semi-empirical absorption correction was applied using SADABS in APEX3 ${ }^{135}$. For complexes 1f, $\mathbf{2 b}, \mathbf{2 c}, \mathbf{3 b}, \mathbf{4 b}$ and $\mathbf{5 b}$ X-ray diffraction data collection was carried out on a Bruker PHOTON III
DUO CPAD diffractometer equipped with an Oxford Cryosystem liquid $\mathrm{N}_{2}$ device, using $\mathrm{Mo}-\mathrm{K} \alpha$ radiation $(\lambda=$ $0.71073 \AA$ ). The crystal-detector distance was $37 \mathrm{~mm}$. The cell parameters were determined (APEX3 software) ${ }^{135}$ from reflections taken from 1 set of 180 frames at $1 \mathrm{~s}$ exposure. The structures were solved using the program SHELXT-2014. ${ }^{136}$ The refinement and all further calculations were carried out using SHELXL-2014.137 For complexes 1f, $\mathbf{2 b}$ and $\mathbf{2 c}$ the hydrogen atoms of the NH groups, $\mathrm{OH}$ groups and of the water molecules were located from Fourier difference. The other $\mathrm{H}$-atoms were included in calculated positions and treated as riding atoms using SHELXL default parameters. The non-H atoms were refined anisotropically, using weighted full-matrix leastsquares on $F^{2}$. For complexes $\mathbf{4 b}$ and $\mathbf{5 b}$, the SQUEEZE instruction in PLATON ${ }^{138}$ was applied. A semi-empirical absorption correction was applied using SADABS in APEX3 ${ }^{135}$

\section{Computational details.}

DFT-D computations. Geometry optimizations of reactants, intermediates, transitions states and products were performed with the methods of density functional theory using the SCM-ADF2019.01 package, ${ }^{139}$ considering the molecules in the gas phase at the singlet state. The $\mathrm{PBE}^{70}$ functional augmented with Grimme's DFT-D3(BJ) implementation of dispersion ${ }^{140,141}$ with a Becke-Johnson (BJ) damping function ${ }^{71-73}$ was used in all geometry optimizations. All geometry computations were carried out using scalar relativistic corrections within the zeroth order regular approximation for relativistic effects with ad hoc allelectron (abbr. ae) single polarization function triple- $\zeta$ Slater type basis sets (TZP). ${ }^{142-144}$ Solvation was treated by the COSMO ${ }^{67-69}$ procedure assuming $\mathrm{CH}_{2} \mathrm{Cl}_{2}(\varepsilon=8.93)$ as the solvent. Geometry optimizations by energy gradient minimization were carried out in all cases with integration grid accuracy comprised between 4.5 and 6.5, an energy gradient convergence criterion of $10^{-3} \mathrm{au}$, and tight to very tight SCF convergence criteria. All transition states were submitted to the Intrinsic Reaction Coordinate (IRC) procedure to verify the connection to their reactive complexes and products. Counterpoise correction for basis set superposition error (BSSE) was neglected throughout this study. Vibrational modes were analytically computed to verify that the optimized geometries were related to energy minima or to transition states. Bader (QTAIM) charges $^{89}$ and Interacting Quantum Atoms ${ }^{86,88}$ analyses (IQA) were carried out using the embedded QTAIM functionalities of the ADF package. For technical reasons regular all electron TZP Slater type basis sets for all elements except for Ir, for which a basis set with a frozen core up to $3 d$ was used for IQA. Drawings of molecular structures were produced with ADFview2019 and with CSD-Mercury. ${ }^{145}$

DLPNO-CCSD(T) computations. For each of the four studied system, DLPNO-CCSD(T) ${ }^{77-83}$ calculations with the TightPNO threshold on the PBE-D3(BJ) optimized geometries for anag, TS-ag, ag, TS-CH and $\mathbf{M C H}$ were performed using the ORCA $^{77}$ program system version 4.1.1. The balanced Karlsruhe 2nd generation default triple- $\zeta$ valence plus polarization (def2-TZVP ${ }^{146}$ ) basis set was used in these calculations, as well as automatically generated aux- 
iliary basis set. The LED ${ }^{82}$ analysis has been performed to quantify the different intra- and inter-fragment contributions to the energy.

NCI plots. The NCI index is based on the analysis of the reduced density gradient ${ }^{84,85}$ :

$$
s(r)=\frac{1}{2\left(3 \pi^{2}\right)^{\frac{1}{3}}} \times \frac{|\nabla \rho|}{\rho^{\frac{4}{3}}}
$$

which depends on the electron density and its gradient. It is based on two simple considerations to define all possible NCIs: $i$ ) given the fact that the density decays exponentially with distance from the nuclear position, the regions of space involved in NCIs have low density, and ii) in the NCI regions the reduced density gradient approaches zero, leading to a local minimum. Combining these two criteria, one can detect NCIs over a three-dimensional grid looking for the low $\rho(r)$ and low $s(r)$ regions of space of a given system. Three-dimensional visualization of NCIs can be obtained by representing isosurfaces of $s(r)$ surrounding the local minimum of $s(r)$. Qualitative information on the strength and sign of the NCI can be obtained from the electron density and the sign of the second eigenvalue of its Hessian matrix, $\operatorname{sign}\left(\lambda_{2}\right)$, which is negative for attractive interactions and positive for repulsive ones. NCIs are normally associated to density values between 0.00 and 0.1 , the weakest interactions, e.g. dispersion, being close to zero and the strongest interactions, e.g. hydrogen bonds, shifted towards larger density values. When $\operatorname{sign}\left(\lambda_{2}\right)$ is taken into account, the range of $\operatorname{sign}\left(\lambda_{2}\right) \rho(r)$ spanned by NCIs extends from -0.1 to 0.1 a.u. It is known that different types of weak interactions decay differently with distance, with the electrostatic terms decaying slower than van der Waals. To mirror this behavior, the volume and $\rho(r)$ were integrated over the volume of NCIs according to two ranges: $i)-0.05<\operatorname{sign}\left(\lambda_{2}\right)<0.00$ corresponding to attractive interactions (attr), ii) $0.00<$ $\operatorname{sign}\left(\lambda_{2}\right)<0.05$, corresponding to repulsive interactions (rep). ${ }^{90,91}$ These values have been chosen to include the interactions around the hydrogen atom. As can be seen in Figure S56, $\mathrm{H}$ interactions cover up to $\rho=0.05$ a.u.

Preparation of LiNHAc. Acetamide (1 eq, $945 \mathrm{mg}$ ) was dissolved in $\sim 20 \mathrm{~mL}$ of THF in a sealed Schlenk vessel under an $\mathrm{Ar}$ atmosphere and the resulting solution was cooled to $-80^{\circ} \mathrm{C}$. The resulting solution was vigorously stirred and added with a solution of $n$-BuLi (1 eq, $10 \mathrm{~mL})$ and the resulting suspension left to react overnight while the vessel was slowly warmed to room temperature. The resulting suspension was filtrated and the collected solid was washed with dry $n$-pentane and dried under reduced pressure. IR (ATR, neat): $v 1588\left(\mathrm{~m}, \mathrm{C}=0\right.$ stretching) $\mathrm{cm}^{-1}$. ${ }^{1} \mathrm{H}$ NMR (400 MHz, CDCl 3 ) $\delta 7.27(\mathrm{~d}, \mathrm{~J}=1.6 \mathrm{~Hz}, 1 \mathrm{H}), 2.02(\mathrm{~d}$, $\mathrm{J}=2.9 \mathrm{~Hz}, 3 \mathrm{H})$.

General Procedure for the Synthesis of Iodocobaltacycles. Under an Ar atmosphere, a mixture of $\left[\mathrm{Cp}^{*} \mathrm{CoI}_{2}\right]_{2}$, LiNHAc and ligand (2-phpyH, 2-tolpyH, 2-anpyH and bzqH) was stirred in $\sim 10-15 \mathrm{~mL}$ of $\mathrm{CH}_{2} \mathrm{Cl}_{2}$ at $50^{\circ} \mathrm{C}$ for $48 \mathrm{~h}$ in a sealed Schlenk vessel. The reaction mixture was filtrated over Celite followed by removal of the solvent. The result- ing residue was then purified by recrystallization with $\mathrm{CH}_{2} \mathrm{Cl}_{2} / n$-pentane and/or washing with $n$-pentane.

General Procedure for the Synthesis of acetonitrilocobalt BArF 24- salts. Under the argon atmosphere, in a Schlenk flask an equimolar mixture of $\left[\kappa^{2}-(C, N)-(\mathbf{L}) \mathrm{CoI}\right]$ and $\mathrm{Na}\left[\mathrm{BArF}_{24}\right]$ was dissolved in acetonitrile $(\sim 7-10 \mathrm{~mL})$. The resulting mixture was vigorously stirred at room temperature within a period not exceeding $6 \mathrm{~h}$, unless otherwise stated. The solution was subsequently filtrated through a pad of celite, and the solvent was removed from the filtrate under reduced pressure. The solid was either recrystallized in a mixture of $\mathrm{CH}_{2} \mathrm{Cl}_{2}$ and $n$-pentane or washed with $n$-pentane, to afford an analytically pure compound.

\section{Iodo(pentamethylcyclopentadienyl)(2-} phenylenepyridine- $\boldsymbol{\kappa}^{2}-\boldsymbol{C}, \boldsymbol{N}$ ) cobalt (III) (1a). $\left[\mathrm{Cp}^{*} \mathrm{CoI}_{2}\right]_{2}$ (448 mg, $0.5 \mathrm{mmol}$ ), LiNHAc (195.1 mg, $3 \mathrm{mmol}$ ), and 2-phenylpyridine (155.2 mg, $1 \mathrm{mmol}$ ) in $10 \mathrm{~mL}$ of $\mathrm{CH}_{2} \mathrm{Cl}_{2}$, yield is $78 \%$ (370 mg). Anal. calcd for $\mathrm{C}_{21} \mathrm{H}_{23} \mathrm{NICo} \bullet \mathrm{CH}_{2} \mathrm{Cl}_{2}$ : C, 52.72; H, 5.03; N, 2.79. Found: C, 52.51; H, 4.91; N, 3.19. ${ }^{1} \mathrm{H}$ NMR (500 MHz, $\left.\mathrm{CDCl}_{3}\right) \delta 9.20(\mathrm{dt}, J=5.6,1.2 \mathrm{~Hz}, 1 \mathrm{H})$, 8.27 (dd, $J=7.7,1.1 \mathrm{~Hz}, 1 \mathrm{H}), 7.66-7.58(\mathrm{~m}, 2 \mathrm{H}), 7.56(\mathrm{dd}, J$ $=7.6,1.5 \mathrm{~Hz}, 1 \mathrm{H}), 7.30-7.26(\mathrm{~m}, 1 \mathrm{H}), 7.04(\mathrm{td}, J=6.2,2.1$ $\mathrm{Hz}, 2 \mathrm{H}), 1.49$ (s, 15H); ${ }^{13} \mathrm{C}$ NMR (126 MHz, $\left.\mathrm{CDCl}_{3}\right) \delta 181.4$, 167.2, 155.0, 145.7, 142.5, 136.6, 129.4, 123.3, 122.7, 121.2, 118.5, 93.5, 10.4. MS-ESI (m/z): [M] calcd for $\mathrm{C}_{21} \mathrm{H}_{23} \mathrm{CoIN}$, 475.02; Found, 475.02; [M-I] ${ }^{+}$calcd for $\mathrm{C}_{21} \mathrm{H}_{23} \mathrm{CoN}$, 348.12; Found, 348.12.

\section{Iodo[2-(2-methylphenylene)pyridine- $\kappa^{2}-$} C,N](pentamethylcyclopentadienyl)cobalt (III) (3a). $\left[\mathrm{Cp}^{*} \mathrm{CoI}_{2}\right]_{2}(216.5 \mathrm{mg}, 0.24 \mathrm{mmol})$, LiNHAc (97.58 mg, 1.5 mmol), and 2-(2-methylphenyl)pyridine (84.61 $\mathrm{mg}, 0.5$ $\mathrm{mmol}$ ) in $10 \mathrm{~mL}$ of $\mathrm{CH}_{2} \mathrm{Cl}_{2}$, yield is $81 \%$ (198 mg). Anal. calcd for $\mathrm{C}_{22} \mathrm{H}_{25} \mathrm{NICo}$ : C, 54.01; $\mathrm{H}, 5.15 ; \mathrm{N}, 2.86$. Found: $\mathrm{C}$, 53.79; $\mathrm{H}, 5.20 ; \mathrm{N}, 2.87 .{ }^{1} \mathrm{H}$ NMR (500 MHz, $\left.\mathrm{CD}_{2} \mathrm{Cl}_{2}\right) \delta 9.38$ $(\mathrm{dd}, J=5.7,1.7 \mathrm{~Hz}, 1 \mathrm{H}), 8.21-8.15(\mathrm{~m}, 1 \mathrm{H}), 7.87(\mathrm{~d}, J=8.3$ $\mathrm{Hz}, 1 \mathrm{H}$ ), 7.62 (ddd, $J=8.5,7.3,1.7 \mathrm{~Hz}, 1 \mathrm{H}), 7.26(\mathrm{~s}, 2 \mathrm{H})$, $7.12(\mathrm{t}, J=7.5 \mathrm{~Hz}, 1 \mathrm{H}$ ), 7.02 (ddd, $J=7.2,5.7,1.4 \mathrm{~Hz}, 1 \mathrm{H}$ ), $6.82(\mathrm{~d}, J=7.2 \mathrm{~Hz}, 1 \mathrm{H}), 2.64(\mathrm{~s}, 3 \mathrm{H}), 1.45(\mathrm{~s}, 15 \mathrm{H}) .{ }^{13} \mathrm{C} \mathrm{NMR}$ $\left(126 \mathrm{MHz} \mathrm{CDCl}_{3}\right) \delta 184.7,167.9,156.2,144.5,140.7,136.4$, $135.3,127.9,127.1,122.1,120.2,94.0,23.9,10.3$. MS-ESI $(\mathrm{m} / \mathrm{z}):[\mathrm{M}+\mathrm{Na}]^{+}$calcd for $\mathrm{C}_{22} \mathrm{H}_{25} \mathrm{NINaCo}, 512.03$; Found, 512.03; [M-I] ${ }^{+}$calcd for $\mathrm{C}_{22} \mathrm{H}_{25} \mathrm{CoN}, 362.13$; Found, 362.13.

\section{Iodo(pentamethylcyclopentadienyl)[4-tertiobutyl,2- (4- $N, N$-dimethylaminophenylene)pyridine- $\boldsymbol{K}^{2}$ -}

C,N]cobalt (III) (4a). [Cp*CoI $]_{2}(225 \mathrm{mg}, 0.25 \mathrm{mmol})$, LiNHAc $(97.58 \mathrm{mg}, 1.5 \mathrm{mmol})$, and 4-(4-(tertbutyl)pyridin-2-yl)- $N, N$-dimethylaniline $(127.18 \mathrm{mg}, 0.5$ $\mathrm{mmol}$ ) in $10 \mathrm{~mL}$ of $\mathrm{CH}_{2} \mathrm{Cl}_{2}$, yield was $82 \%$ (239 mg). Anal. calcd for $\mathrm{C}_{27} \mathrm{H}_{36} \mathrm{~N}_{2} \mathrm{ICo} \bullet \mathrm{CH}_{2} \mathrm{Cl}_{2}$ : C, 55.72; H, 6.35; N, 4.63. Found: C, 55.54; $\mathrm{H}, 6.36 ; \mathrm{N}, 4.92 .{ }^{1} \mathrm{H}$ NMR (500 MHz, $\left.\mathrm{CDCl}_{3}\right)$ $\delta 8.91(\mathrm{~d}, \mathrm{~J}=6.2 \mathrm{~Hz}, 1 \mathrm{H}), 7.62(\mathrm{~d}, \mathrm{~J}=2.5 \mathrm{~Hz}, 1 \mathrm{H}), 7.42(\mathrm{~d}, \mathrm{~J}=$ $8.5 \mathrm{~Hz}, 1 \mathrm{H}$ ), 7.37 (d, J = 2.2 Hz, 1H), 6.89 (dd, J = 6.2, $2.2 \mathrm{~Hz}$, $1 \mathrm{H}), 6.45(\mathrm{dd}, \mathrm{J}=8.5,2.4 \mathrm{~Hz}, 1 \mathrm{H}), 3.12(\mathrm{~s}, 6 \mathrm{H}), 1.50(\mathrm{~s}, 15 \mathrm{H})$, 
$1.30(\mathrm{~s}, 9 \mathrm{H}) .{ }^{13} \mathrm{C}$ NMR $\left(126 \mathrm{MHz}, \mathrm{CDCl}_{3}\right) \delta 182.2,166.8$, $160.4,153.7,150.4,135.5,124.9,123.6,117.4,113.8,108.0$, 93.0, 40.7, 34.9, 30.8, 30.6, 10.5, 1.2. MS-ESI (m/z): [M] calcd for $\mathrm{C}_{27} \mathrm{H}_{36} \mathrm{~N}_{2} \mathrm{ICo}$, 574.13; Found, 574.12; [M+H] ${ }^{+}$calcd for $\left(\mathrm{C}_{27} \mathrm{H}_{36} \mathrm{~N}_{2} \mathrm{ICo}\right) \mathrm{H}, 575.13$; Found, 575.13.

\section{(Benzo[h]quinolynyl- $\kappa^{2}-$} C,N)iodo(pentamethylcyclopentadienyl)cobalt (III) (5a). [Cp*CoI $]_{2}$ (216.25 mg, $\left.0.25 \mathrm{mmol}\right)$, LiNHAc (130 mg, $2 \mathrm{mmol})$, and 7,8-benzo[h] quinoline (89.61 $\mathrm{mg}, 0.5 \mathrm{mmol})$ in $10 \mathrm{~mL}$ of $\mathrm{CH}_{2} \mathrm{Cl}_{2}$, yield was $30 \%$ (75.3 mg). Anal. Calcd for $\mathrm{C}_{23} \mathrm{H}_{23} \mathrm{NICo} \bullet 5 / 4 \mathrm{CH}_{2} \mathrm{Cl}_{2}$ : C, 53.30; $\mathrm{H}, 4.70 ; \mathrm{N}, 2.56$. Found: C, 53.39; H, 4.66; N, 2.72. ${ }^{1} \mathrm{H}$ NMR (500 MHz, $\left.\mathrm{CDCl}_{3}\right) \delta 9.43$ - $9.38(\mathrm{~m}, 1 \mathrm{H}), 8.49(\mathrm{~d}, J=7.3 \mathrm{~Hz}, 1 \mathrm{H}), 8.10-8.05(\mathrm{~m}, 1 \mathrm{H})$, $7.76(\mathrm{~d}, J=8.7 \mathrm{~Hz}, 1 \mathrm{H}), 7.71(\mathrm{t}, J=7.5 \mathrm{~Hz}, 1 \mathrm{H}), 7.51(\mathrm{dd}, J=$ 8.2, $5.6 \mathrm{~Hz}, 2 \mathrm{H}), 7.45$ (dd, $J=7.9,5.3 \mathrm{~Hz}, 1 \mathrm{H}), 1.54(\mathrm{~s}, 15 \mathrm{H})$. ${ }^{13} \mathrm{C}$ NMR $\left(126 \mathrm{MHz} \mathrm{CDCl}_{3}\right) \delta 176.6,156.8,152.6,142.1$, 139.3, 134.9, 133.2, 129.6, 129.4, 126.6, 122.8, 121.1, 120.6 93.1, 10.6. MS-ESI (m/z): [M] calcd for $\mathrm{C}_{23} \mathrm{H}_{23} \mathrm{CoIN}, 499.02$; Found, 499.02; [M-I] ${ }^{+}$calcd for $\mathrm{C}_{23} \mathrm{H}_{23} \mathrm{NCo}, 372.12$; Found, 372.12 .

Acetonitrilo(pentamethylcyclopentadienyl)(2phenylenepyridine- $\kappa^{2}-C, N$ ) cobalt (III) tetrakis[3,5bis(trifluoromethyl)phenyl]borate (1b). 1 a $(47.5 \mathrm{mg}$, $0.1 \mathrm{mmol})$ and $\mathrm{NaBArF}_{24}(88.6 \mathrm{mg}, 0.1 \mathrm{mmol})$ in $10 \mathrm{~mL}$ of acetonitrile, yield is $80 \%$ (100.2 mg). Anal. calcd for $\mathrm{C}_{55} \mathrm{H}_{38}$ $\mathrm{N}_{2} \mathrm{BF}_{24} \mathrm{Co} \bullet 3 / 2 \mathrm{CH}_{2} \mathrm{Cl}_{2}$ : C, 51.25; H, 3.13; N, 2.11. Found: C, 51.34; H, 2.97; N, 2.14. ${ }^{1} \mathrm{H}$ NMR (500 MHz, $\left.\mathrm{CD}_{2} \mathrm{Cl}_{2}\right) \delta 8.92(\mathrm{~d}$, $J=5.7 \mathrm{~Hz}, 1 \mathrm{H}), 8.09-8.04(\mathrm{~m}, 1 \mathrm{H}), 7.90-7.78(\mathrm{~m}, 2 \mathrm{H})$, $7.72(\mathrm{p}, J=2.4 \mathrm{~Hz}, 8 \mathrm{H}), 7.65(\mathrm{dd}, J=7.6,1.5 \mathrm{~Hz}, 1 \mathrm{H}), 7.56(\mathrm{~s}$, $4 \mathrm{H}), 7.40(\mathrm{td}, J=7.4,1.5 \mathrm{~Hz}, 1 \mathrm{H}), 7.31-7.22(\mathrm{~m}, 2 \mathrm{H}), 2.14$ (s, 3H), $1.31(\mathrm{~s}, 15 \mathrm{H}) .{ }^{13} \mathrm{C}$ NMR $\left(126 \mathrm{MHz}, \mathrm{CD}_{2} \mathrm{Cl}_{2}\right) \delta 175.4$, $167.6,162.1$ (dd, $J=99.7,49.8 \mathrm{~Hz}), 153.1,147.1,139.3(\mathrm{~d}, J$ $=17.5 \mathrm{~Hz}), 135.2,131.1,129.9-128.6(\mathrm{~m}), 128.2,126.1$, $125.3,124.7,123.9,123.4,121.7,120.0,118.0-117.7(\mathrm{~m})$, $96.9,9.5,4.7 .{ }^{19} \mathrm{~F}$ NMR $\left(282 \mathrm{MHz}, \mathrm{CD}_{2} \mathrm{Cl}_{2}\right) \delta-62.9 .{ }^{11} \mathrm{~B} \mathrm{NMR}$ $\left(96 \mathrm{MHz}, \mathrm{CD}_{2} \mathrm{Cl}_{2}\right) \delta-6.6(\mathrm{dq}, J=5.4,2.8 \mathrm{~Hz})$. MS-ESI $(\mathrm{m} / \mathrm{z})$ : $\left[\mathrm{M}-\mathrm{BArF}_{24}\right]^{+}$calcd for $\mathrm{C}_{23} \mathrm{H}_{26} \mathrm{CoN}_{2}$, 389.14; Found, 389.14; [BArF 24$]^{-}$calcd for $\mathrm{C}_{32} \mathrm{H}_{12} \mathrm{~F}_{24} \mathrm{~B}$, 863.07; Found, 863.06.

Acetonitrilo[2-(2-methylphenylene)pyridine- $\kappa^{2}-$ $C, N]$ (pentamethylcyclopentadienyl)cobalt (III) tetrakis[3,5-bis(trifluoromethyl)phenyl]borate (3b). 3a (49 mg, $0.1 \mathrm{mmol}$ ) and $\mathrm{NaBArF}_{24}(88.6 \mathrm{mg}, 0.1 \mathrm{mmol})$ in $10 \mathrm{~mL}$ of acetonitrile, yield is $85 \%$ (108.1 mg). Anal. Calcd for $\mathrm{C}_{56} \mathrm{H}_{40} \mathrm{~N}_{2} \mathrm{BF}_{24} \mathrm{Co} \bullet 4 / 3 \mathrm{CH}_{2} \mathrm{Cl}_{2}$ : C, 49.87; $\mathrm{H}, 3.12 ; \mathrm{N}, 2.03$. Found: C, 49.93; H, 3.15; N, 1.95. $\left.{ }^{1} \mathrm{H} \mathrm{NMR} \mathrm{(500} \mathrm{MHz,} \mathrm{CDCl}_{3}\right)$ $\delta 8.95(\mathrm{dd}, J=5.7,1.7 \mathrm{~Hz}, 1 \mathrm{H}), 8.00(\mathrm{~d}, J=8.3 \mathrm{~Hz}, 1 \mathrm{H}), 7.84$ (d, $J=7.6 \mathrm{~Hz}, 1 \mathrm{H}$ ), 7.78 (ddd, $J=8.6,7.4,1.7 \mathrm{~Hz}, 1 \mathrm{H}$ ), 7.70 $(\mathrm{dt}, J=5.0,2.3 \mathrm{~Hz}, 8 \mathrm{H}), 7.52(\mathrm{~s}, 4 \mathrm{H}), 7.24(\mathrm{t}, J=7.5 \mathrm{~Hz}, 1 \mathrm{H})$, 7.12 (ddd, $J=7.2,5.6,1.4 \mathrm{~Hz}, 1 \mathrm{H}), 7.04$ (d, $J=7.4 \mathrm{~Hz}, 1 \mathrm{H}$ ), $2.66(\mathrm{~s}, 3 \mathrm{H}), 2.06$ (s, 3H), 1.22 (s, 15H). ${ }^{13} \mathrm{C} \mathrm{NMR}(126 \mathrm{MHz}$, $\left.\mathrm{CDCl}_{3}\right) \delta 177.99,167.99,161.82(\mathrm{dd}, J=99.6,49.8 \mathrm{~Hz})$, $153.59,145.12,138.96,137.11,136.38,134.93,129.68$ (d, $J=11.0 \mathrm{~Hz}$ ), 129.18 (d, $J=3.2 \mathrm{~Hz}), 128.94,128.40,127.92$, $125.76,117.65(\mathrm{~d}, J=5.9 \mathrm{~Hz}), 96.94,23.63,9.22,4.02 .{ }^{19} \mathrm{~F}$ NMR (282 MHz, $\left.\mathrm{CDCl}_{3}\right) \delta-62.4$. ${ }^{11} \mathrm{~B} \mathrm{NMR}\left(96 \mathrm{MHz} \mathrm{CDCl}_{3}\right) \delta$ $-6.6(\mathrm{p}, J=2.6 \mathrm{~Hz})$. MS-ESI $(\mathrm{m} / \mathrm{z}):\left[\mathrm{M}-\mathrm{BArF}_{24}\right]^{+}$calcd for
$\mathrm{C}_{24} \mathrm{H}_{28} \mathrm{~N}_{2} \mathrm{Co}$, 403.16; Found, 403.16; [BArF 24 ] calcd for $\mathrm{C}_{32} \mathrm{H}_{12} \mathrm{~F}_{24} \mathrm{~B}, 863.07$; Found, 863.06.

Acetonitrilo[4-tertiobutyl,2-(4- $\mathrm{N}, \mathrm{N}$ -

dimethylaminophenylene)pyridine- $\kappa^{2}$ -

$C, N]$ (pentamethylcyclopentadienyl)cobalt

(III)

tetrakis[3,5-bis(trifluoromethyl)phenyl]borate (4b).

$4 a(58 \mathrm{mg}, 0.1 \mathrm{mmol})$ and $\mathrm{NaBArF}_{24}(88.6 \mathrm{mg}, 0.1 \mathrm{mmol})$ in $10 \mathrm{~mL}$ of acetonitrile, yield was $80 \%$ (108.2 mg). Anal. Calcd for $\mathrm{C}_{61} \mathrm{H}_{51} \mathrm{~N}_{3} \mathrm{BF}_{24} \mathrm{Co} \bullet \mathrm{CH}_{2} \mathrm{Cl}_{2}$ : C, 53.68; H, 3.86; N, 3.02. Found: C, 53.53; H, 3.82; N, 3.09. ${ }^{1} \mathrm{H}$ NMR (500 MHz, $\left.\mathrm{CDCl}_{3}\right)$ $\delta 8.57(\mathrm{~d}, J=6.2 \mathrm{~Hz}, 1 \mathrm{H}), 7.69(\mathrm{p}, J=2.4 \mathrm{~Hz}, 8 \mathrm{H}), 7.52(\mathrm{~s}$, $4 \mathrm{H}), 7.49(\mathrm{~d}, J=2.1 \mathrm{~Hz}, 1 \mathrm{H}), 7.47(\mathrm{~d}, J=8.6 \mathrm{~Hz}, 1 \mathrm{H}), 7.28(\mathrm{~s}$, 1H), 7.05 (dd, $J=6.1,2.1 \mathrm{~Hz}, 1 \mathrm{H}), 6.56$ (dd, $J=8.6,2.4 \mathrm{~Hz}$, $1 \mathrm{H}), 3.14(\mathrm{~s}, 6 \mathrm{H}), 2.04(\mathrm{~s}, 3 \mathrm{H}), 1.33(\mathrm{~s}, 9 \mathrm{H}), 1.27(\mathrm{~s}, 15 \mathrm{H})$. ${ }^{13} \mathrm{C}$ NMR $\left(126 \mathrm{MHz}, \mathrm{CDCl}_{3}\right) \delta 176.8,167.2,163.4,162.4$, $162.0,161.6,161.2,151.34,151.3,134.9,134.7,129.4$, $128.9,128.7,128.3,127.9,125.8,125.0,123.6,121.43$, $120.4,118.8,117.6,114.8,109.1,96.1,40.4,35.2,30.4,9.4$, 4.1. ${ }^{19} \mathrm{~F}$ NMR (282 $\left.\mathrm{MHz}, \mathrm{CDCl}_{3}\right) \delta-62.38 .{ }^{11} \mathrm{~B} \mathrm{NMR}(96 \mathrm{MHz}$, $\left.\mathrm{CDCl}_{3}\right) \delta-6.64(\mathrm{dq}, J=5.4,2.8 \mathrm{~Hz})$. MS-ESI $(\mathrm{m} / \mathrm{z}):[\mathrm{M}-$ $\left.\mathrm{BArF}_{24}\right]^{+}$calcd for $\mathrm{C}_{29} \mathrm{H}_{39} \mathrm{~N}_{3} \mathrm{Co}, 488.25$; Found, 488.25; [BArF 24$]^{-}$calcd for $\mathrm{C}_{32} \mathrm{H}_{12} \mathrm{~F}_{24} \mathrm{~B}, 863.07$; Found, 863.06.

\begin{abstract}
Acetonitrilo(benzo[h]quinolynyl- $\kappa^{2}$ -
$C, N)$ (pentamethylcyclopentadienyl)cobalt (III) tetrakis[3,5-bis(trifluoromethyl)phenyl]borate (5b). $5 a$ (50 mg, $0.1 \mathrm{mmol}$ ) and $\mathrm{NaBArF}_{24}(88.6 \mathrm{mg}, 0.1 \mathrm{mmol})$ in $10 \mathrm{~mL}$ of acetonitrile, yield was $79 \%$ (100.9 mg). Anal. calcd for $\mathrm{C}_{57} \mathrm{H}_{38} \mathrm{~N}_{2} \mathrm{BF}_{24} \mathrm{Co} \bullet 7 / 3 \mathrm{CH}_{2} \mathrm{Cl}_{2}$ : C, 50.41; $\mathrm{H}, 3.04 ; \mathrm{N}$, 1.98. Found: C, 50.55; H, 2.85; N, 1.81. ${ }^{1} \mathrm{H}$ NMR (500 MHz, $\left.\mathrm{CDCl}_{3}\right) \delta 9.13(\mathrm{dd}, J=5.3,1.3 \mathrm{~Hz}, 1 \mathrm{H}), 8.28(\mathrm{dd}, J=7.2,0.9$ $\mathrm{Hz}, 1 \mathrm{H}), 8.23(\mathrm{dd}, J=8.0,1.3 \mathrm{~Hz}, 1 \mathrm{H}), 7.84(\mathrm{~d}, J=8.8 \mathrm{~Hz}$, 1H), 7.77 (t, J= 7.5 Hz, 1H), $7.73(\mathrm{~d}, J=0.9 \mathrm{~Hz}, 1 \mathrm{H}), 7.71(\mathrm{dd}$, $J=5.3,2.7 \mathrm{~Hz}, 8 \mathrm{H}), 7.60(\mathrm{~d}, J=8.8 \mathrm{~Hz}, 1 \mathrm{H}), 7.52(\mathrm{~d}, J=1.8$ $\mathrm{Hz}, 4 \mathrm{H}), 7.50$ (d, $J=5.5 \mathrm{~Hz}, 1 \mathrm{H}), 1.94(\mathrm{~s}, 3 \mathrm{H}), 1.31(\mathrm{~s}, 15 \mathrm{H})$. ${ }^{13} \mathrm{C}$ NMR $\left(126 \mathrm{MHz} \mathrm{CDCl}_{3}\right) \delta 170.6,162.4,162.0,161.6$, $161.2,156.5,150.9,142.5,137.32,136.3,134.9,134.0$, $130.5,130.0,129.19,129.17,129.15,129.0,128.94,128.9$, $128.7,127.9,127.4,125.7,123.62,123.6,123.2,122.5$, $121.4,117.7,117.65,117.6,96.2,9.5,4.0 .{ }^{19} \mathrm{~F}$ NMR $(282$ $\left.\mathrm{MHz}, \mathrm{CDCl}_{3}\right) \delta-62.4 .{ }^{11} \mathrm{~B} \mathrm{NMR}\left(96 \mathrm{MHz}, \mathrm{CDCl}_{3}\right) \delta-6.6(\mathrm{dq}, J$ $=5.6,2.8 \mathrm{~Hz})$. MS-ESI (m/z): $\left[\mathrm{M}-\mathrm{BArF}_{24}\right]^{+}$calcd for $\mathrm{C}_{25} \mathrm{H}_{26} \mathrm{~N}_{2} \mathrm{Co}$, 413.13; Found, 413.13; [BArF 24$]^{-}$calcd for $\mathrm{C}_{32} \mathrm{H}_{12} \mathrm{~F}_{24} \mathrm{~B}$, 863.07; Found, 863.06.
\end{abstract}

Acetamidato[2-phenylenepyridine $\kappa^{2}$ -

$(C, N)]$ (pentamethylcyclopentadienyl)cobalt (III) (1f). Under an argon atmosphere, 1a (28.1 mg, $0.059 \mathrm{mmol})$ and excess of LiNHAc (38.4 mg, $0.59 \mathrm{mmol}$ ) were stirred in $\mathrm{CH}_{2} \mathrm{Cl}_{2}(\sim 7-10 \mathrm{~mL})$ in a Schlenk flask at $50{ }^{\circ} \mathrm{C}$ overnight and the resulting solution subsequently filtrated through celite. The resulting filtrate was stripped of the solvents under reduced pressure and the residue was extracted with pentane and filtrated through Celite. The filtrate was stripped of solvent under reduced pressure to afford the product (5.04 mg, yield: 20.8\%). Anal. cald for $\mathrm{C}_{23} \mathrm{H}_{27} \mathrm{CoN}_{2} \mathrm{O} \bullet 0.55 \mathrm{CH}_{2} \mathrm{Cl}_{2} \bullet 0.9 \mathrm{C}_{5} \mathrm{H}_{12}: \mathrm{C}, 65.03 ; \mathrm{H}, 7.57 ; \mathrm{N}$, 5.41. Found: C, 65.14; H, 7.17; N, 5.02. ${ }^{1} \mathrm{H}$ NMR (500 MHz, 
$\left.\mathrm{CDCl}_{3}\right) \delta 9.76(\mathrm{~d}, J=5.7 \mathrm{~Hz}, 1 \mathrm{H}), 8.20-8.15(\mathrm{~m}, 1 \mathrm{H}), 7.64-$ $7.59(\mathrm{~m}, 1 \mathrm{H}), 7.59-7.52(\mathrm{~m}, 2 \mathrm{H}), 7.35(\mathrm{td}, J=7.4,1.4 \mathrm{~Hz}$, $1 \mathrm{H}), 7.19-7.12(\mathrm{~m}, 1 \mathrm{H}), 7.08(\mathrm{td}, J=6.1,2.4 \mathrm{~Hz}, 1 \mathrm{H}), 1.76$ (s, 3H), $1.34(\mathrm{~s}, 15 \mathrm{H}) .{ }^{13} \mathrm{C}$ NMR (126 MHz, $\left.\mathrm{CDCl}_{3}\right) \delta 185.00$, 178.86, 166.31, 155.99, 146.77, 137.74, 136.29, 129.28, 122.96, 122.72, 120.87, 117.49, 93.57, 28.40, 9.41. MS-ESI (m/z): [M-NHAc] ${ }^{+}$calcd for $\mathrm{C}_{21} \mathrm{H}_{23} \mathrm{NCo}, 348.12$; Found, 348.12 .

\section{Acetamidato[2-phenylenepyridine $\kappa^{2}$ -}

$(C, N)]$ (pentamethylcyclopentadienyl)iridium (III) (2b). Under an argon atmosphere, $\mathbf{2 a}(26.6 \mathrm{mg}, 0.0514 \mathrm{mmol})$ and excess of LiNHAc (33.4 mg, $0.514 \mathrm{mmol}$ ) were dissolved in $\mathrm{CH}_{2} \mathrm{Cl}_{2}(\sim 7-10 \mathrm{~mL})$ in a Schlenk flask. The resulting suspension was vigorously stirred at room temperature overnight and the reaction mixture filtrated through celite. The filtrate was stripped of solvents under reduced pressure to afford a solid residue that displayed some reactivity with $\mathrm{SiO}_{2}$, which prevented chromatographic separation. The residue was therefore redissolved in $\mathrm{CH}_{2} \mathrm{Cl}_{2}$ and the resulting solution was swiftly filtered through dry $\mathrm{SiO}_{2}$. The filtrate was stripped of solvent and recrystallized from $\mathrm{CH}_{2} \mathrm{Cl}_{2}$ and pentane to afford $2 \mathbf{b}$ slightly contaminated with acetamide (9.05 mg, yield: 32,6\%). Anal. calcd for $\mathrm{C}_{23} \mathrm{H}_{27} \mathrm{IrN}_{2} \mathrm{O} \bullet 1 / 3 \mathrm{CH}_{2} \mathrm{Cl}_{2} \bullet 4 / 3 \mathrm{NH}_{2} \mathrm{COCH}_{3}$ : C, 48.46; H, 5.35; N, 7.2. Found: C, 48.09; H, 5.71; N, 6.99. ${ }^{1} \mathrm{H}$ NMR (500 MHz, $\left.\mathrm{CDCl}_{3}\right) \delta 9.14-9.11(\mathrm{~m}, 1 \mathrm{H}), 7.79(\mathrm{dd}, \mathrm{J}=$ 7.5, $1.2 \mathrm{~Hz}, 1 \mathrm{H}), 7.74-7.71(\mathrm{~m}, 1 \mathrm{H}), 7.66(\mathrm{dd}, J=7.7,1.5$ $\mathrm{Hz}, 1 \mathrm{H}), 7.57(\mathrm{td}, J=7.7,1.6 \mathrm{~Hz}, 1 \mathrm{H}), 7.19(\mathrm{td}, J=7.3,1.4$ $\mathrm{Hz}, 1 \mathrm{H}), 7.09$ (td, $J=7.4,1.2 \mathrm{~Hz}, 1 \mathrm{H}), 7.01$ (ddd, $J=7.3,5.8$, $1.5 \mathrm{~Hz}, 1 \mathrm{H}), 3.47(\mathrm{~s}, 1 \mathrm{H}), 1.71(\mathrm{~s}, 15 \mathrm{H}), 1.70(\mathrm{~s}, 3 \mathrm{H}) .{ }^{13} \mathrm{C}$ NMR $\left(126 \mathrm{MHz}, \mathrm{CDCl}_{3}\right) \delta 175.14,166.79,163.96,153.82$, $145.26,136.39,134.79,130.36,123.75,121.79,121.60$, 118.08, 88.48, 26.69, 9.10. MS-ESI (m/z): [M-NHAc] ${ }^{+}$calcd for $\mathrm{C}_{21} \mathrm{H}_{23} \mathrm{NIr}$, 482.15; Found, 482.15 .

Determination of the KIE of Cyclocobalation by Parallel Experiments. 2-phpyH and 2- $\left(d_{5} . p h\right) p y D(0.10 \mathrm{mmol}, 2$ eq) were placed in two separate Schlenk vessels to which identical amounts of [ $\left.\mathrm{Cp}^{*} \mathrm{CoI}_{2}\right]_{2}(0.05 \mathrm{mmol}, 1 \mathrm{eq})$, LiNHAc (0.3 mmol, 6 eq), 1,3,5-trimethoxybenzene as internal inert reference and $5 \mathrm{~mL}$ of DCM were added. Upon sealing the vessel, the resulting suspension was vigorously stirred at $50{ }^{\circ} \mathrm{C}$ for $6 \mathrm{~h}$ and aliquots of both vessels were removed every hour, the solvent was evaporated and replaced by $\mathrm{CD}_{2} \mathrm{Cl}_{2}(0.3 \mathrm{~mL})$ and the resulting solution analyzed by ${ }^{1} \mathrm{H}$ NMR spectroscopy for the determination of the yield in $\mathbf{1 a}$ and $d_{4}$.1a. The isotopic effect at time $t$, i.e KIEt was determined by the ratio of the yield in 1a over the yield in $d_{4.1 a}$.

Determination of the KIE of Cyclocobalation by a Onepot Competitive Reaction. [Cp* $\left.\mathrm{CoI}_{2}\right]_{2}(0.05 \mathrm{mmol})$ and $\mathrm{LiNHCOCH}_{3}(0.15 \mathrm{mmol})$ were mixed in $5 \mathrm{~mL}$ of distilled DCM. 2-phpyH $(0.05 \mathrm{mmol})$ and 2-(d5.ph)pyD $(0.05 \mathrm{mmol})$ were added to the suspension. The reaction was stirred vigorously at $50^{\circ} \mathrm{C}$ during 17 hours in a sealed Schlenk vessel. At the end of the reaction, the solution was filtrated through Celite and the solvent was removed under reduced pressure. The resulting solid residue was washed with distilled pentane to remove the soluble components of the mixture to afford a solid composed of a mixture of the desired cobaltacycles $\mathbf{1 a}$ and $d_{4} \mathbf{- 1 a}$ in proportion estimated by ${ }^{1} \mathrm{H}$-coupled ${ }^{13} \mathrm{C}$ NMR. Two signals typical of $\mathbf{1 a}$ and $d_{4}-1$ a were readily discriminated by their isotope shifts. The KIE was determined by comparing the integrations of ${ }^{13} \mathrm{C}$ signals of the Co-bound aromatic carbon of $\mathbf{1 a}$ and $d_{4-1 a}$ as well as those of the vicinal H/D-bound ortho carbon. Two KIE were obtained, 1.7 and 2.0 that are most probably biased by different spin-lattice relaxation times $T_{1}$ in 1a and $d_{4}-\mathbf{1 a}$ for the considered carbon nuclei (Figure 13 ) showing up at $\delta \sim 180.6$ and $141.4 \mathrm{ppm}$.

General Procedure for the Annulation of 2-aryl Pyridines with 1,2-diphenylacetylene. Under an argon atmosphere, 1,2-diphenylacetylene (0.15 mmol), [Cp* $\left.\mathrm{CoI}_{2}\right]_{2}$ (5 mol \%) and LiNHAc (30 mol \%) were added to a Schlenk vessel. Then, the tube was moved to an Ar-filled glove box and 2-arylpyridines ( $0.10 \mathrm{mmol}), \mathrm{AgBF}_{4}(0.20 \mathrm{mmol})$ were added to the load of the vessel. DCE (2 mL) was added to the solid mixture, the Schlenk vessel was sealed and the suspension was stirred at $130{ }^{\circ} \mathrm{C}$ for $24 \mathrm{~h}$. The reaction vessel was hence cooled to room temperature and the suspension diluted with DCM $(10 \mathrm{~mL})$. The mixture was filtered through a Celite pad and the Celite pad was washed with DCM $(30 \mathrm{~mL})$. The filtrate was concentrated and purified by silica gel column chromatography using $\mathrm{DCM} / \mathrm{MeOH}$ (95:5) as eluent to deliver the desired annulation product.

\section{ASSOCIATED CONTENT}

Supporting Information. Spectroscopic information, cartesian coordinates of all stationary points in the .xyz format, energies, details of the LED analysis and plots of NCI, structural information. Crystallographic information files (.cif) for structures CCDC 1996297-1996307 (cmpds 1b, 1d, 1c, 1f, 2b, 2c, 3b, 4a, 4b, 5a, 5b) are available from the CCDC at https://www.ccdc.cam.ac.uk. This material is available free of charge via the Internet at http://pubs.acs.org.

\section{AUTHOR INFORMATION}

\section{Corresponding Author}

*E-mail: djukic@unistra.fr

\section{Author Contributions}

All authors have given approval to the final version of the manuscript.

The manuscript was written through contributions of all authors.

\section{Funding Sources}

Centre National de la Recherche Scientifique ANR-DFG COCOORDCHEM

University of Strasbourg

The authors declare no competing financial interests.

\section{ACKNOWLEDGMENT}

This article is dedicated to Dr Jean-René Hamon, on his $65^{\text {th }}$ birthday. The authors acknowledge the CNRS, the ANR-DFG (COCOORDCHEM), and the university of Strasbourg for financial support. FW thanks the China Scholarship Council for a 
PhD stipend. YC thanks the Centre de Calcul de l'Université de Strasbourg for providing access to the HPC facilities (project g2019a126c).

\section{ABBREVIATIONS}

DCM, dichloromethane; DCE, 1,2-dichloroethane; THF, tetrahydrofurane.

\section{REFERENCES}

(1) Green, M. L. H.; O'Hare, D., The activation of carbon-hydrogen bonds Pure Appl. Chem. 1985, 57, 1897-1910.

(2) Kuhl, N.; Hopkinson, M. N.; Wencel-Delord, J.; Glorius, F., Beyond Directing Groups: Transition-Metal-Catalyzed C-H Activation of Simple Arenes Angew. Chem., Int. Ed. 2012, 51, 10236-10254.

(3) Sambiagio, C.; Schönbauer, D.; Blieck, R.; Dao-Huy, T.; Pototschnig, G.; Schaaf, P.; Wiesinger, T.; Zia, M. F.; Wencel-Delord, J.; Besset, T.; Maes, B. U. W.; Schnürch, M., A comprehensive overview of directing groups applied in metal-catalysed $\mathrm{C}-\mathrm{H}$ functionalisation chemistry Chem. Soc. Rev. 2018, 47, 6603-6743.

(4) Gandeepan, P.; Müller, T.; Zell, D.; Cera, G.; Warratz, S.; Ackermann, L., 3d Transition Metals for $\mathrm{C}-\mathrm{H}$ Activation Chem. Rev. 2019, 119, 2192-2452.

(5) Mishra, A. A.; Subhedar, D.; Bhanage, B. M., Nickel, Cobalt and Palladium Catalysed C-H Functionalization of Un-activated C(sp3)-H Bond Chem. Rec. 2019, 19, 1829-1857.

(6) Xing, Y.-Y.; Liu, J.-B.; Sun, C.-Z.; Huang, F.; Chen, D.-Z. Mechanistic Exploration of Cp*CoIII/RhIII-Catalyzed Carboamination/Olefination of N-Phenoxyacetamides with Alkenes Inorganic Chemistry 2018, 57, 10726-10735.

(7) Song, G.; Wang, F.; $\mathrm{Li}, \mathrm{X} ., \mathrm{C}-\mathrm{C}, \mathrm{C}-\mathrm{O}$ and $\mathrm{C}-\mathrm{N}$ bond formation via rhodium(III)-catalyzed oxidative $\mathrm{C}-\mathrm{H}$ activation Chem. Soc. Rev. 2012, 41,3651-3678.

(8) Satoh, T.; Miura, M., Oxidative Coupling of Aromatic Substrates with Alkynes and Alkenes under Rhodium Catalysis Chem. - Eur. J. 2010, 16, 11212-11222.

(9) Frederic, P.; Joanna, W.-D.; Frank, G., Cp*Rh-Catalyzed C-H Activations. Versatile Dehydrogenative Cross-Couplings of $\mathrm{Csp}^{2} \mathrm{C}-\mathrm{H}$ Positions with Olefins, Alkynes, and Arenes Aldrichim. Acta 2012, 45, 31-45.

(10) Kuhl, N.; Schröder, N.; Glorius, F., Formal SN-Type Reactions in Rhodium(III)-Catalyzed C-H Bond Activation Adv. Synth. Catal. 2014, 356, 1443-1460.

(11) Prakash, S.; Muralirajan, K.; Cheng, C.-H., Cobalt-Catalyzed Oxidative Annulation of Nitrogen-Containing Arenes with Alkynes: An Atom-Economical Route to Heterocyclic Quaternary Ammonium Salts Angew. Chem., Int. Ed. 2016, 55, 1844-1848.

(12) Zell, D.; Bursch, M.; Müller, V.; Grimme, S.; Ackermann, L., Full Selectivity Control in Cobalt(III)-Catalyzed $\mathrm{C}-\mathrm{H}$ Alkylations by Switching of the $\mathrm{C}-\mathrm{H}$ Activation Mechanism Angew. Chem. Int. Ed. 2017, 56, 10378-10382.

(13) Chirila, P. G.; Adams, J.; Dirjal, A.; Hamilton, A.; Whiteoak, C. J., $\mathrm{Cp} * \mathrm{Co}(\mathrm{III})-$ Catalyzed Coupling of Benzamides with $\alpha, \beta$-unsaturated Carbonyl Compounds: Preparation of Aliphatic Ketones and Azepinones Chem. Eur. J. 2018, 24, 3584-3589.

(14) Kenny, A.; Pisarello, A.; Bird, A.; Chirila, P. G.; Hamilton, A.; Whiteoak*, C. J., A challenging redox neutral Cp*Co(III)-catalysed alkylation of acetanilides with 3-buten-2-one: synthesis and key insights into the mechanism through DFT calculations Beilstein J. Org. Chem. 2018, 14, 2366-2374.

(15) Qu, S.; Cramer, C. J., Mechanistic Study of Cp*CoIII/RhIIICatalyzed Directed C-H Functionalization with Diazo Compounds $J$. Org. Chem. 2017, 82, 1195-1204.

(16) Wang, Q.; Huang, F.; Jiang, L.; Zhang, C.; Sun, C.; Liu, J.; Chen, D., Comprehensive Mechanistic Insight into Cooperative Lewis Acid/Cp*CoIII-Catalyzed $\mathrm{C}-\mathrm{H} / \mathrm{N}-\mathrm{H}$ Activation for the Synthesis of Isoquinolin-3-ones Inorg. Chem. 2018, 57, 2804-2814.

(17) Yoshino, T.; Ikemoto, H.; Matsunaga, S.; Kanai, M., A Cationic High-Valent $\mathrm{Cp} *$ CoIII Complex for the Catalytic Generation of Nucleophilic Organometallic Species: Directed C-H Bond Activation Angew. Chem. Int. Ed. 2013, 52, 2207-2211.

(18) Yoshino, T.; Ikemoto, H.; Matsunaga, S.; Kanai, M., Cp*CoIIICatalyzed C2-Selective Addition of Indoles to Imines Chem. Eur. J. 2013, 19, 9142-9146.
(19) Sun, B.; Yoshino, T.; Matsunaga, S.; Kanai, M., Air-Stable Carbonyl(pentamethylcyclopentadienyl)cobalt Diiodide Complex as a Precursor for Cationic (Pentamethylcyclopentadienyl)cobalt(III) Catalysis: Application for Directed C-2 Selective C-H Amidation of Indoles Adv. Synth. Catal. 2014, 356, 1491-1495.

(20) Ikemoto, H.; Yoshino, T.; Sakata, K.; Matsunaga, S.; Kanai, M., Pyrroloindolone Synthesis via a Cp*CoIII-Catalyzed Redox-Neutral Directed C-H Alkenylation/Annulation Sequence J. Am. Chem. Soc 2014, 136, 5424-5431.

(21) Sun, B.; Yoshino, T.; Matsunaga, S.; Kanai, M., A Cp*CoI ${ }_{2}$-dimer as a precursor for cationic $\mathrm{Co}(\mathrm{III})$-catalysis: application to $\mathrm{C}-\mathrm{H}$ phosphoramidation of indoles Chem. Commun. 2015, 51, 4659-4661.

(22) Suzuki, Y.; Sun, B.; Sakata, K.; Yoshino, T.; Matsunaga, S.; Kanai, M., Dehydrative Direct $\mathrm{C}-\mathrm{H}$ Allylation with Allylic Alcohols under [Cp*CoIII] Catalysis Angew. Chem. Int. Ed. 2015, 54, 9944-9947.

(23) Sun, B.; Yoshino, T.; Kanai, M.; Matsunaga, S., Cp*CoIII Catalyzed Site-Selective C-H Activation of Unsymmetrical O-Acyl Oximes: Synthesis of Multisubstituted Isoquinolines from Terminal and Internal Alkynes Angew. Chem. Int. Ed. 2015, 54, 12968-12972.

(24) Bunno, Y.; Murakami, N.; Suzuki, Y.; Kanai, M.; Yoshino, T.; Matsunaga, S., Cp*CoIII-Catalyzed Dehydrative C-H Allylation of 6Arylpurines and Aromatic Amides Using Allyl Alcohols in Fluorinated Alcohols Org. Lett. 2016, 18, 2216-2219.

(25) Tanaka, R.; Ikemoto, H.; Kanai, M.; Yoshino, T.; Matsunaga, S., Site- and Regioselective Monoalkenylation of Pyrroles with Alkynes via Cp*CoIII Catalysis Org. Lett. 2016, 18, 5732-5735.

(26) Yoshida, M.; Kawai, K.; Tanaka, R.; Yoshino, T.; Matsunaga, S., $\mathrm{Cp} *$ CoIII-catalyzed directed $\mathrm{C}-\mathrm{H}$ trifluoromethylthiolation of 2phenylpyridines and 6-arylpurines Chem. Commun. 2017, 53, 5974-5977. (27) Ikemoto, H.; Tanaka, R.; Sakata, K.; Kanai, M.; Yoshino, T.; Matsunaga, S., Stereoselective Synthesis of Tetrasubstituted Alkenes via a $\mathrm{Cp} *$ CoIII-Catalyzed $\mathrm{C}-\mathrm{H}$ Alkenylation/Directing Group Migration Sequence Angew. Chem. Int. Ed. 2017, 56, 7156-7160.

(28) Murakami, N.; Yoshida, M.; Yoshino, T.; Matsunaga, S., Synthesis of Fluorine-Containing 6-Arylpurine Derivatives via $\mathrm{Cp} * \mathrm{Co}(\mathrm{III})-$ Catalyzed C-H Bond Activation Chem. Pharm. Bull. 2018, 66, 51-54.

(29) Kawai, K.; Bunno, Y.; Yoshino, T.; Matsunaga, S., Weinreb Amide Directed Versatile $\mathrm{C}-\mathrm{H}$ Bond Functionalization under ( $\eta^{5}$. Pentamethylcyclopentadienyl)cobalt(III) Catalysis Chem. Eur. J. 2018, 24, 10231-10237.

(30) Fukagawa, S.; Kato, Y.; Tanaka, R.; Kojima, M.; Yoshino, T.; Matsunaga, S., Enantioselective $\mathrm{C}\left(\mathrm{sp}^{3}\right)-\mathrm{H}$ Amidation of Thioamides Catalyzed by a CobaltIII/Chiral Carboxylic Acid Hybrid System Angew. Chem. Int. Ed. 2019, 58, 1153-1157.

(31) Yoshino, T.; Matsunaga, S., Cp*CoIII-Catalyzed C-H Functionalization and Asymmetric Reactions Using External Chiral Sources Synlett 2019, 30, 1384-1400.

(32) Tanaka, R.; Kojima, M.; Yoshino, T.; Matsunaga, S., Cobaltcatalyzed Synthesis of Homoallylic Amines from Imines and Terminal Alkenes Chem. Lett. 2019, 48, 1046-1049.

(33) Tanaka, R.; Tanimoto, I.; Kojima, M.; Yoshino, T.; Matsunaga, S., Imidate as the Intact Directing Group for the Cobalt-Catalyzed $\mathrm{C}-\mathrm{H}$ Allylation J. Org. Chem. 2019, 84, 13203-13210.

(34) Li, J.; Ackermann, L., Cobalt-Catalyzed C-H Cyanation of Arenes and Heteroarenes Angew. Chem., Int. Ed. 2015, 54, 3635-3638.

(35) Li, J.; Tang, M.; Zang, L.; Zhang, X.; Zhang, Z.; Ackermann, L., Amidines for Versatile Cobalt(III)-Catalyzed Synthesis of Isoquinolines through C-H Functionalization with Diazo Compounds Org. Lett. 2016, $18,2742-2745$.

(36) Mei, R.; Loup, J.; Ackermann, L., Oxazolinyl-Assisted C-H Amidation by Cobalt(III) Catalysis ACS Catal. 2016, 6, 793-797.

(37) Moselage, M.; Li, J.; Ackermann, L., Cobalt-Catalyzed C-H Activation ACS Catal. 2016, 6, 498-525.

(38) Nakanowatari, S.; Mei, R.; Feldt, M.; Ackermann, L., Cobalt(III)Catalyzed Hydroarylation of Allenes via C-H Activation ACS Catal. 2017, 7, 2511-2515.

(39) Wang, H.; Lorion, M. M.; Ackermann, L., Domino C-H/N-H Allylations of Imidates by Cobalt Catalysis ACS Catal. 2017, 7, 34303433.

(40) Zell, D.; Bursch, M.; Mueller, V.; Grimme, S.; Ackermann, L., Full Selectivity Control in Cobalt(III)-Catalyzed C-H Alkylations by Switching of the C-H Activation Mechanism Angew. Chem., Int. Ed. 2017, 56, 10378-10382.

(41) Zell, D.; Mueller, V.; Dhawa, U.; Bursch, M.; Presa, R. R.; Grimme, S.; Ackermann, L., Mild Cobalt(III)-Catalyzed Allylative C-F/C-H 
Functionalizations at Room Temperature Chem. - Eur. J. 2017, 23, $12145-12148$

(42) Zhang, Z.; Han, S.; Tang, M.; Ackermann, L.; Li, J., C-H Alkylations of (Hetero)Arenes by Maleimides and Maleate Esters through Cobalt(III) Catalysis Org. Lett. 2017, 19, 3315-3318.

(43) Detmar, E.; Mueller, V.; Zell, D.; Ackermann, L.; Breugst, M., Cobalt-catalyzed $\mathrm{C}-\mathrm{H}$ cyanations: insights into the reaction mechanism and the role of London dispersion Beilstein J. Org. Chem. 2018, 14, $1537-1545$.

(44) Pesciaioli, F.; Dhawa, U.; Oliveira, J. C. A.; Yin, R.; John, M.; Ackermann, L., Enantioselective Cobalt(III)-Catalyzed C-H Activation Enabled by Chiral Carboxylic Acid Cooperation Angew. Chem., Int. Ed. 2018, 57, 15425-15429.

(45) Lorion, M. M.; Kaplaneris, N.; Son, J.; Kuniyil, R.; Ackermann, L., Late-stage peptide diversification through cobalt-catalyzed $\mathrm{C}-\mathrm{H}$ activation: Sequential multicatalysis for stapled peptides Angew. Chem., Int. Ed. 2019, 58, 1684-1688.

(46) Luo, C.-Z.; Gandeepan, P.; Jayakumar, J.; Parthasarathy, K.; Chang, Y.-W.; Cheng, C.-H., RhIII-Catalyzed C-H Activation: A Versatile Route towards Various Polycyclic Pyridinium Salts Chem. Eur. J. 2013, 19, 14181-14186.

(47) Zhang, G.; Yang, L.; Wang, Y.; Xie, Y.; Huang, H., An Efficient $\mathrm{Rh} / \mathrm{O}_{2}$ Catalytic System for Oxidative $\mathrm{C}-\mathrm{H}$ Activation/Annulation: Evidence for $\mathrm{Rh}(\mathrm{I})$ to $\mathrm{Rh}(\mathrm{III})$ Oxidation by Molecular Oxygen $J$. Am. Chem. Soc 2013, 135, 8850-8853.

(48) Yoshino, T.; Matsunaga, S., (Pentamethylcyclopentadienyl)cobalt(III)-Catalyzed C-H Bond Functionalization: From Discovery to Unique Reactivity and Selectivity Adv. Synth. Catal. 2017, 359, 1245-1262.

(49) Cornaton, Y.; Djukic, J.-P., A noncovalent interaction insight onto the concerted metallation deprotonation mechanism Phys. Chem Chem.Phys. 2019, 21, 20486-20498.

(50) Davies, D. L.; Donald, S. M. A.; Macgregor, S. A., Computational Study of the Mechanism of Cyclometalation by Palladium Acetate $J$. Am. Chem. Soc. 2005, 127, 13754-13755.

(51) Davies, D. L.; Macgregor, S. A.; McMullin, C. L., Computational Studies of Carboxylate-Assisted C-H Activation and Functionalization at Group 8-10 Transition Metal Centers Chem. Rev. 2017, 117, 8649-8709.

(52) Davies, D. L.; Donald, S. M. A.; Al-Duaij, O.; Macgregor, S. A.; Poelleth, M., Electrophilic C-H Activation at $\{\mathrm{Cp} * \mathrm{Ir}\}$ : Ancillary-Ligand Control of the Mechanism of C-H Activation J. Am. Chem. Soc. 2006, $128,4210-4211$.

(53) Sanjose-Orduna, J.; Gallego, D.; Garcia-Roca, A.; Martin, E.; BenetBuchholz, J.; Perez-Temprano, M. H., Capturing Elusive Cobaltacycle Intermediates: A Real-Time Snapshot of the $\mathrm{Cp} *$ CoIII-Catalyzed Oxidative Alkyne Annulation Angew. Chem., Int. Ed. 2017, 56, 12016.

(54) Yu, X.; Chen, K.; Guo, S.; Shi, P.; Song, C.; Zhu, J., Direct Access to Cobaltacycles via $\mathrm{C}-\mathrm{H}$ Activation: N-Chloroamide-Enabled RoomTemperature Synthesis of Heterocycles Org. Lett. 2017, 19, 5348-5351.

(55) Martinez de Salinas, S.; Sanjose-Orduna, J.; Odena, C.; Barranco, S.; Benet-Buchholz, J.; Perez-Temprano, M. H., Weakly Coordinated Cobaltacycles: Trapping Catalytically Competent Intermediates in Cp*CoIII Catalysis Angew. Chem., Int. Ed. 2020, Ahead of Print.

(56) Sanjose-Orduna, J.; Sarria Toro, J. M.; Perez-Temprano, M. H., HFIP-Assisted C-H Functionalization by $\mathrm{Cp} * \mathrm{CoIII}$ : Access to Key Reactive Cobaltacycles and Implication in Catalysis Angew. Chem., Int. Ed. 2018, 57, 11369-11373.

(57) Alharis, R. A.; McMullin, C. L.; Davies, D. L.; Singh, K.; Macgregor, S. A., Understanding electronic effects on carboxylateassisted $\mathrm{C}-\mathrm{H}$ activation at ruthenium: the importance of kinetic and thermodynamic control Faraday Disc. 2019, 220, 386-403.

(58) Zhu, C.; Kuniyil, R.; Jei, B. B.; Ackermann, L., Domino C-H Activation/Directing Group Migration/Alkyne Annulation: Unique Selectivity by $\mathrm{d}^{6}$-Cobalt(III) Catalysts ACS Catalysis 2020, 10, 44444450.

(59) Li, L.; Brennessel, W. W.; Jones, W. D., C-H Activation of phenyl imines and 2-phenylpyridines with $\left[\mathrm{Cp} * \mathrm{MCl}_{2}\right]_{2} \quad(\mathrm{M}=\mathrm{Ir}$, Rh): regioselectivity, kinetics, and mechanism Organometallics 2009, 28, 3492-3500.

(60) Zhang, X.-B.; Yu, B.-B.; Si, S.-M.; Wang, S., Theoretical prediction on the synthesis of 2,3-dihydropyridines through $\mathrm{Co}$ (III)-catalysed reaction of unsaturated oximes with alkenes Int. J. Quant. Chem. 2017, $117, \mathrm{e} 25353$

(61) Zhou, X.; Luo, Y.; Kong, L.; Xu, Y.; Zheng, G.; Lan, Y.; Li, X., Cp*CoIII-Catalyzed Branch-Selective Hydroarylation of Alkynes via C -
$\mathrm{H}$ Activation: Efficient Access to a -gem-Vinylindoles ACS Catalysis 2017, 7, 7296-7304

(62) Schmidt, G. F.; Brookhart, M., Implications of Three-Center, TwoElectron M-H-C Bonding for Related Alkyl Migration Reactions: Design and Study of an Ethylene Polymerization Catalyst J. Am. Chem. Soc 1985, 107, 1443-1444.

(63) Vigalok, A.; Uzan, O.; Shimon, L. J. W.; Ben-David, Y.; Martin, J. M. L.; Milstein, D., Formation of $\eta^{2} \mathrm{C}-\mathrm{H}$ Agostic Rhodium Arene Complexes and Their Relevance to Electrophilic Bond Activation $\mathrm{J}$. Am. Chem. Soc 1998, 120, 12539-12544.

(64) Brookhart, M.; Green, M. L. H.; Parkin, G., Agostic interactions in transition metal compounds Proc. Nat. Acad. Sci. USA 2007, 104, 69086914.

(65) Clot, E.; Eisenstein, O. In Principles and Applications of Density Functional Theory in Inorganic Chemistry II; Kaltsoyannis, N., McGrady, J. E., Eds.; Springer Berlin Heidelberg: Berlin, Heidelberg, 2004, p 1-36. (66) Hamdaoui, M.; Djukic, J.-P. In Noncovalent Interactions in Catalysis; Mahmudov, K. T., Kopylovich, M. N., Guedes.da.Silva, M. F. C., Pombeiro, A. J. L., Eds.; The Royal Society of Chemistry: 2019, p 579-607.

(67) Klamt, A.; Schüürmann, G., COSMO: a new approach to dielectric screening in solvents with explicit expressions for the screening energy and its gradient J. Chem. Soc., Perkin Transactions 2 1993, 799-805.

(68) Klamt, A., Conductor-like Screening Model for Real Solvents: A New Approach to the Quantitative Calculation of Solvation Phenomena $J$. Phys. Chem. 1995, 99, 2224-2235.

(69) Klamt, A.; Jonas, V., Treatment of the outlying charge in continuum solvation models J. Chem. Phys. 1996, 105, 9972-9981.

(70) Perdew, J. P.; Burke, K.; Ernzerhof, M., Generalized Gradient Approximation Made Simple Phys. Rev. Lett. 1996, 77, 3865-3868.

(71) Grimme, S.; Hansen, A.; Brandenburg, J. G.; Bannwarth, C., Dispersion-Corrected Mean-Field Electronic Structure Methods Chem. Rev. 2016, 116, 5105-5154.

(72) Grimme, S.; Antony, J.; Ehrlich, S.; Krieg, H., A consistent and accurate $\mathrm{ab}$ initio parametrization of density functional dispersion correction (DFT-D) for the 94 elements H-Pu J. Chem. Phys. 2010, 132, 154104

(73) Grimme, S.; Ehrlich, S.; Goerigk, L., Effect of the damping function in dispersion corrected density functional theory J. Comp. Chem. 2011, 32, 1456-1465.

(74) Alharis, R. A.; McMullin, C. L.; Davies, D. L.; Singh, K.; Macgregor, S. A., The Importance of Kinetic and Thermodynamic Control when Assessing Mechanisms of Carboxylate-Assisted C-H Activation $J$. Am. Chem. Soc. 2019, 141, 8896-8906.

(75) Ernzerhof, M.; Scuseria, G. E., Assessment of the Perdew-BurkeErnzerhof exchange-correlation functional J. Chem. Phys. 1999, 110 5029-5036.

(76) Steinmann, S. N.; Corminboeuf, C., Comprehensive Benchmarking of a Density-Dependent Dispersion Correction J. Chem. Theor. Comp. 2011, 7, 3567-3577.

(77) Neese, F., The ORCA program system WIREs Compt. Mol. Sci. 2012, 2, 73-78.

(78) Riplinger, C.; Neese, F., An efficient and near linear scaling pair natural orbital based local coupled cluster method. J. Chem. Phys. 2013, $138,034106$.

(79) Riplinger, C.; Sandhoeffer, B.; Hansen, A.; Neese, F., Natural triple excitations in local coupled cluster calculations with pair natural orbitals. J. Chem. Phys. 2013, 139, 134101.

(80) Liakos, D. G.; Sparta, M.; Kesharwani, M. K.; Martin, J. M. L.; Neese, F., Exploring the Accuracy Limits of Local Pair Natural Orbital Coupled-Cluster Theory J. Chem. Theor. Comp. 2015, 11, 1525-1539.

(81) Riplinger, C.; Pinski, P.; Becker, U.; Valeev, E. F.; Neese, F., Sparse maps--A systematic infrastructure for reduced-scaling electronic structure methods. II. Linear scaling domain based pair natural orbital coupled cluster theory. J. Chem. Phys. 2016, 144, 024109.

(82) Schneider, W. B.; Bistoni, G.; Sparta, M.; Saitow, M.; Riplinger, C.; Auer, A. A.; Neese, F., Decomposition of Intermolecular Interaction Energies within the Local Pair Natural Orbital Coupled Cluster Framework J. Chem. Theor. Comp. 2016, 12, 4778-4792.

(83) Stoychev, G. L.; Auer, A. A.; Neese, F., Automatic Generation of Auxiliary Basis Sets J. Chem. Theor Comp. 2017, 13, 554-562.

(84) Contreras-Garcia, J.; Johnson, E. R.; Keinan, S.; Chaudret, R.; Piquemal, J. P.; Beratan, D. N.; Yang, W., NCIPLOT: a program for plotting non-covalent interaction regions J. Chem. Theor. Comp. 2011, 7 , 625-632. 
(85) Johnson, E.; Keinan, S.; Mori-Sanchez, P.; Contreras-Garcia, J.; Cohen, A. J.; Yang, W., Revealing noncovalent interactions J. Am. Chem. Soc. 2010, 132, 6498-6506.

(86) Blanco, M. A.; Martín Pendás, A.; Francisco, E., Interacting Quantum Atoms: A Correlated Energy Decomposition Scheme Based on the Quantum Theory of Atoms in Molecules J. Chem. Theor. Comp. 2005, 1, 1096-1109.

(87) Suárez, D.; Díaz, N.; Francisco, E.; Martín Pendás, A., Application of the Interacting Quantum Atoms Approach to the S66 and IonicHydrogen-Bond Datasets for Noncovalent Interactions ChemPhysChem 2018, 19, 973-987.

(88) Francisco, E.; Martín Pendás, A.; Blanco, M. A., A Molecular Energy Decomposition Scheme for Atoms in Molecules J. Chem. Theor. Comp. 2006, 2, 90-102.

(89) Bader, R. F. W. Atoms in Molecules: A Quantum Theory; Clarendon: Oxford, 1990.

(90) Contreras-García, J.; Yang, W.; Johnson, E. R., Analysis of Hydrogen-Bond Interaction Potentials from the Electron Density: Integration of Noncovalent Interaction Regions J. Phys. Chem. A 2011, 115, 12983-12990.

(91) Boto, R. A.; Peccati, F.; Laplaza, R.; Quan, C.; Carbone, A.; Piquemal, J.-P.; Maday, Y.; Contreras-Garcia, J., NCIPLOT4: A new step towards a fast quantification of noncovalent interactions (submitted).

(92) Jerhaoui, S.; Djukic, J.-P.; Wencel-Delord, J.; Colobert, F., Asymmetric, Nearly Barrierless $\mathrm{C}\left(\mathrm{sp}^{3}\right)-\mathrm{H}$ Activation Promoted by EasilyAccessible N-protected Aminosulfoxides as New Chiral ligands ACS Catal. 2019, 9, 2532-2542.

(93) Lu, Q.; Neese, F.; Bistoni, G., Formation of Agostic Structures Driven by London Dispersion Angew. Chem. Int. Ed. 2018, 57, 47604764 .

(94) Altun, A.; Neese, F.; Bistoni, G., Effect of Electron Correlation on Intermolecular Interactions: A Pair Natural Orbitals Coupled Cluster Based Local Energy Decomposition Study J. Chem. Theory Comput. 2019, 15, 215-228.

(95) Lu, Q.; Neese, F.; Bistoni, G., London dispersion effects in the coordination and activation of alkanes in $\sigma$-complexes: a local energy decomposition study Phys. Chem. Chem. Phys. 2019, 21, 11569-11577.

(96) Paulechka, E.; Kazakov, A., Efficient DLPNO-CCSD(T)-Based Estimation of Formation Enthalpies for C-, H-, O-, and N-Containing Closed-Shell Compounds Validated Against Critically Evaluated Experimental Data J. Phys. Chem. A 2017, 121, 4379-4387.

(97) Minenkov, Y.; Chermak, E.; Cavallo, L., Accuracy of DLPNOCCSD(T) Method for Noncovalent Bond Dissociation Enthalpies from Coinage Metal Cation Complexes J. Chem. Theor. Comput. 2015, 11, 4664-4676.

(98) Albrecht, M., Cyclometalation Using d-Block Transition Metals: Fundamental Aspects and Recent Trends Chem. Rev. 2010, 110, 576-623. (99) Scheeren, C.; Maasarani, F.; Hijazi, A.; Djukic, J.-P.; Pfeffer, M.; Zarić, S. D.; Le Goff, X.-F.; Ricard, L., Stereoselective "Electrophilic" Cyclometalation of Planar-Prochiral ( $\eta^{6}$-Arene)tricarbonylchromium Complexes with Asymmetric Metal Centers: pseudo-T-4 $\left[\mathrm{Cp}^{*} \mathrm{RhCl}_{2}\right]_{2}$ and [Cp* $\left.\mathrm{IrCl}_{2}\right]_{2}$ Organometallics 2007, 26, 3336-3345

(100) Boutadla, Y.; Davies, D. L.; Jones, R. C.; Singh, K., The Scope of Ambiphilic Acetate-Assisted Cyclometallation with Half-Sandwich Complexes of Iridium, Rhodium and Ruthenium Chem. Eur. J. 2011, 17, 3438-3448.

(101) Li, L.; Brennessel, W. W.; Jones, W. D., An Efficient LowTemperature Route to Polycyclic Isoquinoline Salt Synthesis via C-H Activation with $\left[\mathrm{Cp} * \mathrm{MCl}_{2}\right]_{2}$ (M ) Rh, Ir) J. Am. Chem. Soc. 2008, 130, 12414-12419.

(102) Duggleby, R. G.; Northrop, D. B., The expression of kinetic isotope effects during the time course of enzyme-catalyzed reactions Bioorg. Chem. 1989, 17, 177-193.

(103) Bigeleisen, J.; Wolfsberg, M. In Advances in Chemical Physics; Prigogine, I., Debye, P., Eds. 1957; Vol. 1, p 15-76.

(104) Gómez-Gallego, M.; Sierra, M. A., Kinetic Isotope Effects in the Study of Organometallic Reaction Mechanisms Chem. Rev. 2011, 111, 4857-4963.

(105) Wesener, J. R.; Moskau, D.; Guenther, H., Intrinsic deuterium/proton NMR isotope effects on carbon-13 chemical shifts: dependence on carbon hybridization and substitution J. Am. Chem. Soc 1985, 107, 7307-7311.

(106) Aydin, R.; Guenther, H., Secondary deuterium/hydrogen isotope effects on carbon-13 chemical shifts in cycloalkanes. Downfield shifts over three and four bonds J. Am. Chem. Soc 1981, 103, 1301-1303.
(107) Simmons, E. M.; Hartwig, J. F., On the Interpretation of Deuterium Kinetic Isotope Effects in $\mathrm{C}-\mathrm{H}$ Bond Functionalizations by TransitionMetal Complexes Angew. Chem. Int. Ed. 2012, 51, 3066-3072.

(108) Bigeleisen, J., The Relative Reaction Velocities of Isotopic Molecules J. Chem. Phys. 1949, 17, 675-678.

(109) Bigeleisen, J., Statistical mechanics of isotopic systems with small quantum corrections. I. General considerations and the rule of the geometric mean J. Chem. Phys. 1955, 23, 2264-2267.

(110) Schaad, L. J.; Bytautas, L.; Houk, K. N., Ab initio test of the usefulness of the Redlich-Teller product rule in computing kinetic isotope effects Can. J. Chem. 1999, 77, 875-878.

(111) Wong, K.-Y.; Richard, J. P.; J., G., Theoretical Analysis of the Kinetic Isotope Effects on Proton Transfer Reactions between Substituted a -Methoxystyrenes and Substituted Acetic Acids J. Am. Chem. Soc. 2009, 131, 13963-13971.

(112) Wong, K.-Y.; Xu, Y.; Xu, L., Review of computer simulations of isotope effects on biochemmical reactions: From Bigeleisen equation to Feynman's path integral Biochim. Biophys. Acta 2015, 1854, 1782-1794. (113) González-Lafon, À.; Lluch, J. M., Kinetic isotope effects in chemical and biochemical reactions: physical basis and theoretical methods of calculation WIREs Comput. Mol. Sci. 2016, 6, 584-603.

(114) Buncel, E.; Lee, C. C. Isotopes in cationic reactions; Elsevier: Amsterdam, 1980; Vol. 5.

(115) Schreiner, P. R., Tunneling Control of Chemical Reactions: The Third Reactivity Paradigm J. Am. Chem. Soc. 2017, 139, 15276-15283.

(116) Schreiner, P. R.; Wagner, J. P.; Reisenauer, H. P.; Gerbig, D.; Ley, D.; Sarka, J.; Császár, A. G.; Vaughn, A.; Allen, W. D., Domino Tunneling J. Am. Chem. Soc 2015, 137, 7828-7834.

(117) Kwart, H., Temperature dependence of the primary kinetic hydrogen isotope effect as a mechanistic criterion Acc. Chem. Res. 1982, 15, 401-408

(118) Djukic, J.-P.; Iali, W.; Pfeffer, M.; Le Goff, X.-F., Synthesis of Planar Chiral Iridacycles by Cationic Metal $\pi$-Coordination: Facial Selectivity, and Conformational and Stereochemical Consequences Chem. - Eur. J. 2012, 18, 6063-6078.

(119) Hamdaoui, M.; Ney, M.; Sarda, V.; Karmazin, L.; Bailly, C.; Sieffert, N.; Dohm, S.; Hansen, A.; Grimme, S.; Djukic, J.-P., Evidence of a Donor-Acceptor $(\mathrm{Ir}-\mathrm{H}) \rightarrow \mathrm{SiR}_{3}$ Interaction in a Trapped $\mathrm{Ir}(\mathrm{III})$ Silane Catalytic Intermediate Organometallics 2016, 35, 2207-2223.

(120) Hamdaoui, M.; Desrousseaux, C.; Habbita, H.; Djukic, J.-P., Iridacycles as Catalysts for the Autotandem Conversion of Nitriles into Amines by Hydrosilylation: Experimental Investigation and Scope Organometallics 2017, 36, 4864-4882.

(121) Binh, D. H.; Hamdaoui, M.; Fischer-Krauser, D.; Karmazin, L.; Bailly, C.; Djukic, J.-P., Entrapment of THF-Stabilized Iridacyclic IrIII Silylenes from Double $\mathrm{H}-\mathrm{Si}$ Bond Activation and $\mathrm{H}_{2}$ Elimination Chem. Eur. J. 2018, 24, 17577-17589.

(122) Ossor, H.; Pfeffer, M.; Jastrzebski, J. T. B. H.; Stam, C. H., Reactivity of cycopalladated compounds. 14. Alkyne insertion into the palladium-carbon bond of a metallacycle stabilized by a weak oxygenpalladium bond leading to an unusual $\left(\eta^{2}\right.$-aryl)-palladium interaction molecular structure of $\left[\mathrm{NC}_{9} \mathrm{H}_{6} \mathrm{CH}_{2} \mathrm{C}\left(\mathrm{CF}_{3}\right): \mathrm{C}\left(\mathrm{CF}_{3}\right)\right] \mathrm{Pd}\left[\mathrm{C}\left(\mathrm{CF}_{3}\right): \mathrm{C}\left(\mathrm{CF}_{3}\right)\left(\eta^{2}-\right.\right.$ $\left.\mathrm{C}_{10} \mathrm{H}_{6}\right) \mathrm{OCH}_{3}$ ] Inorg. Chem. 1987, 26, 1169-1171.

(123) Pfeffer, M., Reactions of cyclopalladated compounds and alkynes: New pathways for organic synthesis? Rec. Trav. Chim. Pays-Bas 1990, $109,567-576$.

(124) Algarra, A. G.; Cross, W. B.; Davies, D. L.; Khamker, Q.; Macgregor, S. A.; McMullin, C. L.; Singh, K., Combined Experimental and Computational Investigations of Rhodium- and Ruthenium-Catalyzed C-H Functionalization of Pyrazoles with Alkynes J. Org. Chem. 2014, 79, 1954-1970.

(125) Han, Y.-F.; Li, H.; Hu, P.; Jin, G.-X., Alkyne Insertion Induced Regiospecific $\mathrm{C}-\mathrm{H}$ Activation with $\left[\mathrm{Cp}^{*} \mathrm{MCl}_{2}\right]_{2}(\mathrm{M}=\mathrm{Ir}, \mathrm{Rh})$ Organometallics 2011, 30, 905-911.

(126) Omae, I., Intramolecular five-membered ring compounds and their applications Coord. Chem. Rev. 2004, 248, 995-1023.

(127) Sanjose-Orduna, J.; Benet-Buchholz, J.; Perez-Temprano, M. H., Unravelling Molecular Aspects of the Migratory Insertion Step in Cp*Co(III) Metallacyclic Systems Inorg. Chem. 2019, 58, 10569-10577. (128) Liao, G.; Zhou, T.; Yao, Q.-J.; Shi, B.-F., Recent advances in the synthesis of axially chiral biaryls via transition metal-catalysed asymmetric C-H functionalization Chem. Commun. 2019, 55, 8514-8523. (129) Luo, J.; Zhang, T.; Wang, L.; Liao, G.; Yao, Q.-J.; Wu, Y.-J.; Zhan, B.-B.; Lan, Y.; Lin, X.-F.; Shi, B.-F., Enantioselective Synthesis of Biaryl 
Atropisomers by Pd-Catalyzed $\mathrm{C}-\mathrm{H}$ Olefination using Chiral Spiro Phosphoric Acid Ligands Angew. Chem. Int. Ed. 2019, 58, 6708-6712.

(130) Song, H.; Li, Y.; Yao, Q.-J.; Jin, L.; Liu, L.; Liu, Y.-H.; Shi, B.-F., Synthesis of Axially Chiral Styrenes through Pd-Catalyzed Asymmetric C-H Olefination Enabled by an Amino Amide Transient Directing Group Angew. Chem. Int. Ed. 2020, 59, 6576-6580.

(131) Han, H.; Zhang, T.; Yang, S.-D.; Lan, Y.; Xia, J.-B., PalladiumCatalyzed Enantioselective C-H Aminocarbonylation: Synthesis of Chiral Isoquinolinones Org. Lett. 2019, 21, 1749-1754.

(132) Jin, L.; Yao, Q.-J.; Xie, P.-P.; Li, Y.; Zhan, B.-B.; Han, Y.-Q.; Hong, X.; Shi, B.-F., Atroposelective Synthesis of Axially Chiral Styrenes via an Asymmetric C-H Functionalization Strategy Chem 2020, 6, 497511 .

(133) Frith, S. A.; Spencer, J. In Inorganic Syntheses; Angelici, R. J., Ed. 2007; Vol. 28, p 273-277.

(134) Li, W.; Weng, L.-H.; Jin, G.-X., Hetero-nuclear Co-W complex $\mathrm{Cp}^{*} \mathrm{CoW}(\mathrm{CO})_{2}\left[\mathrm{Se}_{2} \mathrm{C}_{2}\left(\mathrm{~B}_{10} \mathrm{H}_{10}\right)\right]_{2}$ from 16-electron half-sandwich complex $\mathrm{Cp} * \mathrm{Co}\left[\mathrm{Se}_{2} \mathrm{C}_{2}\left(\mathrm{~B}_{10} \mathrm{H}_{10}\right)\right]$ Inorg. Chem. Commun. 2004, 7, 1174-1177.

(135) M86-EXX229V1 APEX3 User Manual; Bruker AXS Inc.: Madison, USA, 2016.

(136) Sheldrick, G., SHELXT - Integrated space-group and crystalstructure determination Acta Cryst. A 2015, 71, 3-8.

(137) Sheldrick, G., Crystal structure refinement with SHELXL Acta Cryst. C 2015, 71, 3-8.

(138) Spek, A., Single-crystal structure validation with the program PLATON J. Appl. Cryst. 2003, 36, 7-13.
(139) te Velde, G.; Bickelhaupt, F. M.; Baerends, E. J.; Fonseca Guerra, C.; van Gisbergen, S. J. A.; Snijders, J. G.; Ziegler, T., Chemistry with ADF J. Comp. Chem. 2001, 22, 931-967.

(140) Eisenschitz, R.; London, F., Über das Verhältnis der van der Waalsschen Kräfte zu den homöopolaren Bindungskräften Z. Physik 1930, 60, 491-527.

(141) London, F., The general theory of molecular forces Trans. Faraday Soc. 1937, 33, 8b-26.

(142) van Lenthe, E.; Baerends, E. J.; Snijders, J. G., Relativistic regular two-component Hamiltonians J. Chem. Phys. 1993, 99, 4597-4610.

(143) van Lenthe, E.; Baerends, E. J.; Snijders, J. G., Relativistic total energy using regular approximations J. Chem. Phys. 1994, 101, 97839792.

(144) van Lenthe, E.; Ehlers, A.; Baerends, E.-J., Geometry optimizations in the zero order regular approximation for relativistic effects $J$. Chem. Phys. 1999, 110, 8943-8953.

(145) Macrae, C. F.; Sovago, I.; Cottrell, S. J.; Galek, P. T. A.; McCabe, P.; Pidcock, E.; Platings, M.; Shields, G. P.; Stevens, J. S.; Towler, M.; Wood, P. A., Mercury 4.0: from visualization to analysis, design and prediction J. Appl. Cryst. 2020, 53, 226-235.

(146) Weigend, F.; Ahlrichs, R., Balanced basis sets of split valence, triple zeta valence and quadruple zeta valence quality for $\mathrm{H}$ to $\mathrm{Rn}$ : Design and assessment of accuracy Phys. Chem. Chem. Phys. 2005, 7, 3297 3305 . 


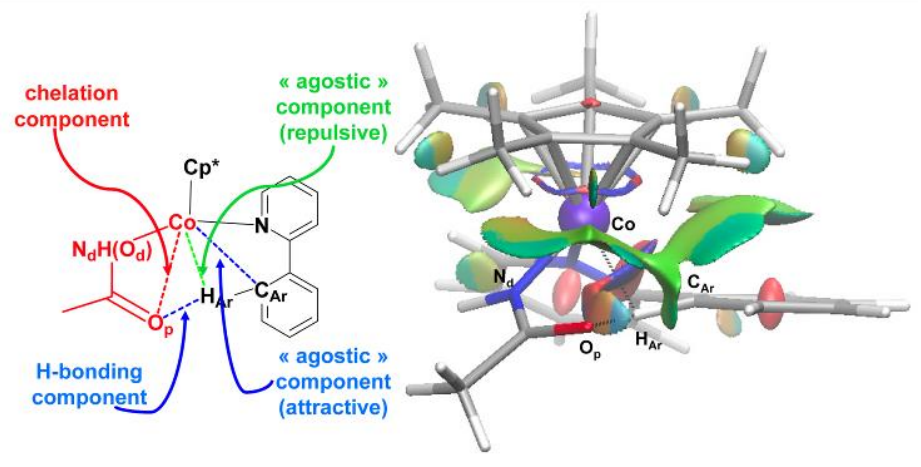

